\title{
The Review and Assessment of Designated Driver Programs As An Alcohol Countermeasure Approach
}


The United States Guvernment does not endorse products or manufacturers. Trade or manufacturers' names appear only because they are considered essential to the object of this report. 
Techaicel Repert Documentetion Page

\begin{tabular}{|c|c|}
\hline $\begin{array}{l}\text { 1. Rosper No. } \\
\text { DOT HS } 807 \quad 108\end{array}$ & 3. Rosipient's Coretes Mo. \\
\hline \multirow{2}{*}{$\begin{array}{l}\text { 4. Tillo and Subitio } \\
\text { The Review and Assessment of Designated Driver } \\
\text { Programs as an Alcohol Countermeasure Approach. }\end{array}$} & $\begin{array}{l}\text { 5. Repow Deto } \\
\text { February } 1987\end{array}$ \\
\hline & 6. Portorming Orgensisetion Code \\
\hline $\begin{array}{l}\text { 7. Author'o) Robert Apsler, PhD; Wayne Harding, EdM; } \\
\text { Jamie Goldfein, BA }\end{array}$ & D. Pertorming Organizention Ropers Mo. \\
\hline 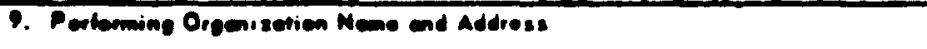 & 10. Woot Uni, Ma. (TRAIS) \\
\hline \multirow{2}{*}{$\begin{array}{l}\text { Harold Russell Associates, Inc. } \\
8 \text { Winchester Place } \\
\text { Winchester, Massachusetts } 01890\end{array}$} & $\begin{array}{l}\text { I1. Controes ex Grent No. } \\
\text { DTWH22-85-R-07251 }\end{array}$ \\
\hline & \multirow{2}{*}{$\begin{array}{l}\text { 13. Troe of Roport and Poried Covered } \\
\text { Final Report } \\
\text { September, 1985-January, } 198\end{array}$} \\
\hline \multirow{2}{*}{$\begin{array}{l}\text { U.S. Department of Transportation } \\
\text { National Highway Traffic Safety Administration } \\
400 \text { Seventh Street, S.W. } \\
\text { Washington. D.C. } 20590\end{array}$} & \\
\hline & 14. Spansecing Aponcy Code \\
\hline
\end{tabular}

15. Supotomontery Notes

Prepared in cooperation with the subcontractor: Social and Behavioral Research, Inc. 4 Austin Park, Cambridge, Massachusetts 02139.

16. Abstreet

Many drinking establishments have instituted designated driver programs (DDPs) which encourage one person in. a group of patrons to remain sober and drive the others home. The primary objectives of this exploratory study were to: 1) identify DDPs throughout the United States, 2) contact and describe a sample of these DDPs, and 3) investigate informal designated driver activities (individuals using a designated driver on their own) at membership organizations, such as veterans, fraternal and university Greek organizations.

The names of 431 public drinking establishments alleged to have formal DDPs were identified. Forty of these and five membership organizations were called and asked to discuss their DDPs. Four other membership organizations were also called about informal designated driver activity.

The opinions of the sources we contacted are reported and the operation and features of DDPs are described. One major result was that although DDPs appear to be an inexpensive way of promoting the designated driver concept, few patrons participated in those we studied. Furthermore, little informal activity took place in membership establishments. Fortunately, there appear to be some simple and inexpensive actions which establishments can take to increase the number of designated drivers.

\section{Kor Worde \\ Alcohol Countermeasures.} Designated Driver Programs. Drinking and Driving. DWI.
II. Distribution Stetement

Document is available to the U.S. public through the National Technical Information Service, Springfield, Virginia 22161.
39. Soeuring Cleseif. (ot mis repert)

Unclassified

\begin{tabular}{|c|c|c|}
\hline $\begin{array}{l}\text { Do. Socuriery Clonsil. (ot thi a popa) } \\
\text { Unclassified }\end{array}$ & $\begin{array}{l}\text { 21. No. of Papos } \\
211\end{array}$ & 22 Price \\
\hline
\end{tabular}

Form DOT F 1700.7 (16-72) Reproduction of form and completed page is authorized 


\section{PREFACE}

The authors of this report wish to acknowledge the assistance of Dr. James Frank, the Contract officer's Technical Representative, National Highway Safety Administration, Office of Driver and Pedestrian Research, Washington, D.C. Dr. Frank provided support and thoughtful advice throughout the project.

We also wish to thank Dr. Hichael Forcier, formerly a senior Research Associate with the prime contractor, Barold Russell Associates, Inc. of Winchester, Massachusetts; and Robert Cowles, formerly a Research Assistant for the sub-contractor, social Science Research and Evaluation, Inc. of Cambridge, Massachusetts. Both participated in many aspects of the project, especially data collection, and provided insights about the data that have been incorporated into the final report.

The success of this project also depended upon the advice and assistance of the many people we contacted for information about designated driver programs. Included were staff of the National Highway Safety Administration in washington, D.C. and in each of the ten NHTSA regional offices; state officials from various agencies; spokespeople for trade organizations, such as the National Restaurant Association; and owners and managers of drinking establishments using a designated driver program. Special mention should be made of four establishments which we visited and which permitted us to observe and interview management, staff and patrons: The Great Escape in Weymouth, Massachusetts; Margaritaville in Capitola, California; Juke Box Saturday Night in Minneapolis; Minnesota; and Graffiti's in Waterford, Connecticut.

The authors assume sole responsibility for the content of this report. 
TABLE OF CONTENTS

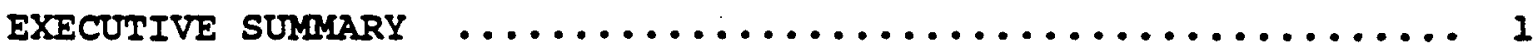

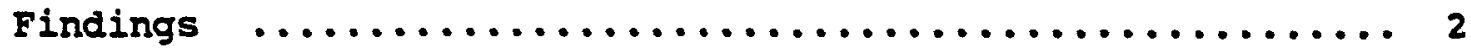

Conclusions $\ldots \ldots \ldots \ldots \ldots \ldots \ldots \ldots \ldots \ldots \ldots \ldots \ldots \ldots \ldots \ldots \ldots \ldots$

BACRGROUND $\ldots \ldots \ldots \ldots \ldots \ldots \ldots \ldots \ldots \ldots \ldots \ldots \ldots \ldots \ldots \ldots \ldots \ldots \ldots \ldots$

Questions and Concerns About DDPs $\ldots \ldots \ldots \ldots \ldots \ldots \ldots \ldots$

GOALS OF THE STUDY $\ldots \ldots \ldots \ldots \ldots \ldots \ldots \ldots \ldots \ldots \ldots \ldots \ldots \ldots$

METHODS $\quad \ldots \ldots \ldots \ldots \ldots \ldots \ldots \ldots \ldots \ldots \ldots \ldots \ldots \ldots \ldots \ldots \ldots \ldots \ldots \ldots$

Problems in Identifying Program $\ldots \ldots \ldots \ldots \ldots \ldots \ldots \ldots$

The Search for People Knowledgeable About DDPs ........ 9

Number of DDPs Identified $\ldots \ldots \ldots \ldots \ldots \ldots \ldots \ldots \ldots \ldots \ldots \ldots$

Informal Designated Driver Activities $\ldots \ldots \ldots \ldots \ldots \ldots \ldots$ Il

Discussion Topics $\ldots \ldots \ldots \ldots \ldots \ldots \ldots \ldots \ldots \ldots \ldots \ldots \ldots \ldots \ldots$

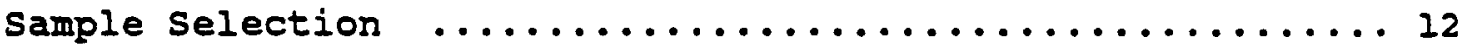

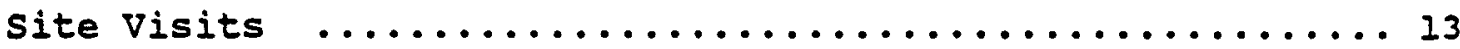

Limitations of the Methodology $\ldots \ldots \ldots \ldots \ldots \ldots \ldots \ldots \ldots$

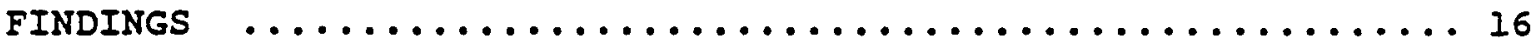

Information Provided by Persons Rnowledgeable About

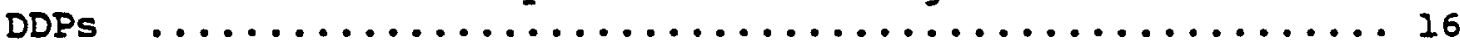

Formal DDPs: Results From Telephone Calls, Written

Materials, and visits $\ldots \ldots \ldots \ldots \ldots \ldots \ldots \ldots \ldots \ldots \ldots$

Characteristics of DDPs $\ldots \ldots \ldots \ldots \ldots \ldots \ldots \ldots \ldots \ldots \ldots$

Costs and Sources of Funds for Operating a DDP .... 19

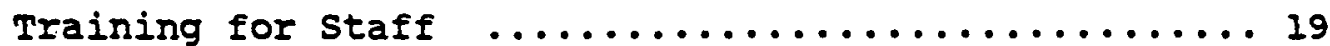

Publicizing the DDP $\ldots \ldots \ldots \ldots \ldots \ldots \ldots \ldots \ldots$

Eligibility for Parties Participating in a DDP .... 19

Incentives for the Designated Driver ...........20 
The Degree of Sobriety That Is Required ......... 20

Who Initiates the Selection of a Designated

Driver?

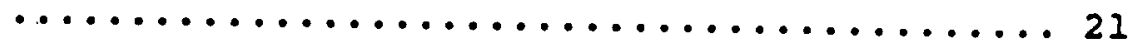

Identification for the Designated Driver ......... 21

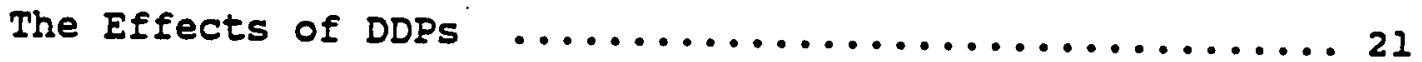

The Number of Designated Drivers $\ldots \ldots \ldots \ldots \ldots \ldots \ldots$

Characteristics of Designated Drivers ........... 24

Do other Members of a Group with a Designated

Driver Drink More Than Normal? ................ 25

The Public Relations value of DDPs $\ldots \ldots \ldots \ldots \ldots \ldots$

The Effectiveness of DDPs in Reducing DWI ......... 26

Defunct DDPs $\quad \ldots \ldots \ldots \ldots \ldots \ldots \ldots \ldots \ldots \ldots \ldots \ldots \ldots \ldots \ldots$

Informal Designated Driver Activities $\ldots \ldots \ldots \ldots \ldots \ldots$

Results of Initial Calls to knowledgeable sources

and Membership Drinking Establishments ............ 28

Veterans organizations $\ldots \ldots \ldots \ldots \ldots \ldots \ldots \ldots \ldots$

Public service or Fraternal organizations ........ 28

Universities $\quad \ldots \ldots \ldots \ldots \ldots \ldots \ldots \ldots \ldots \ldots \ldots \ldots \ldots \ldots \ldots . \ldots \ldots$

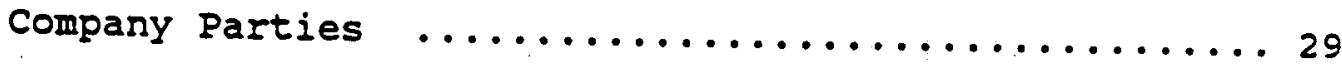

Results of Calls to Membership Establishments

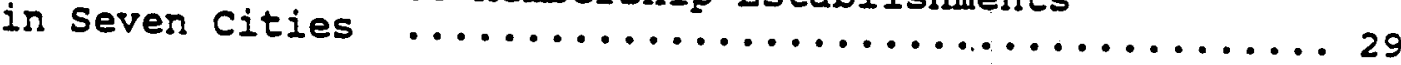

Membership organizations' Concerns About

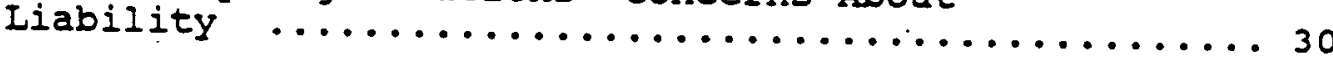

DISCUSSION

What are Reasonable Expectations for Numbers of Designated Drivers?

......... Numers of

Techniques For Increasing the Numbers of Designated
Drivers

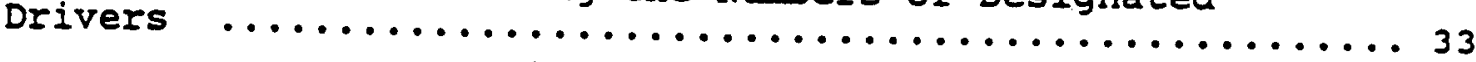

How Extensive Are Informal Designated Driver Activities .. 35

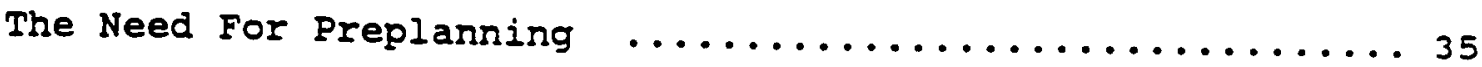


The Public Relations Value of DDPs $\ldots \ldots \ldots \ldots \ldots \ldots \ldots \ldots$

Servers May Be The Victims of DDPs $\ldots \ldots \ldots \ldots \ldots \ldots \ldots \ldots$

Do Designated Drivers Do The Driving? $\ldots \ldots \ldots \ldots \ldots \ldots \ldots$

CONCLUSION $\ldots \ldots \ldots \ldots \ldots \ldots \ldots \ldots \ldots \ldots \ldots \ldots \ldots \ldots \ldots \ldots \ldots \ldots \ldots$

RECOMMENDATIONS FOR FUTURE RESEARCH $\ldots \ldots \ldots \ldots \ldots \ldots \ldots \ldots \ldots$

Evaluation of Effectiveness $\ldots \ldots \ldots \ldots \ldots \ldots \ldots \ldots \ldots \ldots \ldots$

Experimental Comparison of DDP Features ............. 40 APPENDICES

APPENDIX A: AII PUBLIC DRINKING ESTABLISHNENTS PURPORTED TO HAVE A FORMAL DESIGNATED DRIVER PROGRAM (BY

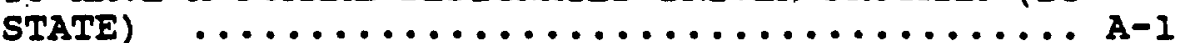

APPENDIX B: MEMBERSHIP ESTABLISHMENTS CONTACTED IN SEVEN

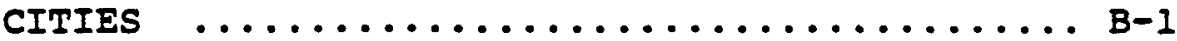

APPENDIX C: DATA COLLECTION FORMAT USED WITH FORMAL

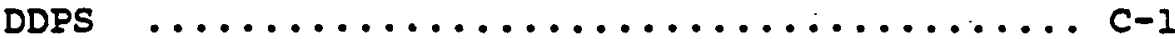

APPENDIX D: DATA COLLECTION FORMAT USED WITH INFORMAI

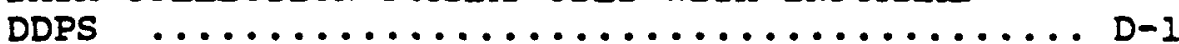

APPENDIX E: IIST OF FORMAL AND INFORMAI DDPS CONTACTED .. E-1 APPENDIX F: INFORMATION ON ALI FORMAL AND INFORMAI DDPS CONTACTED $\ldots \ldots \ldots \ldots \ldots \ldots \ldots \ldots \ldots \ldots \ldots \ldots \ldots \ldots$ F-1

APPENDIX $G:$ DDP KITS $\ldots \ldots \ldots \ldots \ldots \ldots \ldots \ldots \ldots \ldots \ldots \ldots \ldots$ G 1

APPENDIX H: CHARACTERISTICS OF DESIGNATED DRIVER PROGRAMS $\ldots \ldots \ldots \ldots \ldots \ldots \ldots \ldots \ldots \ldots \ldots \ldots \ldots \ldots$ H

APPENDIX I: SAMPLE ITEMS USED TO PUBLICIZE DDPS $\ldots \ldots \ldots \ldots$ I-I APPENDIX J: SAMPIE COUPONS USED AS INCENYIVES IN DDPS $\ldots . \mathrm{J}-1$ APPENDIX K: SAMPLE ITEMS USED TO IDENTIFY DESIGNATED DRIVERS ....................... R-I

\section{IIST OF TABIES}

TABLE 1: REPORTED NUMBER OF DESIGNATED DRIVERS PER WEEK $\ldots \ldots 22$ vii 
TABLE 2: REPORTED NUMBER OF ELIGIBLE PARTIES AND

DESIGNATED DRIVERS IN DRINKING ESTABLISHMENTS

TABLE 3: PREVENTION ACTIVITES AMONG MEMBERSHIP

ESTABIISHMENTS 


\section{EXECUTIVE SUMRARY}

Encouraging groups of drinkers to designate one individual who will remain sober to do the driving for everyone else is one approach to reducing the serious problem of alcohol-related automobile crashes. A major appeal of this "designated driver" concept is that it can be applied to virtually any drinking situation where people drive together after drinking; at restaurants, bars, clubs, private parties, sporting events, and so on. Another appealing aspect of the designated driver concept is that it requires only the willingness of one member in the group to remain sober. For example, there are none of the costs associated with some alternative approaches to preventing drinking and driving, such as taxi-fares or overnight accommodations.

The designated driver concept has been widely used in parts of scandinavia. However, it is only within the last few years that many drinking establishments in the United states have begun formal efforts to introduce their customers to the idea. Although the number of designated driver programs (DDPs) operated by drinking establishments has increased during the past few years, there is no substantive research on this topic. Therefore, there is very little information available about the types of programs that exist, the manner in which they operate, or whether they are effective.

This project was designed to begin to meet the need for more comprehensive information about DDPs. The goals were to:

- Identify formal DDPs throughout the United states and obtain information from a sample of these in order to describe their major features and operation.

- Identify some informal designated driver activities and obtain more limited information from a sample of these in order to describe their operation. Informal designated driver activities were defined as those in which peoples participate on their own without the encouragement of advertising or incentives offered by a drinking establishment.

A "snowball" approach was employed to locate individuals who were knowledgeable about DDPs and to locate DDPs. Approximately 140 names or organizations were identified as potential sources of information about DDPs, and of these, 75 were contacted. In addition to being a geographically diverse group, the sources we contacted represented a wide range of activities, including members of citizen activist groups (such as Mothers Against Drink Driving), prominent academicians and researchers involved in highway safety, members of state restaurant associations, members of server training organizations, and law enforcement personnel. 
Because of NHTSA's interest in informal designated driver activity, we also contacted organizations where drinking took place primarily among the members of those organizations: fraternal organizations, veterans organizations, and university Greek houses. We contacted 54 of these "membership organizations" in seven major cities.

After a list of 431 DDPs had been collected, 40 traditional drinking establishments were called and asked to discuss their programs (three of these DDPs were defunct). In addition, five formal DDPs associated with membership organizations and four membership organizations that allegedly involved informal designated driver activities were called.

The major topics discussed with spokespeople of formal DDPs were: setting, organization, operation, impact, informal designated driver activities, and availability of written information. Discussions with informal designated driver programs were limited to: setting, informal designated driver activities, and other informal programs.

The final step in collecting data on DDPs was to conduct site visits to a small sample of the formal DDPs that had already been contacted by telephone.

On the whole, this study can be characterized as exploratory in nature. Given the lack of previous research, limited resources, and the fact that DDPs collect little, if any, data, it was not possible nor appropriate to undertake a rigorous evaluation. However, we did explore the successes and problems associated with these programs as perceived by those involved in conducting them. Most of the findings are based on anecdotal data received from many sources.

\section{Findings}

Although there were many varieties of DDPs, they all operated ac-. cording to similar general principles. First, the designated driver was expected to remain sober while others in his/her party drank. Second, the ride home was expected to be in a vehicle owned by one of the party.

Over half of the DDPs stated that they have eligibility requirements for participation in their programs. In most cases, the requirement consisted of a minimum number of members in a party of patrons, with the minimum ranging from two to six people. Most establishments provided incentives to promote participation in their DDPs. TYpically, the incentives consisted of free nonalcoholic drinks for the designated driver. Some means whereby the drinking establishment could identify the individuals who elected to be designated drivers was used in all but two of the drinking establishments. The most common type of identification 
was a button carrying messages such as "No thanks, I'm Driving". Establishments tended to advertise their DDPs through the use of posters and table tents. Few DDPs actively recruited designated drivers by having staff speak to the patrons and directly invite their participation. Most of the DDPs were in operation whenever the drinking establishment was open and most establishments operating DDPs had other types of programs for controlling alcohol use, such as providing rides home to intoxicated patrons. Costs for the DDPs varied but were generally regarded as low by the establishments, and it appears that these costs were often offset by Iree publicity generated about the DDP.

The numbers of designated drivers produced by DDPs tended to be low, both in absolute terms and in terms of percentages of eligible parties (though the reliability of the data on eligible parties is especially guestionable). The low levels of participation may be because very few groups of patrons are likely candidates for designated driver activities.

DDPs have some other potential shortcomings. For example, limited data indicate that DDPs impose a hardship on servers in that designated drivers tend not to tip as heavily as other customers. Rnowledgeable sources we spoke with also raised the question of whether DDPs make it more difficult for servers to stop the designated driver's companions from drinking to the point of intoxication. Anecdotal evidence from servers and others indicate this probably was not true to any significant degree. Evidence was inconclusive or unavailable concerning the questions of whether DDPs encourage the drinker's companions to consume more alcohol than they ordinarily would, and whether the designated driver actually does the driving.

Data collected from membership establishments indicated that little informal designated driver activity took place in these settings. However, anecdotal evidence from drinking establishments with formal DDPs indicates that at at least some informal designated driver activity took place among their patrons. The extent of informal activities could not be assessed in this study.

\section{Conclusions}

The implementation of DDPs within drinking establishments is a reasonable way to introduce a large segment of the drinking public to the designated driver concept. Not only will drinkers learn about the program, but they encounter the information at a time when they will be sensitized to the drinking and driving issue - the time when they are getting ready to drink. At the same - time, DDPs are relatively inexpensive to implement, and may generate sufficient goodwill for many drinking establishments to make their adoption cost effective. 
In addition to their main objective of encouraging parties of drinkers to designate a sober driver, DDPs may also have a positive impact in other ways. They may increase the chances of patrons taking positive actions in the future by making them more aware of the drinking and driving problem in general and the designated driver concept in particular.

Despite their potential for impacting the drinking-driving problem, the DDPs we contacted produced relatively few designated drivers, and there is even the suggestion from a very small sample that the designated drivers that did participate in these programs tended to be light drinkers or even abstainers. Also, it is not known whether designated drivers actually did the driving.

Although the low level of participation in DDPs is disheartening, it should not be concluded that DDPs are altogether ineffective or that the present level of participation cannot be improved. It seems clear from our data, even in the absence of a statistical analysis, that there are actions which drinking establishments can take to markedly increase the numbers of groups agreeing to select a designated driver. Two types of actions stand out. One is simply to increase the size of the incentive. The second is for drinking establishments to actively solicit participation in the DDP. DDPs might also be able to increase participation by eliminating, or at least reducing, restrictions. For example. the DDP should idealiy be available whenever the drinking establishment is in operation, and groups of all sizes should be eligible for participation. Furthermore, efforts should be made to reduce any stigma associated with becoming a designated driver. All these actions appear to be both relatively easy to
implement and relatively inexpensive.

Further research will be required to determine the effectiveness of DDPs, the best practices for increasing desirable outcomes and minimizing problems, and the extent of informal designated driver 


\section{BACKGROUND}

Encouraging groups of drinkers to designate one individual who will remain sober to do the driving for everyone else is one approach to reducing the serious problem of alcohol-related crashes. A major appeal of this "designated driver" concept is that it can be applied to virtually any drinking situation where people drive together after drinking; at restaurants, bars, clubs, private parties, sporting events, and so on. Another appealing aspect of the designated driver concept is that it requires only the willingness of one member in the group to remain sober. For example, there are none of the costs associated with some alternative approaches to preventing drinking and driving, such as taxi-fares or overnight accommodations. Also, the designated driver approach may help reduce drinking and driving in two ways. First, it may reduce the chances of having a crash on the way home for those who participate. Second, its use and promotion may make even non-participants more aware of the need to avoid driving while intoxicated.

It is only within the last few years that many drinking estabisshments in the united states have begun formal efforts to introduce their customers to the designated driver concept. Although it appears that designated driver programs operated by drinking establishments have rapidly increased in number during the past few years, there appears to be no comprehensive and systematic information available about the types of programs that exist, the manner in which they operate, and whether they are effective.

It was the potential of DDPs and the lack of research about them that prompted the National Highway Traffic Safety Administration to sponsor this study:

"The importance of this research is that the designateddriver program (DDP) may have high potential for significantIy reducing DWI-related deaths and injuries at a relatively low cost. It is a voluntary, non-coercive approach which can be sponsored by private or public resources or a combination thereof. We need to know what factors influence both a community and its drivers to implement and accept a DDP, and how best to get program information to users. And, where possible, we want to determine the extent to which these programs are actually used in their communities and what effects are achieved." (Statement of work)

\section{Questions and Concerns About DDPS}

This study was also motivated by questions about the limitations, effectiveness and unintended negative consequences associated with DDPs. For example, even if the selection of a designated, 
driver does succeed in reducing the number of intoxicated drivers on the road, it is possible that, at the same time, this approach inadvertently exacerbates the drinking problem in general. One potential negative effect following selection of a designated driver is that the other members of the group may drink more heavily than they would otherwise, simply because they have been freed from worries about their safety while travelling home. In more extreme cases, the presence of a designated driver could be taken by some drinkers as license to binge.

A closely related concern is that servers of alcohol may find it more difficult to fulfill their legal responsibility not to continue to serve an intoxicated person when that person is part of a group which has a designated driver. If people do drink to excess, will a server find it more difficult or be less inclined to discontinue serving alcohol to someone who can accurately and perhaps indignantly reply, "Hey, it's ok; I have a safe ride home?"

As mentioned above, the designated driver concept applies to a wide range of drinking situations. However, the impact of this approach may be limited by the way in which people arrange transportation to and from drinking situations. For example, use of a designated driver does not apply to those people who drive themselves to a place where they meet others and have something to drink. Furthermore, even when a group of individuals goes drinking in one car, it is probably very common for the individuals or couples to drive to a meeting point from which they travel together in a single vehicle. Therefore, one designated driver may be able to get the group back to the meeting place safely, but this may not be sufficient to prevent the others from driving while intoxicated as they drive their own automobiles home from the meeting place. These situations illustrate that in some cases, use of a designated driver requires preplanning and changes in habitual behaviors.

While it seems clear that DDPs have been proliferating, the question remains of how extensively they are actually used by patrons. It is unlikely that the simultaneous proliferation of DDPs and growing concern within the hospitality industry about server liability is a coincidence. Thus, it is possible that the growth of DDPs says much more about the ilability crisis among drinking establishments than it does about a change in public behavior involving driving and drinking. In short, the existence of a DDP does not necessarily mean that groups of drinkers are in fact designating individuals to remain sober to do the driving.

DDPs appear to be an ideal alcohol countermeasure from the standpoint of cost and ease of implementation, but implementation of a DDP can become a charade. A drinking establishment can merely put up a sign announcing that it has a DDP and perhaps even offer the designated driver some minimal incentive, such as a free soft drink, without making a substantive effort to promote the use of 
the program. The drinking establishment can then claim to have instituted a DDP. Although such a "paper" program may help

mitigate the establishment's liability and enhance its public image, it is unlikely to have any impact on drinking and driving behavior. 


\section{GOALS OF THE STUDY}

In brief, the goals of the study were to:

- Identify DDPs throughout the United States by contacting knowledgeable sources and asking them for information.

- Develop a structure for describing DDPs in a standard manner.

- Telephone many of the identified DDPs in order to learn about them.

- Contact fraternal organizations and universities in order to learn about both their formal and informal designated driver activities.

- Visit a few DDPs in order to obtain first-hand experience with their operations. 
METHODS

\section{Problems in Identifying Programs}

We learned during our early discussions with NHISA personnel and other knowledgeable sources that it would be difficult to create a comprehensive list of DDPs. Sources we contacted reported that, by and large, DDPs function autonomously. That is, they are not tied to national networks and are not part of any state systems that could be used to track them down. One reason that DDPs were generally thought to be autonomous was that the programs are inexpensive enough that they could be either selfsupported or at least supported entirely from local sources. Therefore, DDPs would not be known by state and federal agencies or by foundations which fund alcohol countermeasures. Further complicating our search for DDPs was the expectation that, because most programs were probably confined to individual drinking establishments, publicity about them would probably be quite limited geographically. This would again reduce the likelihood of the DDPs becoming known by state or national organizations interested in alcohol countermeasure activities.

\section{The Search for People Knowledgeable About DDPS}

The requirement that our search for DDPs be national in scope had to be balanced against the limited resources that were available to us for conducting the search. Consequently, we decided to begin by contacting a single source in every one of the states. our best guess was that the state offices of the Governor's Representative for Highway safety were most likely to either know directly about DDPs or at least to have contacts with other sources that would have direct knowledge of DDPs.

The offices of the Governor's Representative in all 50 states plus the District of Columbia were called and asked questions about the designated driver concept and about the location of specific DDPs. The Governor's Representative or their staff were asked to discuss such topics as the advantages and disadvantages of the designated driver concept and whether public opinion and current activities concerning DWI countermeasures in their state created an environment conducive to the establishment of DDPs. As part of our effort to locate DDPs, they were also asked whether they were aware of any estabiishments that operated DDPs and whether they knew of other knowledgeable persons whom we could contact.

These conversations and those described below were loosely structured in order to allow the respondents to provide whatever information they felt would be helpful in understanding DDPs. 
A computer database was created to hold information collected from all of the knowledgeable persons contacted. A separate record for each person included information about the person called, the names of DDPs that they provided, their general opinions about the designated driver concept, and the interviewer's assessment of the quality of the information.

After contacting most of the Governor's Representatives, we began contacting those other persons or organizations that they had recommended to us. At the same time, we began contacting some knowledgeable persons we had identified during preliminary work we conducted while preparing a proposal for this contract. We employed a "snowballing" strategy. That is, if an initial respondent provided information on other knowledgeable persons, we followed up with further phone calls to these new leads, and so on.

The number of persons recommended to us by our initial contacts ranged from none or one in some states to five or more in others. All told, approximately 140 names or organizations were recommended to us. Approximately 75 of these were contacted. Many of the 75 persons with whom we spoke were chosen because either the source who recommended him/her was knowledgeable and/or the person was highly recommended. Others were chosen randomly in order to establish a good geographical balance of contacts. More specifically, we took care that calls were made to persons from all of the ten NHTSA regions. These persons were asked the same series of questions that were asked of the Governor's Representatives. In addition to being a geographically diverse group, the sources we contacted represented a wide range in terms of their positions. Among those we spoke with were members of citizen activist groups, such as MADD, prominent academics and researchers involved in highway safety, members of state restaurant associations, members of server training organizations, and law enforce-
ment personnel.

Number of DDPs Identified

Eventually, a list of 431 DDPs in public arinking establishments was compiled. Some of these leads were provided by the sources mentioned above; others came from the DDPs we contacted by phone in the next phase of the project. The 431 DDPs were widely distributed geographicaliy, with 1 or more DDPs in each of 32 states plus the District of Columbia.

All the leads appear in Appendix $A$ and are grouped by state. It should be kept in mind that the fact that a source identified a DDP does not mean that the DDP actualiy exists. As we learned when we tried to telephone DDPs, some drinking establishments are no longer in operation, some have abandoned their DDP, others never had a DDP, some make only a superficial effort to run a $D D P$, and so on. We found it required calls to approximately 1.5 leads in order to contact one DDP. 


\section{Informal Designated Driver Activities}

Even before we had completed the calls to knowledgeable sources discussed above, it became clear that we were obtaining virtually no information about informal designated driver activities, that is, the use of designated drivers by groups of individuals entirely on their own. Because of NHTSA's interest in this type of designated driver activity, we made a series of telephone calls in which we contacted organizations where drinking took place primarily among the members of those organizations such as college fraternities and fraternal organizations. Our assumption was that few of these organizations would have a formal DDP, but their patrons might use designated drivers informally. Moreover, it seemed likely that managers or spokespeople for these "membership" organizations might know the patrons well enough to be aware of any informal designated driver activity taking place.

We contacted 54 organizations consisting of fraternal organizations (eg. Elks, Knights of Columbus, Rotary Club, etc.), veterans organizations (Veterans of Foreign Wars or American Legion), and university Greek houses (fraternities and sororities). The organizations were selected from the following seven city phone books: Atlanta, Georgia, Boston, Massachusetts, Cincinnati, Ohio, Minneapolis, Minnesota, Omaha, Nebraska, Portland, Oregon, San Diego, California. These cities were chosen because they satisfied three criteria. First, they were major cities. Second, we had already identified extensive, traditional DDP a stivity in them. And third, they were spread about the country. Appendix B lists by state the organizations that were contacted.

In addition to the membership establishments, six of the most knowledgeable persons who had been previously contacted were called back so that we could ask explicitly whether they were aware of any informal designated driver activities.

The contact at each of the 54 membership establishments was asked whether his/her establishment was "doing anything to combat the drinking and driving problem." If the answer was in the affirmative, we proceeded by telling them that we were specifically interested in learning about designated driver activities. If they indicated that there were none at their organization, the conversation was terminated. If there were, we asked them to describe the activities. We were careful to determine whether the activities constituted a formal DDP, or whether they could be categorized as informal.

The calls to membership establishments produced leads for 5 formal DDPs and 4 informal DDPs. 


\section{Discussion Topics}

In preparing to make phone calls to DDPs, the topics to be discussed with formal and informal DDPs were developed by reviewing all the information provided by the knowledgeable sources we had contacted. Drafts of the discussion topics were reviewed by NHTSA staff and then revised to incorporate their comments.

The major topics covered for formal DDPs were:

- Setting information.

- Program organization.

- Program operation.

- Program impact.

- Informal designated driver activities.

- Availability of written information.

Fewer topics were discussed with organizations expected to be sources of informal designated driver activities:

- Setting information.

- Informal designated driver activities.

- Other informal programs.

The full lists of discussion items for formal and informal DDPs appear as Appendices $C$ and $D$ respectively.

Discussions with formal DDPs lasted approximately 45 minutes, while those to member organizations lasted approximately 20
minutes.

\section{Sample Selection}

Forty traditional drinking establishments were contacted by telephone. The particular establishments to be called were chosen by applying all of the following criteria:

- The DDP enjoyed a reputation as a superior program, according to the person(s) who identified it for us; - The person(s) who recommended the DDP seemed knowledge-
able;

- The DDPs selected represented all of the NHTSA regions. 
As we called the establishments that had been recommended to us, we learned that many did not actually have a DDP or had gone out of business. We replaced these DDPs with others chosen randomly from our master list of DDPs. A list of the DDPs we contacted appears in Appendix $\mathbf{E}$.

We also called back five formal DDPs associated with membership organizations and four membership organizations that allegedly involved informal designated driver activities. These DDPs also appear in Appendix $\mathbf{E}$.

Appendix $F$ contains information on all the DDPs we contacted and includes data collected through phone calls, extracted from written materials and obtained through site visits.

\section{site visits}

The final step in collecting data on DDPs was to conduct site visits to a small sample of the DDPs that had already been contacted by telephone. The primary reasons for the site visits were to 1) obtain observational information which might enhance our understanding of the data already on hand and (2) obtain more detailed information from which we would prepare more complete descriptions of a few programs than would be possible by relying on information from telephone calls and written materials.

Based on the results of the calls to DDPs, five drinking establishments that appeared to have the most interesting and most active DDPs wer: selected for site visits. More specifically, these establishments were chosen by judging all DDPs against three selection criteria:

- Were there a relatively large number of participating designated drivers?

- Was the DDP in operation for at least one year?

- Did the DDP incorporate a multiple-component alcohol safety program that typically included server training and a safe ride program?

The first criterion was by far the most important one, while the other two were treated as highly desirable, but not absolutely necessary.

After NHTSA approved the targeted sites, we attempted to contact the owner or some representative of management for these establishments in order to arrange a visit. Despite repeated efforts, one of the five sites did not respond in time to permit us to schedule a visit. The four drinking establishments that we visited were: 


$$
\begin{aligned}
& \text { - Graffiti's in Waterford, Connecticut } \\
& \text { - The Great Escape in Weymouth, Massachusetts; } \\
& \text { - Juke Box Saturday Night in Minneapolis, Minnesota; } \\
& \text { - Margaritaville in Capitola, California; }
\end{aligned}
$$

The first step during each site visit was a discussion with the manager and/or owner. The purpose of the discussion was to (I) obtain a detailed description of the program's operation and of the people involved, (2) answer questions raised by the earlier telephone conversation, and (3) enlist the manager's help in arranging activities the remainder of the visit. After meeting with the manager, we spoke to other staff involved with the DDP. Depending on the particular establishment, the staff we spoke with included some or all of the following: waitresses, waiters, doormen, hostesses, floor managers, and bartenders. We also observed the operation of the establishment and noted features, such as signs and buttons, related to the DDP. All site visits were scheduled during weekend evenings so that we could observe operations when the establishments were serving large numbers of patrons and when, in turn, there were likely to be more desig-
nated drivers.

Initially we had hoped to speak both with groups of patrons participating in the DDP and with others who chose not to participate: Unfortunately, in two of the drinking establishments, the combination of very few designated drivers (none in one of them) and very loud music made speaking with patrons nearly impossible. In the other two establishments that we visited (Margaritaville and Juke Box Saturday Night), we were able to speak with a few parties that had designated someone to be a sober driver and also with other parties that elected not to participate in the DDP.

In an effort to augment information from drinkers who do and do not participate in designated driver activities, the authors of this report incorporated relevant items in a telephone survey they conducted as part of another contract. The results from the telephone interviews with 500 randomly selected drivers in a Massachusetts community will be reported in a separate document.

\section{Limitations of the Methodology}

The collection of DDPs that we contacted is not a scientifically drawn representative sample of all DDPs in the United states. Although we contacted a great many knowledgeable sources from different sections of the country, we have no way of knowing how many other DDPs exist that our sources did not know about. on the one hand, we were careful to ensure that we contacted sources likely to know about DDPs in every state, and we know from our. telephone discussions with DDPs that many different types and 
sizes of drinking establishments are included in the sample. On the other hand, we do not know whether the numbers of each type of program in our sample are representative of the population of all DDPs in the country.

The fact that the DDPs mentioned by our sources came to their attention raises the possibility that they are different in some way from the DDPs that did not come to their attention. It is also important to note that the DDPs that were selected for telephone contact and for site visits were not chosen randomly. Instead, only those programs that met the criteria outlined above were chosen. These comments are intended to underscore the need for caution in attempting to generalize the findings presented below to all DDPs.

On the whole, this study can be characterized as exploratory in nature. Its primary objective was to describe the variety of DDPs in operation, noting their major features. Given the lack of previous research, limited resources, and the fact that DDPs do not collect much, if any, data, it was not possible nor appropriate to undertake a rigorous evaluation. However, we did explore the successes and problems associated with these programs as perceived by those involved in conducting them. Most of the findings are based on anecdotal data that we received from many sources. 


\section{FINDINGS}

Information obtained from persons who were knowledgeable about DDPs is presented first, followed by the findings from telephone calls and site visits to formal DDPs. Finally, findings concerning informal designated driver activities are described.

\section{Information Provided by Persons Rnowledgeable About DDPs}

We encountered relatively few individuals who were well-informed about designated driver activities in general and/or could identify drinking establishments that included a DDP. While there are several possible explanations, the most likely is that DDPs have not yet been adopted on a wide-spread basis. It is also possible that the existing DDPs are receiving relatively little publicity and tend not to become known outside of their immediate geographical area.

People who were knowledgeable tended to give a two-sided answer to questions about the merits of DDPs. They felt that DDPs would be appealing to and effective with social drinkers, but then they would indicate that DDPs are not a viable solution for problem drinkers. They tended to feel that problem drinkers would not be interested in participating. Another controversial issue that arose concerned the appropriateness of DDPs for "underage" drinkers. Some sources felt that DDPs should be used whenever people drive after drinking, while others feared that DDPs for underage drinkers would create an image of condoning illegal behavior.

Perhaps the most common positive response concerning DDPs was the contention that they heighten awareness about the importance of avoiding driving after drinking even among groups which do not participate in the program. Similarly, people often remarked that anything that can be done to get bar owners involved in combating the problem of drinking and driving is a good thing. The point they seemed to be making was that drinking establishments are a logical and critical site for the application of alcohol countermeasures.

The respondents split fairly evenly on the issue of whether a DDP leads to excessive drinking by others in the party. However, those who stated that they did not think that excessive drinking should be a concern were frequently the more knowledgeable of our sources on the subject of DDPs in general. Those who raised a concern about excessive drinking tended to be less well-informed and brought it up not so much as their own opinion but as something that they had heard other people complain about. very few people raised a concern about intoxicated passengers distracting the sober driver and possibly causing an accident. 
Several people seemed generally unenthusiastic about DDPs. Their lack of enthusiasm took two forms. Some comments indicated that the DDP concept is a good one, but that it will not be widely adopted: "It's not something that people are going to stand behind" or "It's hard to get the bars seriously involved." Some people felt that the designated driver concept simply does not work when you initiate it after a group of individuals has already reached the drinking establishment. One person elaborated this point and explained that the program is unsuccessful because it isn't planned from the beginning of the evening when the party decides how many cars to take to the bar.

Most people responded that the climate of public opinion in their state was very good for DDPs. Respondents often cited their state's recently passed alcohol countermeasure legislation as evidence that drinking establishments will be forced to become more involved with DDPs.

overall, the impression that we developed from these calls was that there does not appear to be a great deal of DDP activity throughout the country. Even when we were referred to excelient and articulate contacts, DDPs were not usually the subject upon which they were best able to expound. In fact, it often appeared that DDPs were the last thing that people involved with prevention wanted to talk about. Safe ride programs were frequently confused with DDPs, and people often seemed disappointed when the distinction was made clear to them.

The designated driver program seems to be a fledgling idea in most states. For example, several people made comments that it "is too early to say" or that the idea "will probably grow in the future." If some of these optimistic individuals are right, then the number of DDPs in existence could grow considerably.

The increase in publicity for the designated driver concept that is directed at drinking establishments is consistent with the view that DDPs may grow in number. References to DDPs as one example of "responsible serving practices" which may help reduce legal liability are appearing in various trade publications and in meetings and conferences of interest to drinking establishments. Also, several organizations have made DDP kits available to drinking establishments, usually at a low cost. Some kits are designed solely to help establishments implement and maintain DDPs, while other kits address more general alcohol awareness issues and have a DDP component. The kits contain some or all of the following: instructions for program implementation, table tents, buttons, stickers, camera ready art, "mocktail" menus, pamphiets, advertising scripts, posters and sample news releases. Appendix G lists some organizations which provide DDP kits and describes their contents. 


\section{Formal DDPs: Results From Telephone Calls, written}

Materials, and Visits

The following results are based on extended discussions with the managers or owners of 40 traditional drinking establishments. Thirty seven of 40 drinking establishments operated a DDP at the time of the call. The other three had operated DDPs in the past, but their programs were defunct when we spoke with them. Information from the defunct DDPs is combined below with the information from the other programs.

Designated driver programs are a recent phenomenon in this country. In fact, the majority of programs which we contacted were begun in 1984 and 1985, while the oldest DDP that we encountered began in 1981. It was interesting to hear several of our other respondents claiming to be the first DDP in the country, even though their programs began in 1984.

A wide range of reasons was given for starting DDPs. The most common motivation was a general concern with safety when alcohol is consumed. Approximately one fourth of all interviewees gave reasons which fit into this category. Approximately $15 \%$ of the respondents reported that concern about liability spurred the creation of the DDP. Ten percent of the establishments answered that the increased attention among the public to drinking and driving was their motivation. Other reasons which were given only once or twice included a push from citizen groups, efforts to assist with community education, and improved public relations.

Although there were many varieties of DDPs, they all operated according to similar general principles. First, it was intended that the designated driver remain sober while the other(s) in his/her party drank. An interesting and potentially very controversial difference among DDPs was in their definition of "sober" as an eligibility requirement. In nearly all DDPs, the designated driver was required to abstain from alcohol, however, some allowed designated drivers to have up to two drinks. A second general rule was that the ride home was to be in a vehicle owned by one of the party; in two cases, there was an additional vehicle owned by the establishment that was made available if the party was too large to fit in the designated driver's vehicle. Third, most of the DDPs operated whenever the drinking establishment was open. A few drinking establishments did restrict the hours of their DDP, and we encountered two that operated their DDP only on holidays.

DDPs were not the only alcohol countermeasure employed by the drinking establishment that we contacted. Many employed other types of programs or systems for controlling alcohol use. The most common were surveiliance aimed at detecting patrons who be- 
came too intoxicated and some form of a safe ride program (typically not advertised).

\section{Characteristics of DDPs}

Appendix $\mathrm{H}$ consists of a table showing the main characteristics of DDPs and the number of programs associated with each characteristic. The sections below discuss these data.

Costs and Sources of Funds for Operating a DDP. Most respondents claimed that the cost of operation for their DDP was minimal and inconsequential. The primary factor affecting the cost of running the DDP appeared to be the types of incentives offered to designated drivers. Programs that simply provided soft drinks generally cost no more than a few hundred to a few thousand dollars per year. The most expensive DDP that we encountered gave free meals in its restaurant to designated drivers. It cost $\$ 15,000$ per year.

The costs to DDPs of providing refreshments to designated drivers were borne by the drinking establishment. When donated services were mentioned, they tended to be in the form of posters, buttons, and other devices used for conveying messages about the designated driver concept. similarly, some advertising for DDPs was donated by the mass media. It is important to remember that free publicity about a DDP which includes the name of the particular establishment is obviously of value to the establishment and therefore offsets other costs associated with the program.

Training for staff. When asked how they trained staff for the DDP, respondents typically indicated that the training was either part of their general orientation and alcohol awareness training or part of their periodic staff meetings. Few of the establishments had written policies which might have been helpful in training staff and in maintaining consistent practices conceming which patrons were eligible, whether they had to be completely free of alcohol, what to do if a designated driver tried to consume alcohol, etc.

Publicizing the DDP. Most drinking establishments had some kind of in-house publicity which announced their DDP to patrons. The most frequent form of in-house advertising was posters. Table tents were the second most common form. In many cases, the employees wore buttons advertising the program. often the server or doorman promoted the program by talking with patrons. Examples of some of the types of in-house advertising are shown in Appendix I.

Eligibility for Parties Participating In a DDP. Over half of the DDPs stated that they have eligibility requirements for participation in their programs. In most cases, the requirement consisted of a minimum number of members in a party of patrons, with the minimum ranging from two to six people. There were two other 
eligibility requirements that were rare but interesting. First, one DDP specified a maximum size for a party of patrons to be eligible. The reasoning was that if there were more than six people in a party, then they would have to use more than one car. second, another DDP stipulated that there had to be four people riding in one car in order for the party to participate in its program. In the latter case, the reason was to reduce the cost of the program to the establishment by assuring that there would be three drinkers for each designated driver and to free more parking spaces for other patrons.

Incentives for the Designated Driver. All of the establishments provided incentives to promote participation in their DDPs. For example, every public drinking establishment that we investigated offered free non-alcoholic beverages to patrons who designated themselves to stay sober and be the driver for the night. However, in the five formal DDPs at membership establishments, two offered no incentives, and another offered free coffee and donuts.

Among establishments offering free non-alcoholic beverages, there was some minor variation in the precise nature of this incentive. For example, some offered only free soft drinks while others included coffee, non-alcoholic beers and wines, and/or "mocktails", such as a non-alcoholic pina colada.

Other incentives were often offered in addition to free nonalcoholic drinks. In approximately $17 \%$ of the establishments, coupons were distributed to the designated driver that were redeemable for food or arinks at a future date (see Appendix J for examples). Approximately $10 \%$ of the establishments offered free food to the designated driver at the time they elected to participate in the program. Other, more infrequent, incentives supplied to designated drivers included t-shirts, free cover charges, and a contest giving away a car.

The Degree of Sobriety That Is Required. As noted earlier, while most programs required that anyone wanting to be a designated driver had to be sober upon arrival and then remain abstinent, a small number of programs allowed light drinking by their designated drivers. specifically, one program permitted the designated driver to have one drink, and three programs permitted up to two drinks.

Some respondents admitted that in many cases it was difficult to ensure that designated drivers arrived sober and remained sober. Designated drivers who had been drinking before arrival could usually go undetected unless servers got close enough to smell alcohol. The ease or difficulty of making sure they stayed abstinent seemed to vary with the setting. In restaurants, it was easy for the waitress to keep track of the designated driver. In busy bars, however, it could be extremely difficult for the staff to keep track of what the designated drivers drink. 
Who Initiates the Selection of a Desionated Driver? In most DDPs, it was the patron interested in becoming a designated

driver who had to take the initiative. However, not much was required of patrons, since they needed only to express their interest in becoming a designated driver to one of the staff. On the other hand, in over a third of the DDPs, eligible parties were approached by the staff and asked if they wanted to select a designated driver. Tabulation of these indings is complicated by the reports that many DDPs did not employ a consistent procedure for approaching parties. That is, staff sometimes, but not always, approached eligible parties about participation in the DDP. In those cases where the staft spoke to patrons about the DDP, the contact usually was initiated by the server. In fust two cases, the patrons were approached and spoken to at the door.

Identification for the Desionated Driver. Some means whereby the drinking establishment could identify the individuals who elected to be the designated driver was used in all but two of the drinking establishments. This practice enabled the servers of alcohol to keep track of who the designated drivers were during the evening in order to (1) avoid charging them for beverages they were entitled to receive for free and (2) to determine whether the designated driver was drinking only non-alcoholic beverages.

The type of identification varied, but several types were common. Almost 50 of oll the drinking establishments used buttons as identification. Messages on the buttons included "I'm the designated driver," "No thanks, I'm driving," and ":'ve got the key." The second most common form of identification was some type of sticker. Other means of identification included the following: a hand stamp, membership card, and a special (red) cup. Appendix $K$ contains examples of the types of identification used by estab Iishments.

Several respondents noted problems concerning the more visible methods of identifying designated drivers. For example, one stated that patrons were unwilling to wear buttons. Several reported that they had changed the method of identification either by abandoning it altogether or by moving to a less obtrusive form of identification, such as a hand stamp.

The Effects of DDPS

The Number of Designated Drivers. In order to determine the level of participation in DDPs, we first asked about the number of designated drivers who elected to participate in the program. Then in an effort to place the response in perspective, we asked for an estimate of the number of eligible parties. Not all establishments could provide adequate information about either the number of designated drivers or the number of eligible parties. There were several problems. First, not all programs collected systematic data on the numbers of designated drivers, and none. 
apparently collected data on the numbers of eligible parties. second, presumably because of the small number and sporadic occurrence of designated drivers, it was difficult for our respondents to estimate their numbers. Third, we did not administer a standardized interview and allowed respondents to answer in whatever time period was most meaningful to them. Consequently, the responses were made in terms of days, weeks, months, year, weekend evenings, evenings, busy evenings, holidays, and New Years eve. Fortunately, the majority of respondents who answered both questions gave estimates that were either in terms of weeks or could be converted to a weekly basis.

There was wide variation among drinking establishments in the number of individuals who became designated drivers. One establishment reported that there was only 1 designated driver per year, while two other establishments estimated that there were up to 70 participants per week. The majority of drinking establishments reported that the number of designated drivers was 20 or less per week. Table 1 shows the numbers of designated drivers per week for the 29 out of 40 drinking establishments whose data could be presented on a weekly basis.

TABLE I

REPORTED NUMBER OF DESIGNATED DRIVERS PER WEEK. *

\begin{tabular}{|c|c|c|}
\hline $\begin{array}{l}\text { NUMBER OF } \\
\text { DESIGNATED DRIVERS }\end{array}$ & $\begin{array}{c}\text { NUMBER OF } \\
\text { ESTABLISHMENTS }\end{array}$ & $\begin{array}{l}\text { PERCENTAGE } \\
\text { OF TOTAL }\end{array}$ \\
\hline $\begin{array}{l}1 \\
2-5 \\
6-9 \\
10-20 \\
21-30 \\
31-40 \\
41-50 \\
51-60 \\
61-70 \\
\text { over } 100\end{array}$ & $\begin{array}{r}4 \\
6 \\
1 \\
10 \\
2 \\
1 \\
1 \\
0 \\
2 \\
2\end{array}$ & $\begin{array}{r}14 \\
21 \\
4 \\
35 \\
7 \\
4 \\
4 \\
0 \\
7 \\
7\end{array}$ \\
\hline TOTAL & 29 & 1038 \\
\hline
\end{tabular}


Table 2 presents the data for thirteen drinking establishments that reported both the number of designated drivers and an estimate of the number of eligible parties in time frames that could be converted to a weekly basis. Note that since criteria for eligible parties varied, the number of eligible parties served per week varied. considerably from establishment to establishment and may have little relationship to the total number of parties served.

TABLE 2

REPORTED NUMBER OF ELIGIBIE PARTIES AND
DESIGNATED DRIVERS IN DRINRING ESTABIISERENTS *

\begin{tabular}{|c|c|c|}
\hline $\begin{array}{l}\text { NUMBER OF } \\
\text { ELIGIBLE PARTIES } \\
\text { (Per week) }\end{array}$ & $\begin{array}{l}\text { NUMBER OF } \\
\text { DESIGNATED DRIVERS } \\
\text { (Per week) }\end{array}$ & $\begin{array}{l}\text { DESIGNATED } \\
\text { DRIVERS AS PERCENT } \\
\text { OF ELIGIBIE PARTIES }\end{array}$ \\
\hline $\begin{array}{r}240 \\
900 \\
2000 \\
2800 \\
7000 \\
840 \\
228 \\
250 \\
300 \\
1000 \\
50 \\
193 \\
10\end{array}$ & $\begin{array}{c}0.5 \\
5 \\
12 \\
35 \\
105 \\
21 \\
7 \\
10 \\
20 \\
70 \\
12 \\
70 \\
5\end{array}$ & $\begin{array}{l}0.2 \\
0.6 \\
0.6 \\
1.3 \\
1.5 \\
2.5 \\
3.0 \\
4.0 \\
6.7 \\
7.0 \\
24.0 \\
36.0 \\
50.0\end{array}$ \\
\hline
\end{tabular}

*Iimited to 13 establishments that estimated the number of eligible parties in time periods that could be converted to weeks and conducted their program throughout the year.

Observations made during our site visits indicated that the reported numbers of designated drivers were probably overstated. At three of the four sites, the number of designated drivers when we were present was considerably lower than than the number we expected based on the earlier telephone conversation. Since we visited each program on only one night, it is of course possible that the numbers of designated drivers during of our visits were uncharacteristically low. However, our on-site discussions with program staff tended to confirm what we observed, namely that. 
there were probably fewer designated drivers than reported to us during the telephone contacts.

Some over-reporting of the numbers of designated drivers may have been due to the absence of good record keeping. However, in some drinking establishments, an accurate system had been established which enabled managers to determine exactly how many designated drivers had been served. Such systems included keeping a count of the number of buttons or coupons given out each day and marking bills to indicate that a beverage was provided at no cost. We should hasten to add that even where the number of observed designated drivers was lower than the number reported, the discrepancy was not great and could have been due to seasonal or daily variations.

still another factor must be taken into account when judging the numbers of reported designated drivers. We learned that at three of the drinking establishments we visited, staff sometimes approached patrons observed to be drinking only non-alcoholic beverages and asked them if they wanted to become a designated driver. The patrons invariably agreed, since they received some type of free incentive for doing what they were already doing not drinking alcohol. It is not clear how to count this type of patron. In some cases, the non-drinker probably was the driver and perhaps should be counted as a designated driver. In other cases, we fear that the non-drinker simply agreed to participate in the program in order to obtain the incentives, regardless of the actual driving arrangements within the group.

In sum, the absolute values of the reported numbers of designated drivers should be regarded with some skepticism. In our view, the number of designated drivers reported by drinking estabiishments should be considered an upper limit. That is, there may have been that many or fewer designated drivers, but it is very unlikely that there were more designated drivers than reported. And the main point these data make is that, with very few exceptions, there were not many designated drivers being reported.

Characteristics of Designated Drivers. Typically, the respondents either did not have a clear impression of the types of individuals who elected to be or were chosen as designated drivers. Their best guess was usually that there was no particular type of person who became a designated driver and that it could be anyone from the full range of the clientele served by their establishment. The main exception was that some respondents felt that women were more likely than men to be the designated driver. Finally, roughly ten percent of our respondents drew the conclusion that their designated drivers were people who would have stayed sober or would have been light drinkers anyway.

Our interviews with designated drivers during site visits strongly supported this latter view of designated drivers. While our sample of ten designated drivers who were interviewed is extreme- 
Iy small, nevertheless they were without exception either nondrinkers or very light drinkers. Furthermore, we know that because of the policy described above, at least some patrons counted as designated drivers were individuals observed by the staff to be drinking only non-alcoholic drinks.

It is impossible to generalize from our small sample of designated drivers. However, our observations raise the possibility that designated driver programs may not stop many people from drinking. or if they do reduce drinking, the reduction tends to apply to light drinkers who would have been little or no risk even if they consume their normal complement of alcohol.

The above assessment may not be as strong an indictment of DDPs as it first appears. Even if DDPs do not reduce drinking and do not encourage more people to remain sober, they could still be effective in motivating groups of patrons to let the sober person do the driving. While the designated drivers might have abstained or drunk very little even without the program, they may not have been as likely to do the driving without the program. Publicizing DDPs may also encourage drinkers to drink more moderately by reminding them of the dangers of driving after drinking and by communicating a sense that the establishment is concerned about drinking and driving. Unfortunately, we have no evidence bearing on the validity of these conjectures.

Do other Members of a Group with a Designated Driver Drink More than Normal? The evidence concerning this question is inconclusive. Roughly one quarter of our respondents believed that the companions of designated drivers tended to drink more than normal, while another quarter felt that the companions drank the same as usual. The rest provided no information on this issue. one key factor may be the normal drinking level of the group members. Some individuals reported to us that they were normally light drinkers and did not change their drinking behavior just because there was a designated driver in the group. However, there were numerous reports that heavier drinkers often took full advantage of the opportunity to be free of worries about getting home safely and, therefore, allowed themselves the luxury of drinking more than they would if they had to do the driving.

Even if we could be certain that DDPs "encouraged" members of the group to drink more, there would be disagreement among different observers as to how to weigh such evidence. Some would say that by encouraging heavier consumption of alcohol, DDPs contribute to problem drinking and alcoholism. These observers might add that even if DDPs prevent driving after drinking, these programs increase the likelihood of violence, falls, and other untoward consequences associated with the heavier drinking. By contrast, other observers would no doubt point out that if the heavier arinking by patrons is infrequent, there is no real danger of the program contributing to serious alcohol abuse. They might also argue that servers can still intervene to prevent intoxication to 
the point where the dangers of unexpected consequences become significant. There is also the issue of whether the benefits derived from reducing driving after drinking outweigh other negative program consequences.

In the BACKGROUND section we mentioned the concern that DDPs may make it more difficult for servers to stop the designated driver's companions from drinking to the point of intoxication. Anecdotal evidence from our interviews with servers tends to support the view that this is not true to any significant degree. Also, this issue was not cited as a problem during telephone interviews. Finally we should note that establishments that decide to institute a DDP may tend to be those which are most Iikely to enforce the legal prohibition against serving intoxicated patrons. If so, this would tend to counteract the potential problem of DDPs leading to reduced server intervention.

The Public Relations Value of DDPs. Designated driver programs clearly served a public relations role for some drinking establishments. Some drinking establishments reported that their programs have produced goodwill with both patrons and the community. For some drinking establishments, the DDP was a highly visible example of their efforts to deal with the problem of alcoholrelated traffic crashes while continuing to serve their function of providing alcohol.

A closely related issue is the amount of publicity/advertising involving DDPs. In general, we found that there were two primary mechanisms through which DDPs received exposure in the mass media. First, some drinking establishments included information about their DDP in most or all of the advertising for their establishment. Second, the mass media contributed to the dissemination of information about DDPs both through news stories and by offering free public service announcements dealing with
DDPs.

In. the BACKGROUND section we indicated that some concern exists about "paper" DDPs which are unlikely to have any impact on drinking and driving but can serve the interest of the estabiishment by improving its reputation in the community. The criteria we used to select programs for study made it unlikely that we would encounter paper programs, thus we are not in a position to offer clear evidence as to the extent of this problem. On the other hand, when we were engaged in the process of identifying DDPs, we got the distinct impression that some were programs in
name only.

The Effectiveness of DDPs in Reducing DWI

This study was intended to produce descriptive findings and made no pretense of being an evaluation of designated driver activities. In addition, we are unaware of any evaluations of designated driver activities conducted by other investigators. 
Consequently, we can say very little about the effectiveness of the designated driver activities that we examined in reducing alcohol-related crashes.

We hypothesize that DDPs have a modest "direct" impact in reducing the number of intoxicated drivers on the roads. While the programs may do little in terms of getting selected individuals to drink less (since designated drivers may already be abstainers or light drinkers), they could be useful in motivating arinkers to take advantage of the opportunity to ride with a sober driver who happens to be available.

It is also possible that DDPs indirectly effect the number of alcohol-related crashes by heightening the public's general awareness of the drinking and driving problem and ways to combat it. To begin with, we obtained extensive anecdotal evidence from the DDPs that their patrons were drinking less on the average than in the past. This behavior change suggests that attitudes about both drinking, and drinking and driving, may also be changing. If that is the case, then people might be more receptive than in the past to all types of drinking and driving messages. They may be particularly receptive when they experience relevant messages while in a situation where they are drinking and know that they will soon be using an automobile.

\section{Defunct DDPs}

Three of the 40 drinking establishments with which we were able to hold extended discussions were defunct. Since each of the three gave a different reason for their program ending, there is no discernable trend. However, two of the three reasons may be important because of possible implications for the future of the designated driver concept.

The manager of a Holiday Inn explained that he could not justify operating a program containing two inherent flaws. First, while DDPs are a viable solution for the social drinker, they are largely a failure with the problem drinkers who are responsible for most crashes. Second, the program will not work unless a group of individuals is responsible enough to designate a driver at the start of the evening before they arrive at the bar with two or three cars for six people.

Surprisingly, the manager of a TGI Friday's restaurant said that they discontinued their DDP because of a liability problem. She explained that the establishment could be held liable in the event of a crash if a designated driver left the establishment with drunk companions but did not drive them home.

The manager of the third defunct DDP was not sure why it was discontinued, other than pointing out that the DDP did not seem to fit into the prevention plan introduced when new owners took over the establishment. 


\section{Informal Designated Driver Activities}

Results of Initial Calls to Knowledgeable sources and Membership Drinking Establishments

No information came to light about membership organization participation in the designated driver concept during conversations with the Governor's Representatives' offices. As for the many other contacts with whom we spoke (some of whom were very knowledgeable), the information they had about membership organizations was discouraging.

Veterans organizations. While we did not undertake an exhaustive investigation of this category's level of participation, the sources we contacted led us to believe that groups like the Veterans of Foreign Wars and American Legion tended not to be involved in programs that might lead to keeping a drinking-driving member off the road. Some ranking members of these organizations showed little concern about the issue. As Dr. James Schaefer, Director of the Office of Alcohol and Other Drug Abuse Programming at the University of Minnesota, told us, the veterans organizations are the "toughest cookies in the kitchen" when it comes to alcohol prevention issues. Schaefer, one of our most knowledgeable contacts, went on to say that their attitude seems to be "Hey, we fought for our nation. Now we're entitled to drink."

Public service or Fraternal organizations. As with the veterans organizations, spokespeople for the broad category of "Public Service or Fraternal organizations" tended to show little concern about designated driver activities. There appeared to be a general lack of awareness at the administrative level in these organizations. Included in our calls were national organizations such as Rotary, Rnights of Columbus, and Elks, as well as several private clubs. It is important to emphasize that the response from these organizations was generally very cool and defensive. One irritated representative for a private club remarked, "Oh no, we deal with real adults." A higher level of awareness was observed in talking to a Boston Rotary director. He told us that the club used to have a cocktail hour prior to noon meetings, but they discontinued the practice because he felt that it was being abused. He mentioned that they lost about $20 \%$ of their membership as a result of that decision.

Universities. Phone calls to several of Boston's major universities and colleges turned up nothing in the way of DDP participation. Most public relations or student activities representatives with whom we spoke were not knowledgeable about the issue.

There was some DDP participation through Mississippi universities, particularly Mississippi state-University in starkville where Margaret Eatherly, Public Relations Representative for the Mississippi Alcohol Safety Education Program, has developed both 
DDP and Safe Ride campaigns. However, she emphasized that all Mississippi state campuses were "dry" and that their program was in connection with the local bars which neighbor the campus. Despite the prohibitive state laws, Eatherly indicated that drinking undoubtedly occurred in the campus fraternities and sororities where she believed both the DDP \& Safe Ride programs were seeing some participation. She also mentioned Mississippi University for Women in Columbus as having initiated a DDP in which the neighboring bars participated on a volunteer basis.

Company parties. We learned of only one company that made use of a DDP. The DDP we located was with uSI Insurance Company in st. Paul, wn. Rich Cowles, Public Relations Representative, told us of his company's DDP which was established at a recent holiday party. Cowles said that the program was "disappointing". in that less than 20 of the 200 possible Designated Drivers agreed to participate. He indicated that the motivation for initiating the program was "not a liability issue." Rather, he felt that the main factor was the company's status as an insurer (ie. to set a good example). Moreover, he felt that the company has had a commitment to health issues in general (e.g. smoke-free environment) and that this was another way to demonstrate such a commitment.

\section{Results of Calls to Membership Establishments in Seven cities}

As discussed under methods, the primary objective in contacting membership organizations was to learn about informal designated driver activities. We learned, however, that both formal and informal designated driver activities existed among these types of organizations. We treated designated driver activities as informal when there was little or no formal advertising of the program.

A common trademark of membership organizations that engaged in informal designated driver activities was that the proprietors were unconcerned with the terminology (for example, designated driver versus safe ride). Instead, they worried directly about whether or not drinkers would be driving. Accordingly, there was usually no formal designation of a driver and no incentives were offered for participation in program. In one case, the manager described her "designated driver program" by saying that she arranges to have five or six club members "on hand" in case someone has overindulged at a club gathering. While this type of arrangement is not consistent with the designated driver concept, the manager referred to it as a designated driver program.

The most difficult membership organizations to reach were university Greek houses. No one seemed to have information about the - existence of alcohol prevention activities. In one case, we were told that designated drivers were "not really needed" because if someone had overindulged, he will just "spend the night." The respondent gave us this information even though we had been told by another source that the designated driver concept was used, 
albeit very informally at this organization. on the other hand, our search for university-based DDPs was quite limited in scope, and it was hampered by coming at the end of a school term when many students had departed.

The specific results of the calls were that roughly half of the veteran and university organizations that were contacted reported having either formal or informal designated driver activities. In contrast, just seven percent of the fraternal organizations reported designated driver activity. Note that the level of participation by Veterans organizations is much higher than we expected on the basis of our initial calls to knowledgeable sources. Table 3 shows the numbers of formal and informal designated driver activities reported by each type of membership organization.

TABLE 3

PREVENTION ACTIVITIES AMONG MEMBERSHIP ESTABIISHMENTS

\begin{tabular}{lcccc} 
GROUP & $\begin{array}{c}\text { Total } \\
\text { TYPE }\end{array}$ & $\begin{array}{c}\text { FORMAL } \\
\text { Called }\end{array}$ & $\begin{array}{c}\text { INFORMAL } \\
\text { DDP }\end{array}$ & $\begin{array}{c}\text { OTHER } \\
\text { PREVEN- } \\
\text { TION }\end{array}$ \\
\hline VETERANS & 11 & 3 & 1 & 2 \\
FRATERNAI & 32 & 2 & 0 & 8 \\
UNIVERSITY & 11 & 0 & 3 & 7 \\
\hline TOTAL: & 54 & 5 & 4 & 17
\end{tabular}

Note: "Other Prevention" activities, such as safe ride programs, were counted regardless of whether an organization was involved in designated driver activities.

Membership Organizations' Concerns About Liability. All three of the veterans organizations that had implemented formal DDPs commented on the subject of liquor liability, saying that it was the reason for their developing a DDP. The subject of liquor liability did not arise when talking to the two fraternal organizations that had formal DDPs.

In addition to the five formal programs, four more establishments claimed to have informal programs. One of the two fraternal organization spokespersons said that the question of liability was the central issue. The spokesman (bartender) for the other orga- 
nization was quite uninformed about the bar's program. The five informal university programs were extremely sketchy to begin with, consequently, the liability issue was never discussed.

Without exception, if the subject of liability came up during a call to a membership organization, the respondent claimed that liquor liability was the primary, if not sole, reason for the organization taking actions to prevent drinking and driving. In addition, the state office of the VFW for Massachusetts made the statement that anti-drinking and driving actions taken by the VFW have been initiated because of the liability issue.

Finally, our phone calls indicated that membership organizations may differ from many public drinking establishments in an important way. We were left with the impression that members in many of these organizations look out for one another's well-being in an almost familial way. There may be a greater tendency at membership organizations than at other drinking establishments for members to arrive and leave together. Furthermore, since most people know each other, it may be more likely that when it is time to leave and someone appears impaired, there will be someone else who will drive that person home. 


\section{DISCUSSION}

What are Reasonable Expectations for Numbers of Designated Drivers?

The numbers of designated drivers produced by DDPs tended to be low, both in absolute terms and in terms of percentages of eligible parties (though the reliability of this latter figure is especially questionable). However, in order to evaluate these numbers, it is necessary to explore the notion of "eligible parties" in greater detail. This will help place the data we obtained in perspective by considering how many designated drivers it is reasonable to expect from a DDP.

Before pursuing this line of reasoning, a distinction should be made between restaurants that serve alcohol and most other drinking establishments. Respondents at the sites we visited that included restaurants claimed that there tended to be relatively little heavy drinking in the restaurant sections of their establishments. Even people who had drinks before eating and then along with their meal tended to drink relatively little in comparison with people in the lounges and bars where little or no food was served. Furthermore, according to some staff, restaurant patrons tend not to remain in the establishment very long in comparison to some heavy drinkers who spend many hours sitting at a bar. Some staff went so far as to suggest that they restaurant. Therefore, in order to simplify the discussion, we will focus on drinking establishments, such as nightclubs, bars, and lounges, where the primary "refreshment" is alcohol.

It is important to acknowledge the inherent contradiction of expecting significant numbers of people who choose a drinking establishment as their destination to abstain from drinking alcohol. Admittedly, not everyone goes to drinking establishments just to drink. Nevertheless, in this environment, drinking is clearly the focus around which all other activities take place. Despite the inconsistency of remaining abstinent at a drinking establishment, there are designated drivers who do in fact agree to abstain from alcohol. Who are these people?

Theoretically, every party that enters a drinking establishment is a candidate for a DDP. Even someone coming alone could agree to stay sober in order to make driving home safer. Large groups of drinkers are candidates for a DDP as long as there is one designated driver for every car.

Although every party may be a candidate, obviously some parties are less likely than others to select a designated driver. By considering how many parties are likely to participate in a DDP and how many are unlikely to participate, some insights can be 
gained concerning the numbers of designated drivers it is reasonable to expect.

Many drinking establishments serve as meeting places, both for strangers and for people who already know each other. Patrons coming to make new acquaintances probably tend to come alone or in gmall groups of the same sex. Since drinking is one of the fundamental mechanisms available in drinking establishments for meeting and socializing with others, it is unlikely that these patrons who have come to meet others will forego alcohol.

Many other patrons come as couples. Here too, it seems unlikely that many people would be responsive to appeals for selecting designated drivers. We guess that most people will think that if one person drinks whlle the other abstains, the result is likely to be an impediment to socializing.

This type of reasoning leaves larger groups of individuals as the most likely candidates for a DDP. And in fact, while the estimates of our respondents concerning the average size of groups of patrons that produced designated drivers varied considerably, the estimates tended toward groups of four or more. But even with larger groups, some may be much more likely to participate than others. First, there is the obvious limitation that only larger groups of individuals who travel in one car are potential candidates for designated driver activities. In addition, we speculate that it is probably important that most of the group know each other fairly well. our reasoning is that the iess well the group members know each other, the less likely it is that anyone will volunteer to be the only abstainer for fear of appearing odd.

If these speculations are accurate, they may well explain a good part of the difficulty that drinking establishments have in attracting designated drivers. There may in fact be very few groups who meet the "criteria" outlined above for likely candidates for designated driver activities.

\section{Techniques For Increasing the Numbers of Designated Drivers}

It seems clear from our data, even in the absence of a statistical analysis, that there are actions which drinking establishments can take to markedly increase the numbers of groups agreeing to select a designated driver. Two types of actions stand out. One is simply to increase the size of the incentive. For example, Margaritaville in California was unique among our sample of DDPs in offering designated drivers a free meal selected from any item on the menu. Not surprisingly, Margaritavilie reported an unusually high number of designated drivers. Jose's in Arizona, a program that operates only on New Year's Eve, was another establishment reporting much higher than average numbers of designated drivers. At Jose's, designated drivers did not pay a cover charge, and they were given a coupon for a free dinner at a 
later date. This study can not prove that a causal relation exists between size of incentive and number of designated drivers, yet the relationship is certainly a logical one, and the limited data available are consistent with expectations.

Another action drinking establishments can take that appears to be useful for increasing the numbers of designated drivers is to actively solicit participation in the DDP. Recruitment of designated drivers can of course take many forms. At the one extreme of minimal action, some drinking establishments rely on the patron to volunteer after having learned about the program from past experience or from posters, table tents, and/or buttons worn by servers. At the other extreme, we found one drinking establishment, Juke Box Saturday Night in Minnesota, where most larger groups of individuals are asked directly if they would like to participate in the DDP. The question was usualiy posed by doormen or a cashier collecting cover charges. Cocktail waitresses also invited participation, though less frequently.

We do not have the data needed to test the proposition that, all else being equal, active solicitation of patrons tends to produce more designated drivers than a passive approach. However, as indicated above, the proposition is both logical and consistent with the available data. One anecdote in particular is highly suggestive. At Margaritaville, the hostess informed patrons about the DDP, but then if patrons were interested, they had to express their interest later on when the waitress came to the table. A patron who was with a party that chose not to select a designated driver pointed out that it was easy to forget about the program from the time it was announced by the hostess until the waitress arrived. Even though Margaritaville was more active than most drinking establishments because of the person-to-person presentation of the DDP, the absence of a direct request for patrons to participate when they were about to order may have reduced the number of groups that chose to participate.

Although active solicitation may well be one useful way to increase the numbers of designated drivers, several managers stated that they did not want to risk offending their patrons by asking them to participate. After all, patrons do not go to drinking establishments with the expectation that they will have to Iisten to a sales pitch for abstinence. on the other hand, it is by no means clear how many patrons might be offended. The recent growth of public concern about drinking and driving suggests that the risk of offending patrons may be quite low. A telephone survey (conducted by the authors under another contract during 1985) of 500 randomly selected Iicensed drivers living in a Massachusetts working class community showed that $62 \%$ agreed or strongly preventing drunk driving by their patrons." Given this kind of response and the fact that a polite invitation to participate in a DDP is not very intrusive, it may be that patrons are more receptive than some owners feel. 
How Extensive Are Informal Designated Driver Activities

One of the most important unanswered questions that remains involves the extent of informal designated driver activities. Unfortunately, all we can say is that we have anecdotal evidence that some groups of people do, in fact, designate drivers to remain sober and do the driving. And they designate these drivers in the absence of any formal program. This anecdotal evidence does not come from the membership organizations we contacted. As discussed earlier, few of these organizations reported any informal designated driver activity. Rather, the evidence comes form contacts with formal DDPs where many of our respondents stated that they personally knew of instances of informal designated driver activities. Furthermore, some of the groups containing designated drivers that we interviewed during site visits reported that they employed designated drivers on their own whenever there was drinking followed by driving.

One way to determine how common informal designated driver activities are would be to conduct a survey of the general public. At present, we are unaware of any such survey other than the one we are conducting under a separate contract. Its results will be reported at a later date.

\section{The Need For Preplanning}

Some of our respondents and also some NHTSA staff have raised the concern that preplanning may be necessary in order for DUPs to work effectively. The argument is that decisions about who will be drinking and who will remain sober to do the driving must be made at the same time as decisions about how many cars to take and about who will ride in which cars. Otherwise, at least two serious obstacles to participation in DDPs arise. First, groups of individuals may tend to drive in several cars, thereby requiring many drivers. We assume that it is far more difficult to get several people in a group to agree to abstain than it is to get one person to make the sacrifice for the common good.

Another obstacle can arise even if the entire group drives to the drinking establishment in a single vehicle. If members of the group drive to a central meeting place, such as the home of one of the nembers, and then travel together to the drinking establishment, they still face the risks of driving home while intoxicated from their meeting place. Participation in a designated driver program does increase their safety during that part of the journey from the drinking establishment back to the meeting place. But without sufficient preplanning, there may still be several intoxicated drivers returning from the meeting place to members' homes.

In this connection, it is noteworthy that we found no messages concerning preplanning in the advertising for DDPs which we ob: 
served during site visits or in the ads that were mailed to us. It would seem advisable that such advertising contain some references to the advantages of preplanning when employing the designated driver concept.

The Public Relations Value of DDPs

Several of our respondents made clear either explicitly or implicitly that their DDPs served a public relations role for their companies. For example, adoption of a DDP can bring goodwill from various segments of the community toward a drinking establishment. The importance of this finding is that it can be used as an incentive for drinking establishments to institute a DDP. In fact, some respondents felt that the small costs incurred by their DDPs were well worth the gains received from increases in goodwill.

\section{Servers May Be The Victims of DDPs}

The people who actually serve drinks to patrons tend to be dependent on tips for their income. Several bartenders and waitresses explained to us that people receiving free non-alcoholic beverages tend not to tip as much as patrons paying for highpriced alcoholic beverages. Thus, part of the cost of a DDP is borne by the people who serve the alcohol. Unlike the owners of the establishment, they can not write off part of the costs, nor do they have other ways to compensate for their loss of revenue.

One solution would be for the management of the drinking establishment to compensate servers for the loss of tips from designated drivers. Without such an arrangement, it is not reasonable to expect support for the designated driver concept from many of the people most intimately involved in making DDPs work.

Do Designated Drivers Do The Driving?

Here again we are left with a crucial question for which we have no satisfactory data. Drinking establishments do not know whether designated drivers actually do the driving when the party
leaves.

A few establishments took some action at least some of the time to prevent a drinker in the designated driver's party from doing the driving. At the Great Escape, for example, the doormen would sometimes follow patrons to the parking lot to check on who did the driving. We do not have unobtrusive observational data to determine how many designated drivers did the driving with and without such supervision.

Efforts to make certain that designated drivers do the driving would probably be impractical and might be costly. In some locations where patrons do not park near the drinking establishment, such efforts would be virtually impossible. In any case, all 
types of surveillance efforts could easily be defeated by patrons. They would simply need to allow the designated driver to drive out of the parking lot and up to the first convenient place where a switch in drivers could be made.

The obstacles to an establishment exerting complete control over the situation, emphasizes the importance of voluntary participation on the part of patrons. In fact, it may even argue against the use of large incentives for enticing patrons into the DDP. with large incentives, some people who have no intention of doing the driving may volunteer to stay sober merely to obtain the incentives. With smaller incentives, hopefully only those people who believe in the program will agree to be the designated driver. Furthermore, without voluntary participation in the designated driver concept, there will be no way to gain the participation of people when they are drinking at private functions. That is, the ultimate aim of the designated driver concept is that people will choose to employ it whenever there is drinking and not just when large incentives are made available by a drinking establishment. 
The implementation of DDPs within drinking establishments is a reasonable way to introduce a large segment of the drinking public to the designated driver concept. Not only will drinkers learn about the program, but they encounter the information at a time when they are getting ready to drink.

In addition to the objective of inducing patrons to designate a sober driver, DDPs could be having a positive impact on the drinking and driving problem in at least two other ways:

- They may sensitize people to the designated driver concept so that they will be more likely to make use of it in the future.

- Information promoting DDPs almost certainly contributes to an increased awareness about the drinking and driving problem.

At the same time, DDPs are relatively inexpensive to implement, and they may even generate sufficient goodwill and favorable free publicity for many drinking establishments to make their adoption cost effective.

Despite their promise, we found that, overall, DDPs produced relatively few designated drivers. And there was some evidence that the designated drivers that did participate in these programs tended to be light drinkers, or even abstainers.

There are two major reasons why these reservations should not be interpreted to mean that the designated driver concept should be abandoned. First, DDPs may sensitize people to the drinking and driving issue and could result in drinkers taking other types of effective actions (which this project could not measure) to reduce the chances of their having an alcohol-related automobile crash. Note that this potential benefit is not directly tied to the numbers of designated drivers that participate in DDPs. Second, there are strategies for increasing participation in DDPs which are relatively easy to implement and inexpensive.

While our data do not permit us to draw conclusions about the pros and cons of various features of DDPs, we offer several suggestions for increasing participation that are based on a combination of our observations and common sense. Perhaps the most important conclusion is the obvious assumption that the designated driver concept can only work if people know about it. Thus, anyone interested in promoting the concept must make every effort to ensure that the target audience both knows about the designated driver concept and that the option of designating a driver is salient at the appropriate time. In terms of drinking 
establishments, this line of reasoning argues for an active program in which the DDP is presented to patrons by a staff member and then followed immediately by a request for participation. There are perfectly legitimate reasons for drinking establishments to resist this approach, but they should at least be made aware of the option.

Personal contact between the staff and a patron volunteering to be a designated driver can also serve the purpose of helping determine whether the patron is sober. Ideally, all prospective designated drivers should be screened when volunteering to determine if they are sober. One DDP asks them to surrender their driver's license, and this process helps the staff judge whether the prospective designated driver is sober.

Personal contact by the staff when the designated driver leaves the drinking establishment might also be very beneficial. First, the staff has another opportunity to determine whether the designated driver is sober. Second, the staff can request assurances that the designated driver will indeed do the driving. Such assurances do not guarantee that the designated driver will in fact drive, but they do serve as another safety message. Finally, managers in some DDPs thank departing designated drivers for participating in their program as a way of providing additional positive reinforcement.

The level of participation in DDPs can probably be increased by increasing the size of the incentives that are offered to designated drivers. However, there are the possible disadvantages of additional cost to the drinking establishment and the potential for abuse of the program by people who participate solely to obtain the incentive without intending to do the driving. Another alternative involving incentives is for DDPs to offer as wide a variety of incentives as possible in an effort to maximize the chances of potential designated drivers finding one that interests them.

DDPs might be able to increase participation by eliminating, or at least reducing, restrictions. For example, the DDP should ideally be available whenever the drinking establishment is in operation. And groups of all sizes should be eligible for participation.

Efforts should be made to reduce any stigma associated with becoming a designated driver. An interesting approach used in some DDPs is for all staff to wear designated driver buttons. One manager felt that having his doormen wear the buttons showed patrons that being a designated driver is respectable. other DDPs have discarded the use of highly visible devices, such as buttons, in order to avoid drawing attention to the designated driver. If the current trend toward increasing public concern with drunk driving continues, any stigma associated with becoming a designated driver may fade. 


\section{Evaluation of Effectiveness}

Because of the great potential that the designated driver concept holds for reducing the incidence of alcohol-related crashes, research should be undertaken with the specific aim of evaluating the effectiveness of DDPs. This project was basically an exploratory investigation that took the form of a descriptive study of DDPs. More rigorous studies should be undertaken to evaluate the potential benefits of DDPs.

\section{Experimental Comparison of DDP Features}

Research should be conducted in order to explore both the size of incentives for participation as a designated driver and the value of staff making direct requests to patrons as mechanisms for increasing the numbers of individuals who participate in DDPs. We have speculated at length about methods of increasing the numbers of individuals who agree to participate in DDPs, because the number of designated drivers is such a key element in the value of these programs. However, it would be valuable to study these methods in a scientifically controlled manner. Such a study would be relatively simple once the cooperation of a drinking establishment(s) had been obtained. 


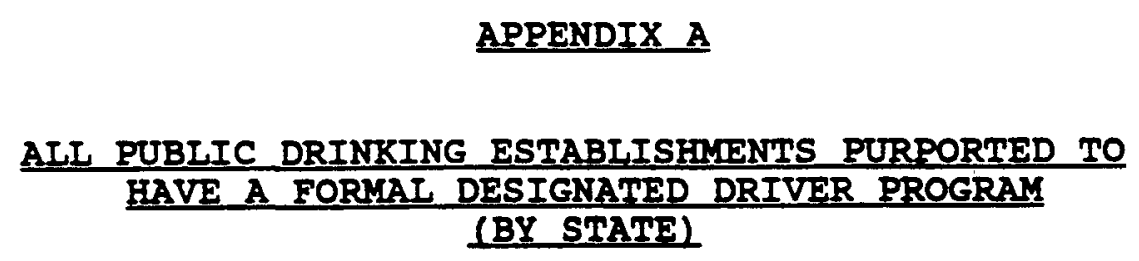

This Appendix lists public drinking establishments which knowledgeable sources reported to have DDPs. At the end of the list is a set of organizations which were reported to conduct DDPs in their member establishments throughout the country.

The entries show if the programs were contacted, and if so whether they had an active or defunct DDP, or whether they did not have a DDP. Any program which does not have this entry was purported to have a DDP, but this information was not verified. People may find this list useful to begin the process of contacting a DDP located near them. The listing includes all the information that was made available to us, and may be missing part of the contact information.

\section{ALABAMA}

Bennigan's, 3782 University Dr., Huntsville, AI 35816. (205) 534-4503. [Contacted: active DDP.]

Darryl's, Birmingham, Huntsville, Montgomery \& Mobile, AL.

El Casino's, Huntsville, AL.

\section{ALASKA}

Northern Iights Inn, $598 \mathrm{w}$. Northern Iights, Anchorage, Ax. 99503. (907) 561-5200. [Contacted: active DDP.]

\section{ARIZONA}

Bobby McGee's Corp., Pheonix, Az. (602) 956-7660.

Bum Steer, Tucson, AZ. (602) 884-7377.

Cowboy's, Pheonix, Az. (602) 838-1178.

Graham Central Station, Pheonix, AZ. (602) 265-4533.

Minder Binder's, 715 S. Hayden, Tempe, AZ. 85281. (602) 966-1911. [Contacted: active DDP.]

Mr. Lucky's, Pheonix, AZ . (602) 246-0686. 


\section{ARKANSAS}

Club. West, Fayetteville, AR. (501) 442-7337.

The Faded Rose, Little Rock, AR. (501) 663-9734. [Contacted: no DDP.]

Jose's, 324 W. Dickson, Fayetteville, AR. 72701. (501) 521-0194. [Contacted: active DDP.]

The Old Post office Gathering Place, Fayetteville, AR. (501) 443-5588.

\section{CALIFORNIA}

Bobby McGee's, 200 S. State College Blvd., Brea, CA. 92621.

(714) 529-1998. [Contacted: active DDP.]

Bull and Mouth, Riverside, CA. (714) 684-7720.

C.D.'s Costa Mesa Omlette Parlor, Costa Mesa, CA.

(714) 645-0740.

Chester Drawer's Inn, Costa Mesa, CA. (714) 631-4277.

Crazy Gringo, San Diego, CA. (619) 297-6940.

Fanny Ann's Saloon, Old Sacramento, CA. (916) 441-0505.

Foggy's Notion, San Diego, CA. (619) 222-2791.

Fresno Omlette Parlor, Fresno, CA. (209) 226-9145.

J. Sloan's, Los Angeles; CA. (213) 659-0250.

Madison Bear Garden, Chico, CA. (916) 891-1639.

Malibu Inn, Malibu, CA. (213) 456-6060.

Malibu Omlette Parlor, Malibu, CA. (213) 456-6106.

Margaritaville, 221 Esplanade, Capatola, CA. 95010.

(408) 476-2263. [Contacted: active DDP.]

Mom's, Los Angeles, CA. (213) 820-1516.

Oar Horse / Buffalo Chips, Santa Monica, CA. (213) 396-4725.

Ocean Park Omlette Parlor, Santa Monica, CA. (213) 399-7892.

Saddlepeak Lodge, Calabasas, CA. (818) 340-6029.

Santa Ana Omlette Parlor, Santa Ana, CA. (714) 550-0846.

$$
A-2
$$


State Armory, Greeley, CA. (303) 352-7424.

St. James Infirmary, Mountain View, CA. (415) 969-0806.

Summerland Omlette parlor, Summerland, CA. (805) 969-1019.

Weber's Place, Reseda, CA. (818) 345-9800.

COIORADO

Hilton Hotel, 743 Horizon Drive, Grand Junction, Co. 81506.

(303) 241-8888. [Contacted: active DDP.]

Hilton South, Denver, Co. (303) 779-6161.

No Frills Grill, 7155 E. Hampden, Denver, Co. 80224. (303) 759-9079. [Contacted: active DDP.]

\section{CONNECTICUT}

Graffiti's, 297 Willetts Ave., Waterford, CT. 06385. (203) 447-0894. [Contacted: active DDP.]

\section{DELAWARE}

Down Under, $60 \mathrm{~N}$. College Ave., Newark, DE. (302) 366-0517. [Contacted: active DDP.]

Ground Round, 801 S. College Ave., Newark, DE. 19711.

(302) 737-0808. [Contacted: active DDP.]

\section{DISTRICT OF COLUMBIA}

Mel Krupin's Restaurant, 1120 Connecticut NW, Washington, DC. (202) 331-7000. [Contacted: active DDP.]

Rumors, 1900 M. St., N.w., Washington, DC. 20036. (202) 466-7378. [Contacted: active DDP.]

FLORIDA

Department of the Navy, Naval Technical Training Ctr., NTTC Corry Station, Pensacola, FL. 32511. (904)452-6317.

[Contacted: active DDP.]

General Mills Restaurant Group, orlando, FL.

GEORGIA

\section{HAWAII}

Miltary Clubs (Pearl Harbor Naval Base). (808) 471-7411.

$$
A-3
$$


IDAHO

IILINOIS

Sage's, 75 w. Algonquin Rd., Arlington Heights, IL. 60005.

(312) 944-1557. [Contacted: active DDP.]

INDIANA

Blue Bird, 216 North Walnut, Bloomington, IN. (812) 336-3984. [Contacted: active DDP.]

Crazy Horse, Bloomington, IN. (8I2) 333-1150.

Gaslight Lounge, Bloomington, IN. (812) 332-1272.

Hooligan's, 430 Kirkwood, Bloomington, IN. 47401. (812) 333-3003. [Contacted: active DDP.]

Jake's, Bloomington, IN. (812) 332-0402.

Nick's, Bloomington, IN. (812) 332-4040.

The ordinary, Nashville, IN. (812) 988-6166.

Peanut Barrel, Bloomington, IN. (812) 336-5121.

Piccadilly's, Indianapolis, IN. (317) 923-7625.

Porthole Inn, Bloomington, IN. (812) 339-1856.

Ramada Inn, Bloomington, IN. (812) 334-3252.

Refuge, Bloomington, IN. (812) 336-4394.

Video Saloon, Bloomington, IN. (812) 333-0064.

Ye Old Regulator, 319 N. Walnut, Bloomington, IN. 47401.

(812) 334-3459. [Contacted: active DDP.]

IOWA

Corso's Pizza, Des Moines, IA. (515) 225-2229.

KANSAS

KENTUCKY

LOUISIANA

Bart's seafood on the Lake Front, New Orleans, IA. (504) 282-0271. [Contacted: no DDP.]

$$
A-4
$$


MAINE

Holiday Inn, 500 Main St., Bangor, ME. 04401. (207) 947-8651. [Contacted: defunct DDP.]

Horse Feathers, Portland, ME. (207) 773-3501.

The Inn at Goose Rocks, Kennebunkport, ME. (207) 967-5425.

John Martin's Restaurants, Waterville, ME. (207) 873-5676.

Snow squall, Portland, ME. (207) 799-2232.

MARYIAND

\section{MASSACHUSETTS}

Amelia's Restaurant, 542 East squantum St., North Quincy, MA.

Bannister's Restaurant, 108 Great Rd., Stow, MA.

BarbyAnn's Restaurant, 251 Iyanough Rd., Hyannis, MA.

Barnaby's Restaurant, 245 Ayer Rd., Littleton, MA.

Barrett's on Boston Harbor, Constitution Plaza, Charlestown, MA. Boathouse Pub, 37 Pope's Island, New Bedford, MA.

Bobby Byrne's Pub, Route $6 A$ and Tupper Rd., Sandwich, MA.

Bobby Byrne's Pub, Route 144, Raynham, MA.

Bobby Byrne's Pub, Lincoln Plaza, Hingham, MA.

Bobby Byrne's Pub, Route 151 and Route 28 a Mashpee Rotary, Mashpee, MA.

Boston Park Plaza Hotel, 50 Park Plaza, Boston, MA.

Bull and Finch Pub, Pickering Wharf, Salem, MA.

Cafe Manhattan, 301 Bridge St., Springfield, MA.

Cafe Montego at Burke H.S., 60 Washington St., Dorchester, MA.

Cap'n Tobey's Chowder House, straight Wharf, Nantucket, MA.

Cappy's Chowder House, Camden, MA.

Capri Restaurant, 139 Cabot st., Beverly, MA. 
Carla's Restaurant, 171 Nahantan St., Norwood, MA.

Chappy's at Hyannis Regency, Route 132, Hyannis, MA.

The Charlie Horse, 99 Main St., Kingston, MA.

The Charlie Horse, 377 Lynnway, Lynn, MA.

The Charlie Horse, 2859 Cranberry Highway, Wareham, MA.

Checker's Cafe, Route 138, Canton, MA.

Chi Chi's Restaurant, 254. Andover St., Peabody, MA.

Christine's Restaurant, 581 Route 28, West Dennis, MA.

Christo's, 782 Crescent st., Brockton, MA.

Coach Lite Restaurant, 1485 w. Housatonic St., Pittsfield, MA.

Colonial country Club, walnut st., Lynnfield, MA.

Colstone Family Restaurant, 226 E. Washington St., North Attleboro, MA.

The Common Market, 97 Willard st., Quincy, MA.

Coonamessett Inn, Jones Rd. and Gifford St., Falmouth, MA.

Copley Square Hotel, 47 Huntington Ave., Boston, MA.

Crossroads Restaurant, 496 Beacon St., Boston, MA.

D'Angelo's, Inc., 385 Weest st., West Bridgewater, MA.

Daniel Webster Inn, 149 Main St., Sandwich, MA.

Delano's Restaurant, 57 North Pleasant, Amherst, MA.

Dome Restaurant, Woods Hole, MA.

Eagle Brook Saloon, 258 Dedham St., Norfolk, MA.

The Edmund Fitzgerald, 542 E. Squantum St., North Quincy, MA.

Finnskinns and Ginns, 165 Yarmouth Rd., Hyannis', MA.

Fiore's (Station One), 296 North St., Hyannis, MA.

Fireside Restaurant and Pub, 171 PeIham St., Methuen, MA.

Fitzgerald's Restaurant, 6 Whitting St., Hingham, MA.

$$
A-6
$$


Fitzwilly's Restaurant, 23 Main St., Northampton, MA.

Foodpublic drinking Concepts, 238 Northampton St., Easthampton, MA.

Friend's and Company, 199 state St., Boston, MA.

Galley Restaurant, Bearskin Neck, Rockport, MA.

Giovanni's, 103 Nogog Square, Acton, MA.

Governor Bradford Restaurant, 312 Commercial St., Provincetown, MA.

Graves Catering and Northampton Country Club; 198 state st., Northampton, MA.

The Great Escape, 500 Washington St., Weymouth, KA. 02188.. (617) 337-7732. [Contacted: active DDP.]

Grendel's Den, 89 Winthrop St., Cambridge, MA.

The Ground Round, 225 Boston Turnpike, Shrewsbury, MA.

Hampshire House, 84 Beacon St., Boston, MA.

Hillcrest Caterers, 220 Bear Hill Rd., Waltham, MA.

Hot Tin Roof, Martha's Vineyard Airport, Edyartown, MA.

Houlihan's Old Place, 60 state st., Boston, MA.

Howard Johnson's/Brambles, 185 Chelmsford St., Chelmsford, MA.

Huskies, 280 Huntington Ave., Boston, MA.

Jimbo's Fish Shanty, 405 Franklin St., Braintree, MA.

John Polcari and Sons, 283 Causeway st., Boston, MA.

Jumbo's Fish Shanty, 245 Northern Ave., Boston, MA.

Joey's Depot, 81-83 Railroad St., Holliston, MA.

J.T.'s Family Restaurant, 1525 Riverside Ave., Somerset, MA.

Justin's Hearthside, Route 53, Hanover, MA.

King's Hill, 120 Bay State Drive, Braintree, MA.

Kowloon Restaurant, 948 Broadway-Route 1 North, Saugus, MA.

Lawrence's Restaurant, 20 Nantucket Ave., Falmouth, Ma. 
IeBiftheque, 210 Union St., Braintree, MA.

LeBiftheque, New River Road, Andover, MA.

Iighthouse Inn-Sand Bar, Iighthouse Rd., West Dennis, MA.

Lombardo's, 6 Billings st., Randolph, MA.

Lombardo's East, 17 Porter St., E. Boston, MA.

Lord Bunbury Pub, 394 N. Market - Fanueil Hall, Boston, MA.

Lowell Hilton, 50 warren st., Lowell, MA.

Mama Josie's Restaurant, 897 Main St., Waltham, MA.

Marriott Hotel, Route 128 and Route 3A, Burlington, MA.

Marriott Long Wharf Hotel, 296 state St., Boston, MA.

Matt Garrett's, 299 Harvard St., Brookline, MA.

Matt Garrett's, West Gate Mall Plaza, Brockton, MA.

Matt Garrett's, 120 Boston Post Rd., Sudbury, MA.

Michael's and Sandy Neck, 674 Route 6A, East Sandwich, MA.

Moynihan's Restaurant, 897 Main St., Worcester, MA.

New Bell Buoy Restaurant, $93 \mathrm{~A}$ Front st., Scituate, MA.

99 Restaurant, 317 Salem St., Lynnfield, MA.

99 Restaurant, 484 Lowell st., Andover, MA.

99 Restaurant, Route 228, Rockland, MA.

99 Restaurant, 267 Chickering Rd., North Andover, MA.

99 Restaurant, 698 Boston Post Rd., Sudbury, MA'.

99 Restaurant, 234 Friend st., Boston, MA.

99 Restaurant, 55 Boston/Providence Tpke., Walpole, MA.

99 Restaurant, 291 Mishawam Rd., woburn, MA.

99 Restaurant, 194 Cambridge Rd., Woburn, MA.

99 Restaurant, 160 Boylston St., Newton, MA. 
99 Restaurant, 13 Commonwealth Ave., Concord, MA.

99 Restaurant, 169 Lexington St., Billerica, MA.

99 Restaurant, 672 Boston Rd., Billerica, MA.

99 Restaurant, 11 Dartmouth St., Malden, MA.

99 Restaurant, 786 River St., Haverhill, MA.

99 Restaurant, Route 2 Fresh Pond Circle, Cambridge, MA.

99 Restaurant, 255 Washington St., Hudson, MA.

Ocean View, Inc., Chapman Ave., Oaks Bluff, MA.

Old Boston's Public House, Webster square, Marshfield, MA.

Plumbley's off the Common, 30 Boltwood Walk, Amherst, MA.

Prince Italian Restaurant, 517 Broadway - Route 1, Saugus, MA.

Rhumb Iine Restaurant, 40 Railroad Ave., Gloucester, MA:

Riverside Restaurant, Cranberry Highway, Middleboro, MA.

Rudy's Cafe, 248 Holland St., Somerville, MA.

The Salty Dog, 206 Faneuil Hall Marketplace, Boston, MA.

scotch 'n sirloin, 77 North Washington St., Boston, MA.

Shakespeare's Restaurant, 114 East India Square, Salem, MA.

Sheraton - Boston Hotel, Prudential Center, Lowell, MA.

The Speare House, 525 Pawtucket Blvd., Lowell, MA.

Spyro's Restaurant, 110 sutton st., North Andover, MA.

Stouffer's Bedford Glen Hotel, 44 Middlesex Turnpike, Bedford, KA.

Stoughton sidetrack, 7 Porter square, stoughton, MA.

Sunset Grove, 1113 Bedford St., Whitman, MA.

. T.C.'s Lounge, I Haviland St., Boston, MA.

Teel's Cabin, 1235 Bedford st., Abington, MA.

Thad's Șteak House, 1313 Ashley Blvd., New Bedford, MA. 
Thompson's Restaurant, 435 Andover St., North Andover, MA.

Tom Foolery's, 95 Turnpike Rd., Westborough, MA. 01581.

(617) 366-5959. [Contacted: active DDP.]

Tweed's Pub, 229 Grove St., Worcester, MA.

Tweed's Pub, 9 Prichard Plaza, Fitchburg, MA.

Tweed's Pub, Route 9, Northboro, MA.

Union Market Station Restaurant, 17 Nichols Ave., Watertown, MA.

Union Oyster House, 41 Union St., Boston, MA.

Wellfleet Beachcomber, Cahoon Hollow Rd., Wellfleet, MA.

Wharf Restaurant, 6 Dock St., Edgartown, MA.

Windsor Mills Restaurant, 819 Merrimack Ave., Dracut, MA.

Wursthaus Restaurant, 4 John F. Kennedy St., Cambridge, MA.

Wursthaus Restaurant, Route 132 - Cape Cod Mall, Hyannis, MA.

MICHIGAN

MINNESOTA

Annie's Liquor and Food, Minneapolis, MN.

Apache Wells Saloon, Minneapolis, MN.

Archie's Bar and Lounge, Minneapolis, MN.

Archie's Bunker, Minneapolis, MN.

Arlington Bowling Center, Minneapolis, MN.

Blondies on the Ave., Minneapolis, MN.

Brandywine, Minneapolis, MN.

Brown Derby Lounge, Minneapolis, MN.

Bulwinkles, 1429 Washington Ave. S, Minneapolis, MN. 55454. (612) 338-8520. [Contacted: active DDP.]

Cabooze, Minneapolis, MN.

The Court Bar, Minneapolis, MN.

China Inn, Minneapolis, MN. 
Dibbos, Minneapolis, MN.

Fandangles, Minneapolis, MaN.

5 Corners Saloon, Minneapolis, MN.

George's Night Club, Kinneapolis, MN.

Iron Horse, Minneapolis, MN.

Juke Box Saturday Night, 14 N. 5th St., Minneapolis, MN. 55402. (612) 339-5890. [Contacted: active DDP.]

Le Bistro, Minnetonka, MN.

The Mermaid, Arden Hills, MN. (612) 784-5221.

Mick's South, Holiday Mall, Moorhead, MN. 56560. (218) 784-5221. [Contacted: active DDP.]

Mill Road Inn, Bayport, MN.

The Northland, Crookston, MN. (218) 281-5210.

Opera Hall Saloon, Minneapolis, MN.

Palm Dale Tap \& Grill, Taylors Falls, MN.

Pheonix II, Duluth, MN.

Pierre's in the 80's, Minneapolis, MoN.

The Polish Palace, Minneapolis, MN.

Pony Express, Minneapolis, MN.

Reiss's, Minneapolis, MN.

Richard's in Shakopee, Minneapolis, MN.

The stonehouse, Minneapolis, MN.

\section{MISSISSIPPI}

Bully III, P.O. Box 390, starkville, MS. 39759. (601) 323-825I. [Contacted: active DDP.]

Oby's, Academy Road, Starksville, MS. 39759. (601) 323-0444. [Contacted: active DDP.]

$$
A-11
$$




\section{MISSOURI}

Ramada Inn, $2431 \mathrm{~N}$. Glenstone, Springfield, Mo. 65803. (417) 831-3131. [Contacted: active DDP.]

\section{MONTANA}

Airport Restaurant and Lounge, Missoula, MT.

The Alibi Room, Missoula, MT.

Alpine Club, Missoula, MT.

Barney's Bar \& Cafe, Missoula, MT.

The Bitterroot Bar, Missoula, MT.

Black Angus, Missoula, MT. (406) 728-2663.

The Boardroom, Missoula, MT.

The Brewery, Missoula, MT. (406) 728-7102.

Cabin Lounge, Missoula, MT.

The Carousel, Missoula, MT. (406) 543-7500.

Casa Pablo's, Missoula, MT.

Charlie B's, Missoula, MT. (406) 728-9593.

Clark Fork station, Missoula, MT.

Corky's Bar \& Lounge, Missoula, MT.

Corner Pocket Billiard Lounge, 2100 stephens Street, Missoula, MT. 59801. (406) 728-9023. [Contacted: active DDP.]

The Cross Cut Saloon, Missoula, MT.

Danny's Lounge, Missoula, MT.

The Depot, Missoula, MT. (406) 728-7007.

Don Tripp Truck stop \& Cafe, Missoula, MT.

Duelin' Dalton's Saloon, Missoula, MT. (406) 721-3086.

East Gate Lounge, Missoula, MT.

Elbow Room, Missoula, MT.

Five Valleys Bowl, Missoula, MT.

$$
\text { A-12 }
$$


Four B's Chain, Missoula, MT. (406) 728-2663. Gay Nineties Lounge, Missoula, MT. Godfather's Pizza, Missoula, MT. Holland Lake Lodge, Missoula, MT. Hungry Bear Steak House, Missoula, MT. Liquid Louie's, Missoula, MT. (406) 754-2391. Ioran's Clearwaer Bar \& Cafe, Missoula, MT. Luke's Tavern, Missoula, MT. Maxwelis, Missoula, MT. (406) 721-7522.

Missoula Club, Missoula, MT.

Montana Mining Company, 1210 W. Broadway, Missoula, MT. 59802. (406) 543-8265. [Contacted: active DDP.]

Mr. C's, Missoula, MT. (406) 728-9042.

Mulligan's, Missoula, MT.

Mustard Seed oriental Cafe, Missoula, MT.

The Outpost Lounge, Missoula, MT. (406) 721-7170.

Overland Express, Missoula, MT. (406) 728-5132.

The Oxford, Missoula, MT.

Piney Woods Bar, Missoula, MT.

Potomac Bar, Missoula, MT.

Quality Inn, Missoula, MT.

The Red Dawg Saloon, Missoula, MT. (406) 273-9916.

The Ritz, Missoula, MT.

Rocking Horse Saloon \& Restaurant, Missoula, MT.

The Roundup Bar, Missoula, MT.

The Savoy, Missoula, MT.

Sheraton Missoula, Missoula, MT. (406) 721-8550. 
The Speakeasy, Missoula, MT.

Squiŕe's Olde English Pub, Missoula, MT.

Stockman's Bar, Missoula, MT. (406) 728-9079.

$T \& C$ Lounge, Missoula, MT.

Turah Pines Inn, Missoula, MT.

Westside Lanes \& Fun Center, Missoula, MT.

Wye West Lounge, Missoula, MT.

NEBRASKA

Holiday Inn, 655 North 108 Ave., Omaha, NE. 68154.

(402) 496-0850. [Contacted: no DDP.]

P.O. Pears, Iincoln, NE. (402) 476-8551.

Rosen's Bar, Omaha, NE. (402) 345-6500. [Contacted: no DDP.]

Todd's at Radisson, 10909 M Street, Omaha, NE. 68137.

(402) 331-8220. [Contacted: active DDP.]

W.C.'s Place, 3520 F St., Omaha, NE. 68107. (402) 733-9501. [Contacted: no DDP.]

NEVADA

NEW HAMPSHIRE

Horse Feathers, Concord, NH.

The Inn at Weirs Beach, Weirs Beach, NH.

King's Grant Inn, Route 11B, Gilford, NH.

NEW JERSEY

Charlie Brown's' Restaurant, 27 Freneau on Rt. 79, Matowan, NJ. 07747. (201) 583-7666. [Contacted: active DDP.]

Hilton, New Brunswick, NJ.

Ramada Inn, New Brunswick, NJ.

Ramada Inn, somerset, NJ. 
Sea Cove Restaurant, 1250 Ocean Avenue, Sea Bright, NJ. 07760. (201) 842-5319. [Contacted: active DDP.]

NEW MEXICO

NEW YORK

NORTH CAROIINA

Angus Barn, PO Box 6357, Raleigh, NC. 27628 (919) 787-3505. [Contacted: defunct DDP.]

Darryl's, 6008 Glenwood Ave, Raleigh, NC. (919) 782-1849. [Contacted: defunct DDP.]

TGI Friday's, Raleigh, NC.

NORTH DAROTA

OHIO

Alex's Honey Cooking House, Cincinnati, OH.

Alpha Restaurant, Cincinnati, OH.

Arlin's Bar, Cincinnati, oH.

Barnesburg Tavern, Cincinnati, OH.

Baron's Inn, Cincinnati, OH.

Blue Iights, Cincinnati, $\mathrm{OH}$.

Blue Moon Saloon, 123 Boggs Lane, Cincinnati, OH. 45246.

(513) 772-5666. [Contacted: active DDP.]

Brief Encounter, Cincinnati, OH.

Chester's Road House, Cincinnati, $\mathrm{OH}$.

The Clarion Hotel, Cincinnati, OH.

Collins Tavern, Cincinnati, OH.

Crossbow Tavern, Cincinnati, OH.

Drawbridge Inn, Cincinnati, OH.

. Easy Times Lounge, Cincinnati, OH.

Elk's Lodge, Cincinnati, OH.

F\& N Steakhouse, Cincinnati, OH. 
Flicker Inn, Inc., Cincinnati, OH.

Gano Alley Bar \& Grill, Cincinnati, OH.

Gatehouse Tavern, Cincinnati, OH.

Golden Lamb, Cincinnati, OH.

Ground Round Restaurant, Cincinnati, OH.

Habig's Restaurant, Cincinnati, OH.

Hampshire House Hotel, Checquer's Pub, Cincinnati, OH.

Holly's Place, Cincinnati, OH.

Hot Shots, Cincinnati, OH.

Hyatt Regency Hotel, Cincinnati, OH.

Jeanne's Lounge, Cincinnati, $\mathrm{OH}$.

Jerry's Disco Palace, Cincinnati, OH.

Joker Club, Cincinnati, OH.

Kenwood Country Club, cincinnati, OH.

King Kwik Mini-Markets

Knotty Pine Bar, Cincinnati, OH.

Kurt's Tavern, Cincinnati, OH.

Lake Nina, Cincinnati, oH.

Ia Normandie, Cincinnati, oH.

Loll Forty Three, Cincinnati, OH.

Maisonette, Cincinnati, OH.

Mick Noll's Covington Haus, Cincinnati, OH.

Mr. D's Lounge, Cincinnati, OH.

Mr. Kelley's Lounge, Cincinnati, OH.

Parkcrest Lane, Cincinnati, OH.

The Pavilion, Cincinnati, OH.

Pepper Lounge, Cincinnati, oH.

$$
\text { A-16 }
$$


Peppermint Lounge, Cincinnati, oH.

The Precinct, Cincinnati, OH.

Prime \& wine, Cincinnati, oH.

Quality Inn, Cincinnati, OH.

Red Lobster Restaurant, Cincinnati, $\mathrm{OH}$.

Republic Mini-Markets

Rocky's Haven, Inc., Cincinnati, OH.

Ron's 301 Bar, Cincinnati, OH.

R. Tapley's, Cincinnati, OH.

Sly Fox, Cincinnati, OH.

Snow's Spring Lake, Cincinnati, OH.

Sorrento's, Cincinnati, oH.

T.J. Mineshaft Lounge, Cincinnati, OH.

Viking Lounge, Cincinnati, OH.

Wedge Inn, Ine., Cincinnati, он.

Westin Hotel, Cincinnati, OH.

Whitey's Cocktail Lounge, Cincinnati, oH.

OKLAHOMA

OREGON

American Legion Post \#83, 3650 River Road, Eugene, OR. 97404.

The Big "Y" Tavern, 2175 w. 7th, Eugene, OR. 97402.

Black Angus, 2133 Franklin Blvd., Eugene, OR. 97403.

Black Forest Tavern, 2657 willamette, Eugene, OR. 97405.

Black Forest Too, 211 Washington, Eugene, OR. 97401.

Emerald Valley Restaurant and Lounge, 83293 Dale Kuni Rd., Creswell, OR. 97426.

Excelsior, 754 E. 13th, Eugene, OR. 97401.

$$
\text { A-17 }
$$


Guido's, 801 E. 13th, Eugene, OR. 97401.

Heaven's Gate Restaurant, 535 Main, Springfield, OR. 97477.

James A. Thomas, 65 N. Division, Eugene, OR. 97404.

Jo Fredrigo's Cafe \& Jazz Bar, 259 E. 5th, Eugene, OR. 97401.

Lori's Tavern, P.O. Box 304, springfield, OR. 97477.

Luckey's, 933 Olive St., Eugene, OR. 97401.

Lucky Logger Inn, P.O. Box 148, Walterville, OR.

Lyon's, 1933 Franklin Blvd., Eugene; OR. 97403.

Oregon Electric Station; 27 E. 5th St., Eugene, OR. 97401.

Pad West, 2165 w. 11th, Eugene, OR. 97402.

Pietro's, I0II Valley River Way, Eugene, OR. 97401. (503) 344-0668. [Contacted: no DDP.]

Poppi's, 675 E. 13th, Eugene, OR.

Ramada, 3450 Gateway, Eugene, OR. 97404.

Ray Norris, P.O. Box 548, Creswell, OR. 97426.

Round Up Tavern, Box 146, 13 N. Front St., Creswell, OR. 97426.

Scotty's Tavern 1714 Main St., springfield, OR. 97477.

Shilo Inn, 3350 Gateway, Springfield, OR. 97477.

Tankard Tavern, 330 Highway 99 S., Junction City, OR. 97448, (503) 998-3123. [Contacted: active DDP.]

The Trawler, 110 S. Park, Eugene, OR. 97401.

Vet's Club, 1626 willamette st., Eugene, OR. 97401.

The woodsman, 117 S. 14th, springfield, OR. 97477.

PENNSYLVANIA

RHODE ISIAND

Wharf Tavern, Providence, RI. (401) 245-5043.

Providence Marriot Lounge, Providence, RI. (401) 272-2400. SOUTH CAROIINA 
SOUTH DAROTA

TENNESSEE

\section{TEXAS}

Azar, Fort Wayne, TX. (219) 424-1972.

S \& A Restaurant Corp., (214) 960-5000.

TGI Friday's, Dallas, TX. (214) 450-5400. [Contacted: defunct DDP.]

UTARH

D.B. Coopers, 19 E. 200 South, Salt Lake City, UT. 84111.

(801) 532-2948. [Contacted: active DDP.]

The Zephyr Club, 301 S. \& W. Temple, Salt Lake City, UT. 84101. (801) 355-9913. [Contacted: active DDP.]

VERMONT

VIRGINIA

The Belle Meade Restaurant, Rockingham, VA. (804) 434-2367.

Blue Stone Inn and Restaurant, Rockingham, VA. (804) 434-0535.

Captain Graham's Seafood, Rockingham, VA. (804) 434-4023.

China Inn, Rockingham, VA. (804) 433-9595.

Coachman Inn and Restaurant, Rockingham, VA. (804) 434-5301.

Donegan's Inn and Pub, Rockingham, VA. (804) 433-1688.

The Famous Restaurant, Rockingham, VA. (804) 434-7253.

Golden China Restaurant, Rockingham, VA. (804) 434-1285.

Howard Johnson's Motor Lodge, Rockingham, VA. (804) 434-2455. [contacted: no DDP.]

The Rettle Room, Rockingham, VA. (804) 289-9441.

JM's Pub \& Deli, Rockingham, VA. (804) 433-8537.

The Little Grill, Rockingham, VA. (804) 434-3594.

Lloyd's steak House, Rockingham, VA. (804) 434-9843 or 434-7124.

Mr. Gatti's, Rockingham, VA. (804) 433-0606.

$$
\text { A-19 }
$$


Scruples at Sheraton Harrisonburg Inn, 1400 E. Market st., Harrisonburg, VA. 22801. (804)433-2521. [Contacted:

- active DDP.]

Spanky's, Rockingham, VA. (804) 434-7647.

The Train Station, Rockingham, VA. (804) 434-0505.

Victor's Restaurant, at Holiday Inn, Harrisonburg, VA. (804) 434-9981.

Woody's Restaurant, Rockingham, VA. (804) 828-3002.

WASHINGTON

Cheers West, 710227 th St. W., Tacoma, WA. 98466.

(206) 565-9378. [Contacted: active DDP.]

WEST VIRGINIA

WISCONSIN

Hylander, Holton, WI.

WYOMING

\section{NATION-WIDE EFFORTS}

Darryl's, Gilbert Robinson, 47th and Main, Po Box 16000, Kansas City, KS 64112. [Contacted: defunct DDP.]

Ground Round.

Howard Johnson's - Lounges and Motels.

Muggs (Owned by Benigan's, Headquarters in Dallás, TX.).

$S \&$ A Restaurant Corp. (Headquarters in TX.) (214) 960-5000.

Steak and Ale (Owned by Benigan's, headquarters in Dallas, TX.).

TGI Friday's (headquarters in Dallas, TX.).

450-5400. [Contacted: defunct DDP.] 


\section{APPENDIX B}

\section{MEMBERSHIP ESTABIISHYIENTS CONTACTED IN SEVEN CITIES}

City

San Diego, CA

Atlanta, $G A$

Boston, MA

Minneapolis, MN

\section{orqanization}

American Legion

VFW

Rnights of Columbus

Loyal Order of Moose

University of $C A$, San Diego

San Diego Rotary Club

San Diego State University

VFW

Atlanta Masonic Temple

Elks Club

Rnights of Columbus

Loyal Order of Moose

Sports Car club of America

Emory University

Georgia State University

American Legion

VFW

Elks Club

Knights of Columbus

Loyal Order of Moose

Boston Rotary club

Boston Ski and Sports Club

The People Network

St. Botolph Club

Northeastern University

Tufts University

American Legion

VFW

Elks Club

Riwanis

Loyal Order of Moose

Minneapolis Rotary Club

University of Minnesota,

Minneapolis 
Omaha, NE

Cincinnati, OH

Portland, OR
American Legion

Krights of Columbus

Omaha Masonic Temple

Omaha Rotary Club

University of Nebraska,

Ormaha

VFW

Cincinnati Masonic Temple

Cincinnati Rotary club

Elks Club

Loyal Order of Moose

University of Cincinnati

American Legion

VFW

Elks club

Rnights of Columbus

Loyal order of Moose

Portland State University

Portland Masonic Temple

Portland Rotary Club

University of Portland

Portland State University 


\section{APPENDIX C}

\section{DATA COLLECTION FORMAT USED WITH FORMAL DDPS}

\section{SETTING INFORMATION}

A. Describe your establishment, organization, etc. (e.g. bar, sports arena, etc.) and its location.

B. How large are you (number of clientele and seating capacity)?

C. Describe your clientele (age and Socio-Economic status - eg. blue collar or white collar, what level of education, etc.).

D. What is the availability of alternative transportation, such as public transportation and taxi service?

\section{PROGRAM ORGANIZATION}

A. When did the program get started and what was the motivation?

B. Is there any coordination with other organizations such as other Designated Driver Programs, private organizations or public organizations

(Ask additional questions as necessary to clarify the organizational unit and to determine whether it is a unit within a larger organization).

\section{PROGRAM OPERATION}

A. How and when is the designated driver selected, and is some form of identification used (such as a button)? Does the server ever initiate the conversation, and if so, what are some reasons that customers have refused to participate?

B. How are groups encouraged to designate a driver (are there posters up, servers wearing buttons, servers talking up the program, etc.)?

C. Are designated drivers treated differently - are they given incentives?

D. What people are involved? Are they different from those who don't use designated drivers? IF YES, How do they differ?

E. Does anyone make sure that the designated drivers don't drink, and if so, how?

$$
\text { C-1 }
$$


F. Are there any eligibility requirements for groups or for the individuals selected as designated drivers (eg. minimum number in party, age, etc.)?

G. Tell me about any advertising of the program, including whether you seek free publicity? Is there any ongoing publicity needed to keep the program running?

H. Could you describe the staffing of the program, including supervisors and any training they receive? Is there any ongoing training needed to keep the program running?

I. When does the program operate (What hours and days)?

IV. MORE PROGRAM ORGANIZATION

A. What changes in the program have taken place since it started?

B. Roughly, what is the total annual cost of running the program, including donated services?

C. Where do the resources come from?

D. Are any other anti-drunk driving programs in operation along with the DDP? Some places have a safe rides program which provides patrons with a ride home. Do you have a program like that? IF YES, could you tell me a little about it?

V. PROGRAM IMPACT

A. How well do you feel that the program has worked?

B. What reactions to the program have you heard from:

(a) designated drivers, (b) companions of designated drivers, (c) people who do not participate, (d) staff, and (e) community groups?

c. On the average, how many individuals elect to participate in the program? On the average, how many potential groups would you say there are?

D. What size are the groups that participate, and has the size of these groups changed since you started the program?

E. Have there been changes in the drinking level of non-drivers in parties with a designated driver? 
VI. INFORMAL DESIGNATED DRIVER ACTIVITIES

A. Do people ever assign designated drivers on their own when there is no formal program? For example, do they select a designated driver before leaving home, or do people at private parties, sports events, group picnics, and so on, select designated drivers to make sure they get home safely?

IF YES,

1. Tell me what you know about these informal designated driver activities:

a. What are the situations in which designated drivers are used? What types of events? When and where do they take place?

b. How are designated drivers selected?

c. How widespread would you say that the practice is?

d. How have you learned about these designated driver activities?

e. Is there anything else that you can tell me about informal designated driver activities that you think I should know?

\section{AVAIIABILITY OF WRITTEN INFORMATION}

A. Are any written materials available on your program, such as press releases, press reports, advertising materials, training materials, and so on? If so, could we obtain copies? 


\section{APPENDIX D}

\section{DATA COLLECTION FORYAT USED WITH INFORYAL DDPS}

\section{SETTING INFORMATION}

A. Describe your establishment, organization, etc. (e.g. bar, sports arena, etc.) and its location.

B. How large are you (number of clientele and seating capacity)?

C. Describe your clientele (age and Socio-Economic status - eg. blue collar or white collar, what level of education, etc.).

D. What is the availability of alternative transportation, such as public transportation and taxi service?

\section{INFORMAI DESIGNATED DRIVER ACTIVITIES}

A. Do your people ever assign designated drivers on their own in the absence of a formal program? For example, do they select a designated driver before leaving home enroute to one of your gatherings? Do you get a feeling that your people designate drivers at other events such as private parties, sports events, grou? picnics, and so on, to make sure that they get home safely?

IF YES,

1. Tell me what you know about these informal designated driver activities:

a. What are the situations in which designated drivers are used? What types of events? When and where do they take place?

b. Do you have a feeling for how designated drivers are selected?

c. How widespread would you say that the practice is?

d. How have you learned about these designated driver activities?

e. Is there anything else that you can tell me about informal designated driver activities that you think I should know? 


\section{OTHER INFORMAL PROGRAMS}

a. Are any other anti-drunk driving efforts being practiced on your premises? Some places have a safe rides program which provides patrons with a ride home. Do you do anything like that? IF YES, Could you tell me a little about it? 


\section{APPENDIX E}

\section{LIST OF FORMAL AND INFORMAL DDPS CONTACTED}

This Appendix lists the DDPs we contacted. The information presented in brackets indicates whether a given DDP was active or defunct. The list is divided into formal DDPs in service establishments, formal DDPs in membership establishments, and informal DDPs in membershhip establishments. Entries are sorted by state under each of these three headings.

FORMAL DDPS IN "PUBLIC DRINKING" ESTABLISERENTS

\section{ALABAMA}

Bennigan's, 3782 University Dr., Huntsville, AL 35816. (205) 534-4503. [active DDP.]

\section{ALASKA}

Northern Lights Inn, 598 w. Northern Iights, Anchorage, AK. 99503. (907) 561-5200. [active DDP.]

\section{R.RIZONA}

Minder Binder's, $715 \mathrm{~S}$. Hayden, Tempe, AZ. 85281. (602) 966-1911. [active DDP.]

\section{ARRANSAS}

Jose's, 324 W. Dickson, Fayetteville, AR. 72701. (501) 521-0194. [active DDP.]

\section{CALIFORNIA}

Bobby McGee's, 200 S. State College Blvd., Brea, CA. 92621. (714) 529-1998. [active DDP.]

Margaritaville, 221 Esplanade, Capatola, CA. 95010.

$$
\text { (408) 476-2263. [active DDP.] }
$$

\section{COLORADO}

Hilton Hotel, 743 Horizon Drive, Grand Junction, Co. 81506. (303) 241-8888. [active DDP.]

No Frills Grill, 7155 E. Hampden, Denver, CO. 80224. (303) 759-9079. [active DDP.]

$$
E-1
$$


CONNECTICUT

Graffiti!s, 297 willetts Ave, Waterford, CT. 06385. (203) 447-0894. [active DDP.]

\section{DEIAWARE}

Down Under, $60 \mathrm{~N}$. College Ave., Newark, DE. (302) 366-0517. [active DDP.]

Ground Round, 801 S. College Ave., Newark, DE. 19711. (302) 737-0808. [active DDP.]

DISTRICT OF COLUMBIA

Mel Krupin's Restaurant, 1120 Connecticut NW, washington, DC. (202) 331-7000. [active DDP.]

Rumors, 1900 M. St., N.W., Washington, DC. 20036. (202) 466-7378. [active DDP.]

FLORIDA

Department of the Navy, Naval Technical Training Ctr., NTTC Corry Station, Pensacola, FL. 32511. (904)452-6317'. [active DDP.]

ILIINOIS

Sage's, 75 w. Algonquin Rd., Arlington Heights, II. 60005. (312) 944-1557. [active DDP.]

INDIANA

Blue Bird, 216 North Walnut, Bloomington, IN. (812) 336-3984. [active DDP.]

Hooligan's, 430 Kirkwood, Bloomington, IN. 47401. (812) 333-3003.' [active DDP.]

Ye Old Regulator, 319 N. Walnut, Bloomington, IN. 47401. (812) 334-3459. [active DDP.]

MAINE Holiday Inn, 500 Main St., Bangor, ME. 04401. (207) 947-8651.
[defunct DDP.]

\section{MASSACHUSETTS}

The Great Escape, 500 washington St., Weymouth, MA. 02188. (617) 337-7732. [active DDP.]

$$
E-2
$$


Tom Foolery's, 95 Turnpike Rd., Westborough, MA. 01581. (617) 366-5959. [active DDP.]

\section{MINNESOTA}

Bulwinkles, 1429 Washington Ave. S, Minneapolis, MN. 55454. (612) 338-8520. [active DDP.]

Juke Box Saturday Night, 14 N. 5th St., Minneapolis, MN. 55402. (612) 339-5890. [active DDP.]

Mick's South, Holiday Mall, Moorhead, MN. 56560. (218) 784-5221. [active DDP.]

\section{MISSISSIPPI}

Bully III, P.O. Box 390, Starkville, MS. 39759. (601) 323-8251. [active DDP.]

Oby's, Academy'Road, Starksville, MS. 39759. (601) 323-0444. [active DDP.]

\section{MISSOURI}

Ramada Inn, $2431 \mathrm{~N}$. Glenstone, Springfield, Mo. 65803. (417) 831-3131. [active DDP.]

\section{MONTANA}

Corner Pocket Billiard Lounge, 2100 Stephens Street, Missoula, MT. 59801. (406) 728-9023. [active DDP.]

Montana Mining Company, 1210 พ. Broadway, Missoula, MT. 59802. (406) 543-6192. (406) 543-8265. [active DDP.]

\section{NEBRASKA}

Todd's at Radisson, 10909 M Street, Omaha, NE. 68137. (402) 331-8220. [active DDP.]

NEW JERSEY

Charlie Brown's Restaurant, 27 Freneau on Rt. 79, Matowan, NJ. 07747. (201) 583-7666. [active DDP.]

Sea Cove Restaurant, 1250 Ocean Avenue, Sea Bright, NJ. 07760. (201) 842-5319. [active DDP.]

NORTH CAROLINA

Angus Barn, PO Box 6357, Raleigh, NC. 27628 (919) 787-3505. [defunct DDP.]

$$
\text { E-3 }
$$


Darry! 's, 6008 Glenwood Ave, Raleigh, NC. (919) 782-1849. [defunct DDP.]

OHIO

Blue Moon Saloon, 123 Boggs Lane, Cincinnati, OH. 45246. (513) 772-5666. [active DDP.]

OREGON

Tankard Tavern, 330 Highway 99 S., Junction City, OR. 97448, (503) 998-3123. [active DDP.]

UTAH

D.B. Coopers, 19 E. 200 South, Salt Lake City, UT. 84111. (801) 532-2948. [active DDP.]

The Zephyr Club, 301 S. \& W. Temple, Salt Lake City, UT. 84101. (801) 355-9913. [active DDP.]

VIRGINIA

Scruples at Sheraton Harrisonburg Inn, 1400 E. Market St., Harrisonburg, VA. 22801. (804)433-252]. [active' DDP.]

WASHINGTON

Cheers West, 710227 th st. W., Tacoma, WA. 98466 . (206) 565-9378. [active DDP.]

FORMAL DDPS IN MEMBERSHIP ESTABLISHMENTS

\section{CALIFORNIA} VFW, 4370 Twain Ave., San Diego, CA. 92106. (619) 281-0137.
[active DDP.]

GEORGIA

Elks \#78, 2728 Northeast Expressway, Access Rd., Atlanta, GA. 30345 (404) 634-0169. [active DDP.]

MINNESSOTA

. VFW, 1040 Osborn Rd., Fridley, MN. 55432 (612) 780-3694. [active DDP.]

VFW, 8100 Pleasant View Dr., Spring Lake Park, MN. 55432. (612) 780-1900. [áctive DDP.]

$$
\text { E-4 }
$$


OHIO

Moose, 607 Vine St., Cincinnati, OH. 45216. (513) 242-2760. [active DDP.]

\section{INFORMAI DDPS IN MEMBERSHIP ESTABLISFRENTS}

\section{CALIFORNIA}

San Diego State University, Housing and Residential Iife office. San Diego State University, San Diego, CA.

(619) 265-5742. [active DDP.]

\section{NEBRASKA}

University of Nebraska-Omaha - Pi Kappa Alpha, Omaha, NE.

(402) 331-2122. [active DDP.]

OHIO

University of Cincinnati, Alpha Tao Omega, Cincinnati, OH. (513) 281-0881. [active DDP.]

OREGON

VFW, Sandy, OR. (503) 668-5211. [active DDP.] 


\begin{abstract}
APPENDIX $F$
INFORYATION ON ALI FORKAL AND INFORYAL DDPS CONTACTED

Public Drinking Establishments
\end{abstract}

Eormal programs

Angus Barn (in Raleigh, NC) - Thad Eure - 919-787-3505.

Note: This establishment no longer has a DDP; program faded after only one year of operation. "We didn't seem to be having a problem."

Date of Interview: $6 / 17 / 86$

Position: Owner

Address: PO BOx 6357, Raleigh, NC 27628

I. SETTING INFORMATION

A. Description of Establishment/Location. They serve only the dinner meal; average dinner check is $\$ 25$ per person.

B. Size. Seating Capacity: 550 .

C. Description of Clientele. Ave::age age is 40 .

D. Availability of Public Transportation. It is not easy to get a taxi and there is no bus.

II. PROGRAM ORGANIZATION

A. When and Why was the Program started. The program started in 1983. The motivation was a general concern to show awareness.

B. Coordination with other organizations. They followed the NC Restaurant Association ideas but were largely independent.

III. PROGRAM OPERATION

A. How Is the Designated Driver selected and Identified. The program is strictly volunteer. The designated drivers do not wear buttons.

B. How Are Participants Recruited. Waitress announces existence of program and they leave cards on the table.

c. What Incentives Are offered to The Designated Driver. They provide a free non-alcoholic drink or a "nice dessert or whatever they wanted." He said that it is not much of an incentive since it's such a nice restaurant. Since a party of four is easily going to spend $\$ 100$ for the evening, what kind of incentive is a free sprite? It would seem that this is part of why the program fizzled - because there is so little incentive, patrons are as likely to just do it on their own. (informaliy). 
D. Who Uses The DDP. They are generally people who do not drink in the first place.

E. Monitoring Drinking by The Designated Driver. Designated driver could change their mind and they then would start serving them alcohol; he has not noticed any deception/abuse.

F. Eliqibility Requirements. None.

G. Publicity. None.

H. Staffing the DDP and Training staff. Loose ongoing training; certainly nothing structured. "The only time you can do training is when the server is personable, friendly and outgoing so that the customer is not offended by the suggestion that people use the program." (See V. A.)

I. When Does the Program operate. Anytime, but they serve only the dinner meal.

\section{MORE PROGRAM ORGANIZATION}

A. Changes in the DDP since It Began. None.

B. Annual Cost. Nominal.

C. Resources For Meeting costs. Independent.

D. Are Other Anti-drunk Driving programs Present. Safe Ride done informally. They will drive someone home. "Most restaurants do that." He said he's been doing that for many years as a courtesy to his guests. He will call cab or drive them himself. He will accommodate the guests one way or another that's all he cares about.

\section{PROGRAM IMPACT}

A. How Well Does the Program Work. It wasn't as successful as he'd hoped. "You can't make somebody do it." Turn-over of staff made it difficult to train. It's only going to work if the people (the customers) want it to work. He's glad they did it. He has no quarrel with the program; he simply didn't think that his clientele was the type of crowd that needed such a program.

B. Reactions to the Program. Not much feedback.

C. What Number Participate/Number of Potential Groups. 2 or 3 per night.

D. Size of Participating Groups. 5 or 6 .

E. Changes in the Drinking of Non-Drivers in Parties with a Designated Driver. No change. "Most of our people are mature; they'll drink whatever they want to drink regardless of whether there's a DDP."

\section{INFORMAL DESIGNATED DRIVER ACTIVITIES}

A. Do People Assign Designated Drivers on Their own, without Encouragement By A Formal Program. Yes. I've noticed that a 1 . great deal.

a. In What situations and for what Events. sporting events, whatever.

In-house parties,

$$
\text { F-2 }
$$


b. How Is the Designated Driver Selected. Those who don't drink in the first place.

c. How Widespread Are Informal Designated Driver Activities. Very widespread.

d. How Have You Learned About This. Talking to customers.

e. Other Information About Informal Activities. People will often just hire a driver for the evening if they know they're going to be drinking.

\section{WHAT WRITHEN INFORYATION IS AVAIIABIE}

A. MATERIAI RECEIVED: Poster, pamphlet (from Missoula DDP), servers' button, BAC/Safe Ride card, \$l coupon, newspaper article.

Comments :

Bennigan's (in Huntsville, AI) - Harlan Epstein - 205-534-4503

[RB: Lucretia Foster, AL Beverage Control Agency.

(Bennigan's is owned by S.\& A. Corp.)

Date of Interview: $6 / 12 / 86$

Position: General Manager

Address: 3782 University Dr., Huntsville, AL 35816

\section{SETTING INFORMATION}

A. Description of Establishment/Location. Full-service restaurant in the middle of the urban, commuter town (in a "restaurant row").

B. Size. Seating Capacity: 185 .

C. Description of Clientele. Some yuppies, mostly "Hicks."

D. Availability of Public Transportation. Taxi, no public transit.

\section{PROGRAM ORGANIZATION}

A. When and why was the Program started. Early 1985. Bennigan's has a written liquor philosophy which is approximately the following: "We will not let an intoxicated person leave and drive a car. We encourage our staff to report to the management if their is a case of excessive drinking. We are committed to responsible alcohol serving..."

B. Coordination with other organizations. Bennigan's is owned by S.\& A. Corp. DDP used throughout all Bennigan's and all it's subsidiaries (eg. Bay State, J.J. Muggs, Steak and Ale).

\section{PROGRAM OPERATION}

A. How Is the Designated Driver selected and Identified. Servers ask whether there is a designated driver; they do not use any form of identification.

B. How Are Participants Recruited. No publicity on walls, but he made it sound like every drinking table is asked whether thepy have designated a driver.

$$
\text { F-3 }
$$


c. What Incentives Are offered to The Desianated Driver. Free non-alcoholic beverages.

D. Who Uses The DDP. Yuppies tend do it, but "hicks tend to drink themselves silly." Females are more often the designated drivers - in mixed groups also.

E. Monitoring Drinking by The Designated Driver. A manager personally visits any table where there is a designated driver. He says they watch it carefully and they have not observed any abuse.

F. Eliqibility Requirements. None.

G. Publicity. "I don't think that we seek enough" (publicity).

H. Staffing the DDP and Training Staff. Managers are trained at the outset, but there is nothing for the designated driver Program per se.

I. When Does the Program Operate. Anytime.

IV. MORE PROGRAM ORGANIZATION

A. Changes in the DDP since It Began. None.

B. Annual Cost. Nominal.

C. Resources For Meeting Costs. No data.

D. Are Other Anti-drunk Driving Programs Present. Safe ride done (informally?). They will pay for a cab. They will also pay for any food for the customer while he/she is waiting for the $\mathrm{cab}$ and will pay for cab to bring customer back the next day to pick up the customer's car! "Oh, yeah, I'Il do anything. What's $\$ 20$ tonight when it could be $\$ 100,000$ (as the result of a law suit) later?"

V. PROGRAM IMPACT

A. How Well Does the Program Work. Needs more national publicity. They have had fairly good success up until now, but it could be better.

B. Reactions to the Program. Nothing but praise. The staff is not apt to complain about the program because if a server loses a tip due to a disagreement over the designated driver Program or the like, the management guarantees a $15 \%$ tip.

c. What Number Participate/Number of Potential Groups. I - 3 per week.

D. Size of Participating Groups. Average of 6 .

E. Changes in the Drinking of Non-Drivers in Parties with a Designated Driver. Drinking by others in party has increased.

VI. INFORMAL DESIGNATED DRIVER ACTIVITIES

A. Do People Assign Designated Drivers on Their Own, without Encouragement By A Formal Program. He has heard about that 1. happening.

a. In What situations and for what Events. Any event is likeIy to have designated drivers.

b. How Is the Designated Driver selected. The one that drinks the least is chosen to do the driving. 

c. How Widespread Are Informal Desiqnated Driver Activities. Quite widespread, except amongst "the hicks."
d. How have You Learned About This. From customers and from his own experience.
e. Other Information About Informal Activities. No data.

\section{WHAT WRITIEN INFORMATION IS AVAITABLE}

\section{A. See comments.}

Comments: Suggested that we call Bennigan's headquarters in Dallas - I(800)527-0255 to get 1) information about what advertising is sought, 2) information about from where they get their resources, and c) any written materials mailed to us.

Blue Bird (in Bloomington, IN) - Steve Roth - 812-336-3984. [RB: Indiana University Panhellenic office].

Date of Interview: $6 / 20 / 86$

Position: Owner

Address: 216 North Walnut, Bloomington, IN 47401

\section{SETTING INFORMATION}

A. Description of Establishment/Location. A night club with live entertainment; open 6 nights a week.

B. Size. Seating Capacity: 400; 600 including standing room.

C. Description of clientele. $70 \%$ students -21 and older. ("The students all have their parents' Master Charge... the students are an upper class market.") Remaining 308 are town people who range from lower to upper middle class.

D. Availability of Public Transportation. Taxi available, no bus at night.

\section{PROGRAM ORGANIZATION}

A. When and Why was the Program Started. Mid-1985. Motivation was to help clientele as well as to fight liability. The Panhellenic office made a big push; but that was 7 months after the Blue Bird DDP began.

B. Coordination with other organizations. They are now loosely connected to the Panhellenic office.

\section{PROGRAM OPERATION}

A. How Is the Designated Driver selected and Identified. Hand stamp is used for identification. Generaliy people have made a decision about who the designated driver is before they arrive. They volunteer to the doorman as they walk into the bar ("... and (the DDs) usually make a big deal out of it"). Sometimes the staff asks, but not usually.

B. How Are Participants Recruited. Posters are above each bar.

C. What Incentives Are offered to The Designated Driver. Free non-alcoholic drinks. No break on cover charge is given.

$$
\text { F-5 }
$$


D. Who Uses The DDP. Amongst students, the ones who have been "very friendly" patrons tend to use the program. If two couples come in, it's usually one of the women who is the designated driver.

E. Monitoring Drinking by The Designated Driver. Bartenders and waitresses try to watch. Stamps on hand are in black ink, but on a busy night it's hard to keep track. He says that they have caught people abusing the program; when a designated driver is caught abusing the program, an $x$ is placed through their stamp.

F. Eligibility Requirements. There must be a minimum of two in the party.

G. Publicity. Radio ads for their bar mention the DDP. They also have mentioned it in their print media.

H. Staffing the DDP and Training staff. No training per se. Generally, they're just told to monitor the designated drivers.

I. When Does the Program operate. Anytime.

IV. MORE PROGRAM ORGANIZATION

A. Changes in the DDP since It Began. None.

B. Annual Cost. Nominal. The "... cost of a coke is a couple cents." In order "to insure that people get home safely (the cost) is well worth it."

c. Resources For Meeting Costs. Panhellenic provides some materials - other materials are independently printed.

D. Are Other Anti-drunk Driving Programs Present. Informal safe ride done. They want to keep it informal because he thinks that people would abuse the policy if it were publicized that they will call a cab for you and foot the bill.

\section{PROGRAM IMPACT}

A. How Well Does the Program Work. The program has worked "fairly well." Despite a large quantity of publicity, the response to the program has not been overwhelming. There's really not much call for the program since not much driving is done (the bar is 7 blocks from campus, so many patrons just walk).

B. Reactions to the Program. Most participants like it. Generally favorable.

c. What Number Participate / Number of Potential Groups. "If we'd get 5 a week I'd be surprised." There are 900 parties per week on the average.

D. Size of Participating Groups. 3 to 5 .

E. Changes in the Drinking of Non-Drivers in Parties with a Designated Driver. No. He has overheard someone remark "HeY So-and-So, since you're the designated driver I'm going to go ahead and get plastered." But overall, he doesn't think it's being abused much.

VI. INFORMAL DESIGNATED DRIVER ACTIVITIES

$$
F-6
$$


A. Do People Assion Designated Drivers on Their Own. Without Encouragement By A Formal program. Yes, I've seen that 1 . kind of thing go on.

a. In That situations and for what Events. Some parties, but mostly nights on the town (bar hopping).

b. How Is the Designated Driver selected. Some alternating goes on.

c. How Widespread Are Informal Designated Driver Activities. No idea.

d. How Have You Learned About This. Overheard it at parties he's attended.

e. Other Information About Informal Activities. No data.

VII. WHAT WRITTEN INFORMATION IS AVAIIABLE

A. He will send materials (if he can find them).

Comments :

Blue Moon Saloon (in Cincinnati, OH) - Robert Funk -513-772-5666 (one of three, all participate in DDPS).

Date of Interview: $7 / 28 / 86$

Position: Bar Manager

Address: 123 Boggs Lane, Cincinnati, OH 45246

\section{SETTING INFORKATION}

A. Description of Establishment/Location. It's a saloon, serving sandwiches and drinks, located in a business area.

B. Size. Seating Capacity: 300 .

C. Description of clientele. Mostly young professionals, some students.

D. Availability of Public Transportation. Alternative transportation is limited. Taxis are 45 minutes away; buses are very sporadic - often have to wait 45 minutes to an hour.

\section{PROGRAM ORGANIZATION}

A. When and Why was the Program started. The program started 2 Years ago on New Year's Eve. The motivation was general attention on drunk driving. Cincinnati is very conservative, so it is taking action against drunk driving.

B. Coordination with other organizations. There are three Blue Moon Saloons; he thinks they all have DDPs.

\section{PROGRAM OPERATION}

A. How Is the Designated Driver selected and Identified. Designated driver volunteers him/herself while sitting down. No initiation by servers. People were aware of DDPs, but lately.

$$
\text { F-7 }
$$


people are not so aware; people think about it a lot during the holidays, but forget about it other times. People refuse because they have a mental barrier - they have their own ideas about self-control. designated driver wears a sticker.

B. How Are participants Recruited. Posters and table tents up during holidays.

c. What Incentives Are offered to The Designated Driver. After 1 alcoholic drink, designated driver can get free non-alcoholic drinks.

D. Who Uses The DDP. Majority of clientele is aged 20-26. College students and young professionals are more perceptive; not much difference among young clients.

E. Monitoring Drinking by The Designated Driver. Servers monitor. There is never a problem; he has never seen abuse of DDP.

F. Eligibility Requirements. There are no eligibility requirements at this point. He thinks that there should be the requirement that people have to be able to fit into one car. They focus on "celebrations," and not just people who are out for a drink or two.

G. Publicity. He has seen commercials on T.V. There needs to be ongoing publicity, but they don't seek to initiate it.

H. Staffing the DDP and Training staff. No training at this time. He would like to see training programs nationwide about things to do when someone drinks too much ("stalling tactics"). He doesn't know of any other bars which have training programs.

I. When Does the Program operate. The program is more intensive during Christmas/New Year's. He would Iike to see material available to the public more often. The program is offered all the time, but it is not advertised except during the holiday season.

\section{MORE PROGRAM ORGANIZATION}

A. Changes in the DDP since It Began. No changes.

B. Annual cost. No idea.

C. Resources For Meeting Costs. He doesn't know.

D. Are Other Anti-drunk Driving Programs present. At special times (holidays), taxis drive people for free and the city pays. They used to have a breathalizer test, but they didn't like it.

\section{PROGRAM IMPACT}

A. How Well Does the Program Work. The program is effective during the holiday season. At other times, there is no attention, no publicity.

B. Reactions to the Program. Overall, people think it's a smart way to go.

C. What Number Participate / Number of Potential Groups. Approximately $10 \%$ during the holidays.

D. Size of Participating Groups. Generally 4-6.

$$
\text { F-8 }
$$


E. Changes in the Drinking of Non-Drivers in Parties with a Desionated Driver. No change; some will drink more, but it depends on the occasion.

VI. INFORYAL DESIGNATED DRIVER ACTIVITIES

A. Do People Assion Designated Drivers on Their own. Without Encouragement By A Formal Program. Not aware of it; he thinks yes, but few and far between.

\section{WHAT WRITTEN INFORYATION IS AVAILABLE}

A. No information available. He would like to receive manual if we do one.

Comments: He was full of suggestions: more public awareness and publicity is needed; restaurants should be helped to supply incentives (meals, etc.); young people should be focused on. He also commented that people are drinking less alcoholic content drinks --eg. wine coolers and beer instead of hard liquor.

Bobby McGee's (in Brea, CA) - Rich Morris, Executive Manager 714-529-1998 (one of chain of 20) [RB: Dave Dalton, Hensley \& Co.]

Date of Interview: $6 / 6 / 86$

Position: Executive Manager (Former Director of Human Resources in Phoenix)

Address: $200 \mathrm{~S}$. State College Blvd. Brea, CA 92621

\section{SETTING INFORMATION}

A. Description of Establishment/Location. Dinner house and night club with Disco.

B. Size. Seating Capacity: 225 in dining room, 160 in lounge.

c. Description of Clientele. In the dining room: early teens to 50-60s; in the lounge:

25-40, white collar mid-high economically.

D. Availability of Public Transportation. Taxis and busses are available.

\section{PROGRAM ORGANIZATION}

A. When and Why was the Program started. He started a general alcohol awareness program (of which DDP is a part) for Bobby McGee's in Phoenix 16 months ago. DDP started 8 months ago in Brea. The climate was right.

B. Coordination with other organizations. No coordination with outside agencies in Brea restaurant anyway. 


\section{PROGRAM OPERATION}

A. How Is the Designated Driver selected and Identified. Customer approaches a server or manager saying they want to be a designated driver. It is a voluntary program; the conversation initiated by customer. For some, the program is of no interest because the main reason they go out is to drink. The person is given a button which says "I have the key to safe driving."

B. How Are Participants Recruited. Disc jockey in lounge promotes the program; they have table tents, posters.

c. What Incentives Are offered to The Designated Driver. Person is issued a card which will get the person free non-alcoholic beverages.

D. Who Uses The DDP. Concerned, responsible, probably white collar.

E. Monitoring Drinking by The Designated Driver. Servers watch it. It is rare that someone will flim-flam their way through being a designated driver.

F. Eligibility Requirements. Must be 21. The maximum is 6 in the party because any more than 6 won't be able to fit in the designated driver's car.

G. Publicity. In-house publicity only.

H. Staffing the DDP and Training Staff. Every person who is involved with alcohol goes through an alcohol awareness program which involves DDP training. The training is part of the orientation for every new employee.

I. When Does the Program Operate. No data.

IV. MORE PROGRAM ORGANIZATION

A. Changes in the DDP since It Began. None.

B. Annual Cost. Couldn't say.

C. Resources For Meeting Costs. Corporate office - initiated by him in Phoenix.

D. Are Other Anti-drunk Driving Programs Present. Some stores have Safe Ride, but there have been some difficulties with it. The hard part is funding. They don't have a safe Ride program in Brea, but in Phoenix there is activity and KDKB radio in Phoenix supported it. He had heavy involvement initially in Phoenix. He'll back in Phoenix in July 86 and would be good person to talk to about Phoenix safe ride activity.

V. PROGRAM IMPACT

A. How Well Does the Program Work. He has worked okay in Brea. he says the issues which determine whether a program is successful are: 1) Is there support amongst the staff? and 2) Is there support in community?

B. Reactions to the Program. Staff and designated drivers have been very positive. They feel that "it's nice to know you're doing this for community." It's good Public Relations.

$$
\text { F-10 }
$$


c. What Number Participate / Number of Potential Groups. On a given Friday or Saturday, they have anywhere from 3-4 designated drivers to 8-9 designated drivers.

D. Size of participating Groups. Big groups participate - 2 or 3 designated drivers in group of 20 , especially when it is happy hour. The program is popular during happy hour.

E. Changes in the Drinking of Non-Drivers in Parties with a Desiqnated Driver. This is one thing that you have to monitor. In general it is not too bad ( about 15-20 have the tendency to over indulge).

VI. INFORYAI DESIGNATED DRIVER ACIIVITIES

A. Do People Assign Designated Drivers on Their own. Without Encouragement By A Formal Program. Yes; he's heard about that vaguely.

1.

a. In What situations and for what Fvents. Parties.

VII. WHAT WRITTEN INFORMATION IS AVAILABLE

Will send complete alcohol awareness manual.

COMAENTS :

Bully III (in Starkville, MS) - Reith Vance - 601-323-8251. [RB: Margaret Eatherly, Mississippi Alcohol Safety Education Program ].

Date of interview: $6 / 13 / 86$

Position: General Manager

Address: P.O. Box 390, Starkville, MS 39759

\section{SETTING INFORMATION}

A. Description of Establishment/Location. Hotel with a restaurant and lounge located in a small southern town in the heart of the Bible Belt.

B. Size. Seating capacity: 75 .

C. Description of clientele. Middle age adults, white collar.

D. Availability of Public Transportation. Very poor alternative transportation: there is one taxi in town.

\section{PROGRAM ORGANIZATION}

A. When and Why was the Program started. Program started in 1985. They received buttons in the mail and the suggestion from Mississippi Alcohol Safety Education Program that they serve non-alcoholic beverages to designated drivers who wore these buttons or tags.

B. Coordination with other organizations. No other coordination.

$$
\mathbf{F}-11
$$


III. PROGRAM OPERATION

A. How Is the Designated Driver Selected and Identified. Person volunteers as the designated driver and wears the button/tag. Server does not initiate conversation since they don't want to lose liquor sales or tips. He didn't know why some people refuse to participate.

B. How Are Participants Recruited. There is no encouragement. People must have heard about the program and ask for the button.

C. What Incentives Are offered to The Designated Driver. Free non-alcoholic drinks.

D. Who Uses The DDP. Never met a designated driver so he couldn't say.

E. Monitoring Drinking by The Designated Driver. "We don't monitor them; we just don't serve alcohol to them."

F. Eligibility Requirements. 2 or more.

G. Publicity. None.

H. Staffing the DDP and Training staff. Regular staff run the program but there is no training and none is needed.

I. When Does the Program operate. DDP operates whenever they are open which is from 1l:30 a.m. to midnight.

IV. MORE PROGRAM ORGANIZATION

A. Changes in the DDP since It Began. No changes.

B. Annual cost. Maybe $\$ 5.00$.

C. Resources For Meeting costs: Resources (soda) provided by him; buttons by the Mississippi Alcohol Safety Education Pro-

D. Are Other Anti-drunk Driving Programs Present. No other antiDUI programs exist.

V. PROGRAM IMPACT

A. How Well Does the Program Work. Program is a good idea but has not been handled well; it needs more publicity.

B. Reactions to the Program. No reaction from any of these groups.

C. What Number Participate / Number of Potential Groups. Bar averages 25-30 groups a night but in all last year they only had one designated driver that he was aware of.

D. Size of Participating Groups. Average groups size is 4 ; no change since program started.

E. Changes in the Drinking of Non-Drivers in Parties with a Designated Driver. No data.

VI. INFORMAI. DESIGNATED DRIVER ACTIVITIES

A. Do People Assign Designated Drivers on Their Own, without Encouragement By A Formal Program. He does not know. 


\section{WHAT WRITTEN INFORMATION IS AVAIIABLE}

A. No materials that he is aware of. Check with Mississippi Alcohol safety Action Project.

\section{COMREENTS :}

Bulwinkles (in Minneapolis, MN) - Jackie Iverson - 612-338-8520. [RB: saw in newspaper].

Date of Interview: $7 / 8 / 86$

Position: Manager

Address: 1429 Washington Ave. S, Minneapolis, in 55454

\section{SETTING INFORMATION}

A. Description of Establishment/Location. Bar and restaurant (with a small menu) - largely liquor sales. "Most people don't drive" - since the college is close to the bar.

B. Size. Seating Capacity: 120.

C. Description of Clientele. Majority - 808 - is college students $(19-24)$.

D. Availability of Public Transportation. Taxi and bus line.

\section{PROGRAM ORGANIZATION}

A. When and Why was the Program Started. Started on New Year's eve (1984), and have continued it ever since. started when some other groups were doing it too.

B. Coordination with other organizations. Independent.

\section{PROGRAM OPERATION}

A. How Is the Desionated Driver selected and Identified. No button anymore. It is strictly a volunteer program.

B. How Are Participants Recruited. Occasional ad in the paper. They do not have posters, nor on-premise encouragement, yet "most seem to know about it."

c. What Incentives Are offered to The Designated Driver. Free non-alcoholic drinks.

D. Who Uses The DDP. Usually groups of friends tend to participate and take turns. The decision is made before they come before to the bar - mixture of male and female participants.

E. Monitoring Drinking by The Designated Driver. It is hard for the bartenders to monitor, but the waitresses watch. There is some abuse going on. They are trying to watch it more closely than before.

F. Eligibility Requirements. 3 or more.

G. Publicity. Occasional ad in newspaper; very minimal.

H. Staffing the DDP and Training Staff. None.

I. When Does the Program Operate. Anytime. 
IV. MORE PROGRAM ORGANIZATION

A. Changes in the DDP since It Began. Buttons discontinued. The buttons didn't say "Bulwinkles" so they didn't want to use it.

B. Annual Cost. Nominal.

C. Resources For Meeting Costs. Dian't know where buttons came from.

D. Are Other Anti-drunk Driving Programs Present. Drunks are followed into the lot and are watched to see if they're going to drive; They will call cab if necessary and will begrudgingly foot the bill although they prefer calling the cops to footing the bill. An informal safe Ride.

V. PROGRAM IMPACT

A. How Well Does the Program Work. Working well. It made people aware. She is glad to see it.

B. Reactions to the Program. Not much feedback.

C. What Number Participate/Number of Potential Groups. + to to 15 / week; 50 potential groups per week.

D. Size of Participating Groups. 4 or 5 ; no change.

E. Changes in the Drinking of Non-Drivers in Parties with a Designated Driver. They're drinking more.

VI. INFORMAI DESIGNATED DRIVER ACTIVITIES

A. Do People Assign Designated Drivers on Their Own, Without Encouragement By A Formal Program. Yes.

1.

a. In what Situations and for what Events. Bar hopping.

b. How Is the Designated Driver selected. Alternating.

c. How Widespread Are Informal Designated Driver Activities. Not widespread; couldn't say.

d. How Have You Learned About This. Talking to customers.

e. Other Information About Informal Activities. No data.

VII. WHAT WRITTEN INFORMATION IS AVAILABLE

A. None.

Comments:

Charlie Brown's Restaurant (in Matawan, New Jersey) - Jim

Belavance - 201-583-7666. [RB: Nancy Kelly, NJ Restaurant Association and John Bussey.]

Date of Interview: $7 / 2 / 86$

Position: District Manager in Northeast Region

Address: 27 Freneau on Rt. 79, Matowan, NJ 07747

I. SETTING INFORMATION

A. Description of Establishment/Location. Family restaurant with a separate lounge and bar.

$$
\text { F-14 }
$$


B. Size. Seating capacity: 200 .

C. Description of Clientele. Liquor crowd: ages 25-45; dinner crowd: ages 30-60; mix of blue and white collar, but a little more blue than white.

D. Availability of public Transportation. Taxi readily available; no bus in the evening.

II. PROGRAY ORGANIZATION

A. When and why was the Program started. Iate 1984 . The program was started due to a crunch of liability costs.

B. Coordination with other organizations. Corporate effort.

III. PROGRAY OPERATION

A. How Is the Desiqnated Driver selected and Identified. After the second round, the server will ask parties of 4 - 8 who is driving.

B. How Are Participants Recruited. 2 Posters at the front door, and it is explained to customers at the table by the server.

c. What Incentives Are offered to The Designated Driver. Free non-alcoholic beverages.

D. Who Uses The DDP. Usually female, usually someone who is a "fairly intelligent ... and responsible individual."

E. Monitoring Drinking by The Designated Driver. The server stays in close contact with the situation. The manager will intervene if the designated driver is drinking, but this happens only occasionally. They let the designated driver have two alcoholic drinks before they intervene.

F. Eligibility Requirements. No.

G. Publicity. Mostly in-house; they are a low budget restaurant chain.

H. Staffing the DDP and Training staff. Basic alcohol awareness training.

I. When Does the Program operate. Anytime.

IV. MORE PROGRAM ORGANIZATION

A. Changes in the DDP since It Began. No change.

B. Annual cost. They have not tracked it, but he does not think it is very costly. "It's worth the cost whatever it might be."

c. Resources For Meeting Costs. From Charlie Brown's Corporation.

D. Are Other Anti-drunk Driving Programs Present. Formal (advertised) announcement that they will call a cab if necessary. Safe Ride is a corporate program. The Manager will even drive a customer home if necessary. He said that if no one wants to let up on the drinking or be a designated driver that they will go after the Safe Ride idea. 


\section{PROGRAM IMPACT}

A. How Well Does the Program Work. Pretty well. He has not heard of any problems.

B. Reactions to the Program. Not much feedback; he feels that people generally see it as positive.

c. What Number Participate / Number of Potential Groups. 20 a week; 300 parties a week possible.

D. Size of Participating Groups. 5 or more; bigger groups who stay out longer and do more drinking tend to use it. There has not been a change in the size of groups.

E. Changes in the Drinking of Non-Drivers in Parties with a Designated Driver. No change. Laws have made people very aware.

VI. INFORMAL DESIGNATED DRIVER ACTIVITIES

A. Do People Assign Designated Drivers on Their Own, Without Encouragement By A Formal Program. Yes, it is used more 1. now than two years ago due to increased awareness.

a. In what situations and for what Events. Anytime alcohol is consumed.

b. How Is the Designated Driver selected. In the first place, they are people who do not drink or are lighter drinkers.

c. How Widespread Are Informal Designated Driver Activities. "Anyone who has been arol.nd and has any intelligence is going to use it."

d. How Have You Learned About This. Basic communication with customers.

e. Other Information About Informal Activities. No data.

VII. WHAT WRITTEN INFORMATION IS AVAIIABLE

A. None to speak of - if you really want information from charlie Brown's, call Rick Hendrie at 201-232-1920.

Comments :

Cheers West (in Tacoma, WA) - Frank Messina (206) 565-2626 or 565-9378 - [RB: Carol Knight-Wallace, WA Traffic Safety Commission.]

Date of Interview: $6 / 23 / 86$

Position: Owner and Operating Manager

Address: 7102 27th St. W., Tacoma WA 98466

\section{SETTING INFORMATION}

A. Description of Establishment/Location. Bar and restaurant (tavern): Because of a state law, they do not serve hard liquor; deli food.

B. Size. Seating Capacity: 225 .

$$
\text { F-16 }
$$


c. Description of Clientele. On Fridays (the busiest night) he sees the under 30 crowd (lots of college students); other times, clientele are aged 30 - 40, middle to upper class.

D. Availability of public Transportation. Taxis are available.

II. PROGRAM ORGANIZATION

A. When and Why was the procram stanted. In operation since they opened in 1985; motivation was liability concern.

B. Coordination with other organizations. Got information and resources initially from state liquor control board; now they are essentially independent.

\section{PROGRAY OPERATION}

A. How Is the Desionated Driver selected and Identified. They provide a sticker that goes on the designated driver's clothes. It is strictly a volunteer program.

B. How Are participants Recruited. They have one sign up in the whole place. The clientele were encouraged by the initial publicity; he feels that their clientele doesn't change much.

c. What Incentives Are offered to the Designated Driver. Free non-alcoholic drinks.

D. Who Uses The DDP. Predominantly women.

E. Monitoring Drinking by The Designated Driver. Waitresses monitor; no abuse has been noticed.

F. Eligibility Requirements. 3 or more.

G. publicity. Initial blitz; it has been written up in a popular column of a local newspaper.

H. Staffing the DDP and Training staff. When someone is hired they are given a general alcohol awareness orientation.

I. When Does the Program operate. Anytime.

\section{MORE PROGRAM ORGANIZATION}

A. Changes in the DDP since It Began. None.

B. Annual Cost. Nominal; he guessed $\$ 2$ each time it's used.

C. Resources For Meeting Costs. State.

D. Are other Anti-drunk Driving Programs Present. Safe Ride is very informal.. Will call a cab but, "I don't think that's ever happened." Usually, a friend will take a drunk home. Free coffee and free food has been offered to the person who is drunk.

\section{PROGRAM IMPACT}

A. How Well Does the Program Work. "I don't think people are that interested in it; people who come here want to do some social drinking - they aren't going out to drink pop."

B. Reactions to the program. Not much feedback; but he has heard some positive reactions.

c. What Number Participate / Number of Potential Groups. Once or twice a month. 
D. Size of Participating Groups. Usually 3.

E. Changes in the Drinking of Non-Drivers in Parties with a Designated Driver. Not that he's noticed.

VI. INFORMAI DESIGNATED DRIVER ACTIVITIES

A. Do People Assign Designated Drivers on Their Own, Without Encouragement By A Formal program. Maybe they do, but not to the point where someone will completely abstain. often they just let whoever is the most sober at the end of the night drive people home. They don't tend to plan ahead.

VII. WHAT WRITTEN INFORMATION IS AVAIIABLE

A. Will send materials.

Comments :

Corner Pocket Billiard Lounge (in Missoula, MT) - Tom Baber 406-728-9023. [RB: Ellen Leahy, Missoula City-County Health Dept. ]

Date of interview: June 10, 1986

Position: Owner

Address: 2100 Stephens Street, Missoula, MT 59801

I. SETTING INFORMATION

A. Description of Establishment/Location. Bar and billiard lounge.

B. Size. Seating Capacity: 150.

C. Description of Clientele. Clientele is varied, age range of 25-45, mixed social class with white collar and blue collar.

D. Availability of public Transportation. Taxi service is available 24 hours a day; bus service is available until 9 or 10 in the evening.

\section{PROGRAM ORGANIZATION}

A. When and Why was the Program started. The program got started in 1985. The motivation was provided by the Missoula CityCounty Health Department which initiated the program and made it available to interested establishments.

B. Coordination with other organizations. The only coordination is with the Missoula City-County Health Department. The other bars may start (or have started) this DDP program but there is no coordination that he is aware of.

\section{PROGRAM OPERATION}

A. How Is the Designated Driver selected and Identified. A person volunteers to be designated driver by asking for a designated driver button. Usually, the customers initiate the con-

$$
\text { F-18 }
$$


versation concerning the DDP although the server may. He could not speculate as to why some people refuce to participate. Perhaps they just want to be able to drink alcoholic beverages.

B. How Are Pafticipants Recruited. DDP posters are posted in the establishment and elsewhere. servers do not wear buttons, but they may talk about the program.

c. What Incentives Are offered to The Desionated Driver. Free non-alcoholic drinks. When they leave the establishment and turn in their button, they are given a card for a free alcoholic drink to be redeemed the next time they return.

D. Who Uses The DDP. It is hard to say what differences there are between participating and non-participating customers. He ventured to say that participating customers are more concerned about highway safety and drunk driving and less concerned with partying than non-participating customers.

E. Yonitoring Drinking by The Designated Driver. Usually, it is up to the server to insure that the designated driver does not drink alcohol. There is no rigid monitoring, but they may happen to notice a violation.

F. Eliaibility Requirements. 2 or more.

G. publicity. DDP is basically advertised via posters, although there have been PSAs on TV, media articles, etc. The ongoing publicity helps to keep the program running.

H. Staffing the DDP and Training staff. The program is basically staffed by Baber and his staff; no training is provided.

I. When Does the Program Operate. Anytime.

\section{MORE PROGRAM ORGANIZATION}

A. Changes in the DDP since It Began. No changes except for the addition of some public information materials on drunk driving.

B. Annual Cost. No administrative costs are involved.

C. Resources For Meeting Costs. Resources come from a grant from the Missoula City-County Health Department.

D. Are other Anti-drunk Driving Programs Present. There is a safe rides program called HOME FREE which provides 24 hour free taxi service. They are billed by the taxi company. In contrast to the DDP, this safe rides program is heavily used.

V. PROGRAM IMPACT

A. How Well Does the Program Work. Not as well as the safe rides program. Judging by the number of people coming back for free alcoholic drinks, the DDP has not been used much. He does not have many free drink cards returned and this indicates to him that there is low utilization.

B. Reactions to the program. Community groups and the cops like it. Anything to reduce DWI is seen as positive. Patrons appreciate it when they use it. staff like it. He does not know how non-participating patrons feel about the DDP.

$$
\text { F-19 }
$$


c. What Number Participate / Number of Potential Groups. Hard to determine; not many people have used it in contrast to the safe rides program in which they provide on the average 30 free taxi rides home per week.

D. Size of Participating Groups. Average size of participating groups is 3 to 4 persons. He has not noticed any changes in the size of the groups since the program started.

E. Changes in the Drinking of Non-Drivers in Parties with a Designated Driver. He does not think that the drinking level of non-drivers in the DDP party has changed. They just don't have to worry about driving.

VI. INFORYAT DESIGNATED DRIVER ACTIVITIES

A. Do People Assion Desianated Drivers on Their own. Without Encouragement By. A Formal Program. Not applicable.

VII. WHAT WRITTEN INFORYATION IS AVAILABLE

A. We don't have any written materials, although the Missoula City-County Health Department might.

COMDENTS :

D. B. Coopers (in Salt Lake City, UT) - Mike LaPrey, Manager 801-532-2948 or 532-6105 (office). RB: Don Beck, Utah Licensed Club Owners Assoc.

Date of Interview: $6 / 26 / 86$

Position: Manager

Address: 19 E. 200 South, Salt Lake City, UT 84111

I. SETTING INFORMATION

A. Description of Establishment/Iocation. Dinner club - one fourth is lounge and three quarters is restaurant.

B. Size. Seating Capacity: 160 total; lounge $=70$ and restaurant $=90$.

c. Description of Clientele. Varies from day to evening; ages range from 25-50, white collar.

D. Availability of public Transportation. Taxi readily available, bus stops at 9:00 p.m.

II. PROGRAY ORGANIZATION

A. When and why was the Program started. November 1985 . He read about it in a magazine and thought it would be good.

B. Coordination with other organizations. No.

III. PROGRAM OPERATION

A. How Is the Desionated Driver selected and Identified. Button used; strictly volunteer. 
B. How Are participants Recruited. Poster up prominently at front door.

c. What Incentives Are offered to The Designated Driver. Free non-alcoholic drink and free appetizers.

D. Tho Uses The DDP. In the first place they are people who are usually outgoing but non-drinkers; it is not likely that a drinker is going to abstain for an entire evening just to be a designated driver.

E. Monitoring Drinking by The Designated Driver. Servers watch the button. He does not think it is abused.

F. Elialbility Reculrements. None.

G. Publicity. Newsletter to members of club.

H. Staffing the DDP and Training staff. All servers are trained initially. The program is "fairly basic and simple."

I. When Does the Program Operate. Anytime.

\section{YORE PROGRAM ORGANIZATION}

A. Changes in the DDP since It Began. Table tents are no longer used. The staff used to wear buttons. They discontinued both of these after the program got off the ground.

B. Annual cost. He has not calculated it; not much.

C. Resources For Meeting Costs. Independent.

D. Are other Anti-drunk Driving Programs Present. Formal safe Ride was offered during one annual club event last year, and no one took them up on it. They probably will try again this year.

V. PROGRAM IMPACT

A. How Well Does the Program Work. Has worked "fair." Not used very often.

B. Reactions to the Program. Positive all around.

C. What Number Participate / Number of Potential Groups. Not more than 10 in a week; he could not say about total possible number of parties.

D. Size of Participating Groups. 4 to 8 .

E. Changes in the Drinking of Non-Drivers in Parties with a Designated Driver. Not that he has noticed.

\section{INFORYAL DESIGNATED DRIVER ACTIVITIES}

A. Do People Assign Designated Drivers on Their own, Without Encouragement By A Formal Program. Yes, as much as in a bar.

1.

a. In what situations and for what Events. Parties, anywhere.

b. How Is the Designated Driver Selected. Designated driver is a non-drinker in the party in the first place; he doesn't think that people take turns.

c. How Widespread Are Informal Desionated Driver Activities. Quite widespread.

d. How Have You Learned About This. Talking to clientele. 
e. Other Information About Informal Activities. No data. VII. WHAT WRITTEN INFORMATION IS AVAILABLE

A. None.

Comments:

Darryl's (in Raleigh, NC) - Carl Ritz - 919-782-1849: [RB: T. Jarry Williams, NC Rest. Association.]

Date of Interview: $6 / 17 / 86$

Position: Area Director

Address: 6008 Glenwood Ave, Raleigh, NC

Main Address: Gilbert Robinson, 47th and Main, PO BOX 16000 Kansas City, RS 64112 .

NOTE: DARRYL'S NO LONGER USES THE DDP; ONLY SAFE RIDE. PROGRAM ENDED IN NOV. 1985

I. SETTING INFORMATION

A. Description of Establishment/Location. Family restaurant, bar and lounge.

B. Size. 288 .

C. Description of Clientele. 25-45 - white collar.

D. Availability of Public Transportation. Busses and taxis are available.

II. PROGRAM ORGANIZATION

A. When and Why was the Program Started. Dec. 1982; motivation was to help educate the public.

B. Coordination with other Organizations. Independent.

\section{PROGRAY OPERATION}

A. How Is the Desionated priver selected and Identified. Button used; server often initiated conversation.

B. How Are Participants Recruited. Table tents, posters, literature, employees wore buttons.

C. What Incentives Are offered to The Designated Driver. Free non-alcoholic drinks, plus a $\$ 5.00$ gift certificate to be used on a future date.

D. Who Uses The DDP. No generalizations can be made.

E. Yonttoring Drinking by The Designated Driver. They watched carefully since be mentioned that if the designated driver had one drink, they were not permitted to participate further; they also were forbidden to drink a friend's drink.

F. Bliaibility Requirements. Party of 3 or more - didn't ask why.

G. Publicity. Internal promotion, rewspapers did articles on the program. 
H. Staffing the DDP and Training Staff. Normal staffing; "very brief training program" ( hour).

I. When Does the Program operate. Anytime.

\section{MORE PROGRAM ORGANIZATION}

A. Changes in the DDP since It Began. None.

B. Annual Cost. Nominal.

C. Resources For yeeting Costs. Independent.

D. Are other Anti-drunk Driving Programs Present. Has Safe Ride (informal); as part of that, customers are issued a card saying that the management has determined you to be unfit to drive and that you may have complimentary non-alcoholic drinks or some free food; after this a taxi, or an employee or the manager will drive you home.

\section{PROGRAM IMPACT}

A. How Well Does the Program Work. Well.

B. Reactions to the Program. Some stores reacted positively; others not so well.

c. What Number Participate / Number of Potential Groups. Up to 20-25 drivers per week, or as few as 10 per week.

D. Size of Participating Groups. 3 to 5 .

E. Changes in the Drinking of Non-Drivers in Parties with a Designated Driver. No. Excessive drinking is not a problem because servers are instructed to cut people off regardless of whether there is a DDP.

VI. INFORMAI DESIGNATED DRIVER ACTIVITIES

A. Do People Assign Desiqnated Drivers on Their own, Without Encouragement By A Formal Program. With the laws the way they are, the general public has become more responsible in the area of drinking and driving; he was not aware of activities which were specifically DDP.

VII. WHAT WRITTEN INFORMATION IS AVAIIABLE

A. None.

Comments: Unclear why they discontinued it beyond the fact that . that it was not a part of the new ownership's well-developed prevention program.

Department of the Navy - Naval Technical Training Ctr. (in Pensacola, FI) - AM Schmidt, MWR Director - 904-452-6317 or 452-6389. [RB: Peggy Pearce, Media Information and Marketing office.]

Date of Interview: $6 / 13 / 86$

Position: MWR Director 
Address: NTTC Corry Station, Pensacola, FI 32511

I. SÉTTING INFORMATION

A. Description of Establishment/Location. $\$ 225,000 /$ month operation. Over half of sales is liquor, a lot of entertainment.

B. Size. Five seating areas: $175,240,80,140$ and 350 .

C. Description of clientele. 17-60 years old - navy, air force, marines, army and foreign students are the clientele.

D. Avallability of public Transportation. Commercial taxi outside the gate; tipsy taxi used.

II. PROGRAM ORGANIZATION

A. When and Why was the Program started. Mid-1984. Motivation: Big push from MADD and SADD and dram-shop law; Navy encouraged
it also.

B. Coordination with other organizations. They follow the guidelines of the Navy.

III. PROGRAM OPERATION

A. How Is the Designated Driver selected and Identified. Doorpeople ask ("solicit") customers as they walk in whether they would like to designate a driver; big groups are targeted; button used.

B. How Are Participants Recruited. Signs are inside of door; table tents from time to time. (He said he doesn't like to saturate them with the same kind of promotion - otherwise they get used to it being there. Accordingly, they try to vary the
promotion methods.)

c. What Incentives Are offered to The Designated Driver. Free non-alcoholic drinks.

D. Who Uses The DDP. Can't generalize - 19-34 group more likely to participate; older groups will participate on New Year's Eve and other big events.

E. Yonitoring Drinking by The Designated Driver. Waitress watches ("polices") the situation.

F. Elialbility Requirements. None.

G. Publlcity. Base newspaper, recreation area bulletin boards, and base radio station promotes it.

-H. Staffing the DDP and Training staff. Staff made aware of it "almost continuously;" weekly staff meetings; department heads are concerned with it also and discuss it at meetings.

I. When Does the Program operate. Anytime.

IV. YORE PROGRAM ORGANIZATION

A. Changes in the DDP since It Began. "When it first started it was taken sort of lightly; now it's almost a house-hold word." Throughout the Navy, people are made aware of it.

B. Annual Cost. Hard to estimate. 
c. Resources For Meeting Costs. Some resources produced independently; others from the main naval headquarters.

D. Are Other Anti-drunk Driving Programs present. Safe Ride formal (Tipsy Taxi). However, he went on to describe another program - independent from Tipsy Taxi - occasionally used where they will provide free taxi service (Let Us Drive You). couldn't get him to clearly distinguish between the latter and Tipsy Taxi. Call back for safe Ride project.

\section{PROGRAX TYPACT}

A. How Hell Does the Program Work. Driving fatalities are way down this year. He couldn't say whether it's working well otherwise; all he knows is that there have not been many DUIs.

B. Reactions to the program. Generally positive.

C. What Number Participate/Number of Potential Groups. 10-20 per night; 1,000 total parties per night.

D. Size of Participating Groups. 4 or more.

E. Changes in the Drinking of Non-Drivers in Parties with a Designated Driver. No change; overall throughout the whole Navy, they're "drinking a lot smarter" especially the younger ones.

VI. INFORMAL DESIGNATED DRIVER ACTIVITIES

A. Do People Assion Designated Drivers on Their Own, Without Encouragement By A Formal Program. "I would hope so." Couldn't say for sure. Personally, he does it.

VII. WHAT WRITTEN INFORMATION IS AVAILABLE

A. None

COMRENTS :

Down Under (in Newark, DE) - Larry Garyantes - 302-366-0517 or 366-8593. [RB originally: Francis Ianni, Office of Highway Safety.]

Date of Interview: $6 / 11 / 86$

Position: Owner

Address: $60 \mathrm{~N}$. College Ave. Newark, DE 19711

I. SETTING INFORMATION

A. Description of Establishment/Location. Bar and restaurant; entertainment, more bar than restaurant - college community.

B. Size. Seating Capacity: 175 .

C. Description of clientele. Primarily college students especially at night when they do most of their business.

D. Availability of public Iransportation. No transportation not even taxi. 


\section{PROGRAY ORGANIZATION}

A. When and why was the Program started. Summer 1985; started when MADD pushed it. (Garyantes is active with MADD.)

B. Coordination with other Organizations. MADD is the main outside agency; plans to start using Anheuser-Busch DDP kit.

\section{PROGRAM OPERATION}

A. How Is the Designated Driver selected and Identified. Staff asks if one would volunteer to be designated driver; issued a pin saying "I'm the Driver."

B. How Are Participants Recruited. Publications are posted on bulletin board; Anheuser Busch table tents are starting to be used.

C. Mat Incentives are offered to The Deslanated Driver. Free non-alcoholic drinks given out for that evening; upon completion of evening, designated driver gets a certificate good for $\$ 2.50$ worth of food or one free drink (alcoholic or nonalcoholic) of his/her choice on a future date.

D. Who Uses The DDP. College age patrons don't generally participate in the program because they walk from their dorms to the Down Under; the 28-45 crowd (after work parties) that comes on Friday often participates.

E. Monitoring Drinking by. The Designated Driver. Designated drivers are allowed up to two alcoholic drinks! After that it's monitored. He hasn't noticed abuse.

F. Eligibility Requirements. At least 3. Generally they choose their own driver; sometimes they need mediation in which case he comes in and will have them draw straws or the like. He tries to keep it light-hearted.

G. Publicity. Mostly in-house; bar DJ makes at least one announcement per night about DDP. Garyantes is active around the state so he makes the program known one way or the other; publicity has increased since the program began.

H. Staffing the DDP and Training Staff. Attendance of alcohol awareness seminars is required 3 times per year.

I. When Does the Program operate. Tues.-Thurs.: 8:00 - closing (1:00); Fri. and sat.: 6:00 - closing $(1: 00)$.

\section{YORE PROGRAY ORGANIZATION}

A. Changes in the DDP since It Began. Originally there was no return trip for free food or a free drink awarded.

B. Annual cost. Under $\$ 100$.

C. Resources For Keeting Costs. Highway Safety; Delaware Restaurant Association.

D. Are Other Anti-drunk Driving Programs Present. They do safe ride informally, but he didn't seemed too fond of the program; he says there is a problem with liability. In some cases when the customer is known to them they will use it; if it's a new customer they don't use it. 


\section{PROGRAM IYPACT}

A. How Welf Does the Program Work. On a scale of 1 - 10 he'd put it at a 6; program is more effective from an awareness standpoint than from standpoint of number of persons who participate.

B. Reactions to the Program. Basically well-received.

C. What Number Participate/Number of Potential Groups. 10 parties per week participate. 200-300 possible driving parties.

D. Size of Participating Groups. Usually more than 5 in group; size has increased somewhat; it seems to be catching on.

E. Changes in the Drinking of Non-Drivers in Parties with a Desianated priver. He doesn't think drinking level has changed. 998 of people who come into the bar have 3 drinks; generally, people don't get drunk as much as they used to. They're well aware of laws.

VI. INFORMAL DESIGNATED DRIVER ACTIVITIES

A. Do People Assion Designated Drivers on Their own, Without Encouragement By A Formal Program. Not aware of anything

VII. WHAT WRITTEN INFORKATION IS AVAIIABLE

A. Will send materials.

COMMENTS :

Graffiti's (in Waterford, CT) - David waddington; 203-447-0894

[RB: Frank Francisconi, office of Highway Safety.]

Note: SV: indicates data from site visit conducted $8 / 22 / 86$, data from written materials collected at site visit has been entered and noted as such. At site visit interviewed owner, manager, bartenders, doorman, cocktail waitress. Interview with patrons not possible cause of noise level.

Date of Interview: $6 / 4 / 86$

Position: owner

Address: 297 Willetts Ave., Waterford, CT 06385

\section{SETTING INFORYATION}

A. Description of Establishment/Location. Lounge, kitchen open until 10:00; they serve two hot meals, the lunch crowd. Dance club. SV: plays 50's 60's and some $70^{\prime}$ s rock and roll. Six nights a week they have a $D$ from about 8:45 till closing. Ritchen serves food till 10:00 p.m. Iunch: 10:00 a.m. until 2:00 p.m. They are located in a neighborhood with private homes, not among other retail establishments. The front of a 1950 's automobile projects from the front of the building. Another half of a car ('57 Chevy) is located immediately in: 
side the front door. During the evening the front door is barred and people enter through a rear entrance off a rear parking lot. This allows doormen to check people in through one entrance. Decor is modest homey, lots of film posters and vintage memorabilia on the walls, tables and booths in several areas; tables spaced to allow relatively easy passage among them; 2 levels, 2 bars, dance floor, disco lighting, sound system. Opened in November 1985, Naddington orginal and sole owner. Iocated in southern coastal Cr., in a resort area.

B. S1ze. 288 seating capacity.

C. Description of clientele. Between 21 and 65 , vast audience, play wide variety of music from $50 \mathrm{~s}$ - 808; mixture of blue and white collar (50-50). He hinted that they are attracting the crowd that goes a little lighter on the booze. He indicated that certain people are staying away (because heavy drinking is discouraged). No last calls, no 100 proof, no doubles, etc. are served. SV: there are no happy hour laws in CT. Crowd is drawn from several surrounding communities, people come from $20+$ miles away.

D. Availability of Public Transportation. Limo, taxi service available; no public transportation.

\section{PROGRAY ORGANIZATION}

A. When and Why was the Program started. Spring 1985. SV: Became more aware of his responsibilities; he became determined to make it "a fun place, not a place where people get drunk". Part of the motive was to mitigate liability; Graffiti's was sued but won the case - the man claimed he left drunk at 9:00 p.m. and the result was a traffic accident several hours later. There was a jury trial. Now David Waddington is self insured because costs went up. The insurance agency wanted $\$ 48,000$ for renewal of a policy which was too costly. WH notes that responsible service is an especially important issues for those establishments like Graffiti's and the Great Escape which self-insure.

B. Coordination with other organizations. Independently operated. SV: Waddington had been active in responsible server programing in the state through the connecticut cafe and Restaurant Ifquor Council. The council sponsored server training workshops throughout the state at which Waddington taught free courses; not going on at present but other activities are underway to promote responsible serving including an effort, of which he is part, to make server training mandatory under state law. The DDP he runs is independent, but he has used original and adapted promotional materials from the Anheuser-Busch "I'm Driving" DDP kit. The kit, which is purchased from Anheuser-Bush, provides counter cards, table tents, posters, buttons and the like. He uses the buttons as is but has had many of the other materials reprinted to include the Graffiti logo. He provided an example of materials from the kit. He also obtained a similar DDP kit from Coca-

$$
\mathbf{F}-28
$$


Cola, but does not use it because it emphasizes coke as the alternative beverage.

\section{PROGRAK OPERATION}

A. How Is the Designated Driver Selected and Identified. Buttons are used. Waddington and his managers are the only ones to give pins. He feels that this will help to make the designated drivers feel important. Once a customer expresses interest, the server must get waddington or manager to give out the button and explain program in detail. strletly voluntecr program. SV: Naddington or manager ask potential DD qual ifying questions: Are you driving at least 3 other people home? DId you have a drink before you came? If it is a new customer, they. may let them become a designated driver even if they have had a drink. The manager said: "We may let it go by the first time if the person is not intoxicated and I believe he has had only one drink. I usually say, 'I can let you qualify this time, but now that you know the rules you will know what to do next time." Patrons are told about free drinks and a gift certificate for a free open faced sandwich they can use on the next visit. Get coupon when they turn in pin at end of the evening. Waddington or manager thank them then: "thank you for taking such good care of our customers."

B. How Are Participants Recruited. Table tents; heavily promoted within bar in general. SV: promotion is almost exclusively by printed media, but DJ often announces DDP and waitress noted that customer who orders coke or another non-alcoholic beverage might be asked if they would like to become the DD. All personnel wear very large (about 4" in diameter) pins that say: "I'M DRIVING;" many people ask about them.

C. What Incentives Are offered to The Designated Driver. Frozen drinks (mocktails), soda, juice, non-alcoholic wine and beer; a wide variety of alternative beverages. At the end of the evening, the designated driver turns in his/her button and gets a coupon for an open-face sandwich on a future date. In addition, patron is asked to turn in pin at end of the evening, at which point Waddington or manager goes over to their table at the end of the night to thank them and present them with certificate for free open face sandwich on a later visit. sv: Waddington feels incentives are important to encourage DDP; he and servers interviewed feel that patrons feel that the free drinks and coupon for a sandwich are generous offerings and appreciate the attention they receive from the management.

D. Who Uses The DDP. His clientele seem to be especially attuned to idea of designated driver.

E. Monitoring Drinking by The Designated Driver. On the honor system. SV: When asked what would happen if the server noticed a designated driver sneaking an alcoholic drink, Waddington stated that he would ask for the pin back, but that there are almost no occasions of people cheating in any way. No one checks on who drives.

F. Eligibility Reouirements. Must have 4 people in car. If . there are 2 cars at a 4 person table, they are not eligible: 
Reason is a big benefit and selling point for the hesitant bar owner: Customers take up 1 booth instead of 2 booths because they have to sit together. It also saves on parking spaces. SV: extending the program to couples would increase his cost and reduce the above benefits which he sees as important for himself and other owners. See V B for comment on problem related to minimum size.

G. Publicity. Iocal newspaper (New Iondon Daily) - when program started. Other newspapers and radio stations air it as a "news-related 1tem." SV: in advertising Graffiti's, the DDP is sometimes mentioned.

H. Steffing the DDP and Training staff. Training of the entire staff: he trains. He has staff meetings to refresh their memory and to introduce the idea to new people. SV: doormen, bartender, and waitresses all trained. About 20-30 staff per evening on duty. He has trained people from other establishments through the CT restaurant association (see II $B$ above). Training is constant, ongoing. Staff arrive 15 minutes early to permit meetings and discussion and there are discussions at the end of the evening as well. All staff receive a training package which includes a statements about serving policy. There is a staff bulletin board on which he puts notices and stafe must sign them to indicate that they have read them.

I. When Does the Program Operate. The program is used only at night (it's available during the day, but no one ever uses it). He's trying to build a crowd. Therefore; he's leary about designating a driver at midnight or later when the bar is only open until 1:00. He said that it is bad for business as if be wants customers to spend a good amount of time at his place, so he doesn't want to offer it late when they won't be staying long. SV: 2 reasons given for this (1) good chance that $D D$ has had a drink somewhere beforehand when they start this late and (2) patron takes advantage by getting goodies without chance that the party will spend enough to offset cost in the little time remaining.

IV. MORE PROGRAY ORGANIZATION

A. Changes in the DDP since It Began. None. sV: no plans to change the program. Staff interviewed wonders about extending the program to couples, although they realized this would cost more.

B. Annual cost. He couldn't give an estimate. sv: emphatic that he could not estimate, because the cost was so little. He characterized the cost as "petty cash" noting that the program may actually make him money in at least 2 ways (I) encourages better clientele and reduces hassles with heavy drinkers (2) other members of the designated driver's party probably drink more and this offsets small cost of incentives given to designated driver.

c. Resources For Meeting Costs. Anheuser-Busch kit, but he has modified the kit to fit his establishment's specific needs. SV: No donated resources. No impact on liquor revenues that

$$
\mathbf{F}-30
$$


he can attribute to DDP. No change in ratio of liquor to food sales.

D. Are other Anti-drunk Driving programs present. None. SV: They have an informal safe rides program. People occasionally "leak" through the system; "nothing is perfect." When this occurs, they try to get the patron a ride home with another sober patron; they may pay taxi fare for the patron, or the doormen may drive home (two - one to drive patron's car and one to follow). No special insurance for this. It is a very rare event that ride is provided in any form; perhaps they a provide ride by doormen once every 3 months. Other efforts also. They do not serve doubles or discount drinks. During happy hours, he serves snacks and raises the price of drinks rather than lowering. He does not serve high proof alcohol, e.g. his Vodka is 80 proof, not 100 proof, etc. Personnel guidelines note that "all drinks will be measured by means of a shot glass. At not time will persons free pour drinks. Any drink which calls for a half shot means liquor will be poured into the shot glass up to the line and not any further." The coffee pot is always on and always visible. Employee training. Manipulates environment to reduce rowdiness and excessive drinking; can pass between tables easily, music not too loud. They have a dress code to keep troublesome people out; code permits jeans etc., but discourages slovenly dress, bikers, etc. (no baseball caps, no work shoes - eliminates construction workers on the way home, no black leather, no holes in clothes). Two doormen on duty. They pay a $\$ 10$ bounty for discovering fake IDs. If a fake ID is found, the doorman distracts the customer by saying he must get the owner's or manager's approval; then he shows the ID to waddington or manager, and then they call the police and have would-be patron arrested. The result is that very few people try to get in with fake ID; has paid out only once or twice in the last 6 months. Signs and posters announce DD program, in parking lot exit he has 2 signs encouraging use of seat belts. Waddington said, "last thing they see on the way out is another message about safety."

\section{PROGRAM IMPACT}

A. How Well Does the Program Work. Buttons heighten awareness just by their presence, no question about it. It has really caught on. He is in favor of the program loof. His goal is to have a designated driver at every table. sv: No problems noted by the staff. The standing joke in the place among the staff is that the problem with the program is that wearing the buttons puts holes in blouses and shirts. One problem noted in other context concerns "cheaters": very rarely, a party of 4 lies about the designated driver driving them home because they really come in two cars. When this happens, Waddington or manager speaks with them and explains that they cannot be taken advantage of. There are no regular checks on who drives; just sometimes they see who does.

$$
\text { F-31 }
$$


B. Reactions to the program. Designated driver's thank them, others are positive, no complaints, nothing but favorable.

c. What Number Participate / Number of Potential Groups. 5 cars participating per weekend night. 38 (guess) of eligible groups.

D. Size of Participating Groups. No data.

E. Changes in the Drinking of Non-Drivers in Parties with a Desionated Driver. They do drink more; everyone is paranoid of anti-drunk driving laws; so when they can get home safely they binge. SV: David and staff are pretty emphatic that while others in party may drink more, they do not over-serve to the point of intoxication, and do cut people off.

\section{INFORYAI DESIGNATED DRIVIR ACTIVITIES}

A. Do People Assiom Desimated Drivers on Their own. Without Encouragement By A Formal Program. Yes; he's aware of it happening.

1.

a. In What Situations and for what Events. No data.

b. How Is the Desionated Driver Selected. No data.

c. How Widespread Are Informal Designated Driver Activities. Trend is growing. Mocktails are being sold like crazy; good sign that trend is growing.

d. How Have You Learned About This. Clients tell him about it

e. Other Information bout Informal Activities. No data.

\section{WHAT WRITTEN INFORYATION IS AVAILABLE}

A. Will send materials. Received.

Materials retrieved during site visit: table tent, personnel guldelines, good customer relations instructions, Graffiti's lounge price list, menu, take home recipes for mocktails, I'M DRIVING instructions by Anheuser -Bush, news release re: the DDP.

COMMENTS: Good Iighting, non-acid-rock music, larger dance floor all encourage less heavy drinking. SV: Emphasized that DDP offers owners many advantages and that it is these which make the program work: (1) 4 people in one car saves parking; (2) 4 people in one booth or at one table saves room inside; (3) promotes a general atmosphere of responsible drinking which in turn cuts down on problem drinkers and encourages a better clientele; "sends a message to everyone that we are promoting moderation here and that drunks are not wanted... one intoxicated customer can lose you 10 other customers who are made to feel uncomfortable;" (4) others in the party do drink more which offsets the cost of incentives. Waddington wants "a good crowd, not problems". Have had only 4 fights in 2 years. "People who don't cause problems for me have as much money to spend and are less trouble;" (5) good for community relations; (6) important to minimize liability.

$$
F-32
$$


The Great Escape (in Weymouth, MA) - Wade Federici, owner 617-337-7732. [RB: Wayne Harding, Jim Peters.] Site visit by

Note: SV: indicates data from site visit conducted $8 / 2 / 86$, data from written materials collected at site visit has been entered and noted as such. At site visit interviewed Wade Federici and bartenders, waitresses, and doormen $(N=4)$.

F: indicates entries from printed materials from "wade

Federicl and the DWI 'writing on the wall'", Nation's

Restaurant News, April 23, 1984; p.77 whe Great Escape

GE: indicates information from "Corporate Policy Regarding The Service of Alcohol"

Date of Interview: 6/11/86

Position: owner

Address: 500 Washington St., Weymouth, MA 02188

\section{SETTING INFORYATION}

A. Description of Establishment/Location. Restaurant, lounge and night club. SV: nightclub is called "Escape", establishment opened in 1975; Wade has been there since it opened. 1118 square feet, 3 bars, 8 bartenders, 156 total staff. F: "entertainment complex", 15 minutes south of Boston.

SV description: the 3 operations are separate. one can pass between lounge and dining area through a door, but nightclub has totally separate entrance with no pass through except for staff. Nightclub has $\$ 3.00$ cover charge. Restaurant prices are moderate by standards of downtown Boston; it is possible to get a full meal for $\$ 15.00$. There is live entertainment in the lounge after about $9: 30 \mathrm{p.m}$. There is recorded music in the nightclub, and a small disco dance area with lighting display. By 9:30 the noise level in the lounge was painful, the disco noise level was also painful.

B. Size. Restaurant: 158; Lounge: 250; Night Club: 470 (seating capacities). SV: lower attendance in summer than winter is attributed to people on vacation. They serve approximately 5000 people per week.

C. Description of Clientele. "Mr. and Mrs. Average America" cross section, from business executives to senior citizens; mix of blue and white collar. SV: patrons come from immediate area and from distance. Weymouth has median income of $\$ 14,000$. Median age of lounge customers is about 28 , and the same is true in the nightclub. Big elderly crowd during lunch, and many business lunches served in lounge.

D. Availability of public Transportation. Bus and taxi available. 


\section{PROGRAM ORGANIZATION}

A. When and Why was the Program started. Started a little over three years ago. (First DDP in the country). SV: Wade noted that they always have had "conservative policies" about serving alcohol even when direct competitor a short distance away was serving 1 dollar drinks from 4 to 8:00 p.m. "It never made sense to give liquor away from a business point of view and we didn't want loaded customers". Prior to MA "Happy Hours" legislation they didn't offer two for one drinks, sell pitchers of beer, discount price or do other things which are now outlawed. (See F: for good quote about these practices.) They have been offering rides for 11 years. They have lots of repeat customers - generates good will by them and the community. F: quoting Federici, "If we as the industry do not control ourselves and stop somehow the carnage on the highways... we'll be either legislated or litigated out of business, and the restaurant lounge business will no longer exist as we know it today."

B. Coordination with other organizations. The initial operation was independent; now operate in coordination with recently promoted "I've Got the Reys" local campaign. Promoted by Massachusetts Restaurant Association and WBZ TV4. Federici is the driving force of this current campaign. Program was patterned after "The Great Escape's" original program. sV: WBZ came to Massachusetts Restaurant Association; they renamed the prcgram "I've Got..." because WBZ felt it would be best not to identify it specifically with The Great Escape. Wade is on the board of the Massachusetts Restaurant Assoc.

\section{PROGRAY OPERATION}

A. How Is the Designated Driver selected and Identified. It is generally up to the customer to volunteer; occasionaliy a server will initiate the conversation particularly with larger groups. SV: DDs are given buttons so they can be identified by servers.

B. How Are Participants Recruited. There is print media on tables and walls. SV: lots of materials are displayed, including:

SV: Signs announcing the DDP, e.g., at the entrance to the nightclub, read: " Be a designated driver... The person of your group who takes responsibility for the safety of your group as whole... Agrees to drink only non-alcoholic beverages compliments of the Great Escape/Escapade for that evening... Is presented and wears a Designated Driver badge which may be redeemed for a complimentary drink at any future date. We appreciate your concern. Thank you for being a friend. The
management."

SV: Various signs in various locations which carry safety messages about alcohol and driving. BAC charts posted in all bathrooms. 
c. What Incentives Are offered to The Designated Driver. originally the incentive was free non-alcoholic beverages plus any free drink at a later date. Recently however, as a result of the Massachusetts ABC "Happy Hour" ruling, they've been forbidden from giving out the drink at a later date; now they just provide free soft drinks the night of the original outing. SV: Change in incentive has had no effect on the level of participation. Wade feels that the incentive plays a negligible role.

D. Who Uses The DDP. Not really different; since 33 of people in U.S. don't drink, he doesn't find it too remarkable that people are volunteering. Sv: Some participants wouldn't drink anyway, but this of no consequence to Wade because costs for program are so minimal.

E. Yonitoring Drinking by The Degionated Driver. Servers try to watch. If someone cheats, he/she is re-charged for the drinks that were previously free. If a designated driver leaves, and it's not too busy, the doorman will follow them part-way out to make sure that people are getting into the cars that they're supposed to. SV: doormen will check people and will take keys, call police, etc.

F. Eligibility Requirements. 2 minimum. No maximum.

G. Publicity. Aside from WBZ and Massachusetts Restaurant Association promotions, it's all in-house. SV: newspaper ads do not refer to the DDP.

H. Staffing the DDP and Training staff. Ongoing training is constant; they have staff meetings once a month. They devote a lot of time to the DDP. They have to rely on staff (as opposed to management) to make the program work since they're such a big operation. SV: in september, the entire staff is trained together, otherwise each month a different group meets (bartenders one month, waitresses another). TIPS instructor is used to train new employees at least once a year or new employees are sent to other sites where TIPS training is taking place. All new employees are trained by experienced staff and there is written serving policy [see GE] which every employee must sign. Wade with others is making a 1 hour video training tape.

I. When Does the Program operate. Anytime store is open. SV: 1:30 p.m. to $1: 00 \mathrm{a.m}, 7$ days a week.

IV. MORE PROGRAM ORGANIZATION

A. Changes in the DDP since It Beqan. They stopped using their own logo pins and have started using Massachusetts Restaurant Association and TV4 materials. Another change is in what their incentive is as a result of ABCC ruling. (See III. C. above).

B. Annual cost. "It's got to be one of the least expensive programs." Estimates under $\$ 5,000 /$ year which, considering the size of his overall operation, is "not much."

c. Resources For Meeting Costs. They print up their own table tents, etc. SV: costs are not shared by another organization.

$$
\mathrm{F}-35
$$


The cost of pins and table tents is down since they now get "I've Got the Keys" materials from the Massachusetts

Restaurant Association which prints both in bulk quantities. Pins went from $\$ 0.52$ each to $\$ 0.10$. This is a good example of how broader sponsorship can reduce at least some costs.

D. Are other Anti-drunk Driving Programs Present. Safe Ride done although it wasn't clear whether he was familiar with the term. The doorman will stop anyone that they feel needs a ride. If someone has had too much to drink and insist they need to get home, Escape solves the problem in the following order: 1) Can have a friend drive them home; if not, then 2) call a taxi, Federici offers to pay as necessary; if not, then 3 ) the doorman offers to drive the person home with a another doorman driving behind in a second car; if not, then 4) The last resort, they call the police. (see GE p. 5 for quote on policy). Nightclub doorman estimated they provide 3-5 cab ride per week and 7-10 patrons shut off per night. Lounge doorman estimate $3-4$ rides per night. May well be more safe ride than DDP participants. Doorman in lounge (C.) pretty articulate. C. felt most problems arise from people drinking alone, usually men, may have come in for dinner at 6:00 then to lounge and stay till closing at 1:00 a.m. If they drank the whole evening they will get drunk... C. says if they have shut off someone they may take their keys if necessary. C. noted that regular customers know rides are given, but no abuse of this occurs. Iog book can be used to identify people who repeatedly drink too much. They may be asked not to come back, at least for a while. F: quoting Federici, the restaurant's staff no longer asks intoxicated customers not to drive themselves. "We just tell them firmly, 'You're not leaving.' I'm not treating people nicely about this matter any more. We assume people are driving. And the doormen are responsible for watching whether customers who say they're not driving try to get into a car after all." some customers have tried to charge Great Escape with false imprisonment, but all complaints squashed by the courts who understand what they are doing. The clerk of the court talks complainer out of filing a suit they will not win.

\section{PROGRAY IMPACT}

A. How Well Does the Program Work. It's one of the few tools we can use to stop the intoxicated driver from getting on the road. SV: No problems noted by Wade.

B. Reactions to the program. Staff is very happy; most designated drivers like it; generally very positive.

c. What Number Participate / Number of Potential Groups. A dozen pins per week. 2,000 parties/week sv: bartender in nightclub estimated less than 1 per night; doorman 3-5: per week; waitress in lounge/restaurant said very few designated drivers, and people do know about DDP; doorman in lounge said few designated drivers.

D. Sire of Participating Groups. Usually larger groups participate -4 or 5 . 
E. Changes in the Drinking of Non-Drivers in Parties with a Desionated DFiver. He was emphatic that others in the party do not overindulge. They are very careful not to serve an intoxicated person. He says that drinking in general is down. SV: lots of evidence that over-serving is well monitored apart from DDP. During some quieter times they keep track of drinks per customer over time by using bar receipts; it is not possible to do when it gets very crowded because at bars themselves there is no time to run a bill for people. They shut people off and offer them free non-alcoholic beverages. The strategy is to get them to stay until they sober up, or they must have alternative transportation home (they can't leave drunk). Story by Wade $F$. about a regular customer who came with his family and had 5 drinks in about 2 hours. He was shut off. The guy was probably about 200 pounds so his BAC would be under .10 , the legal limit. It appears that they shut off before people are at .10. This guy left, no anger, said he would be drinking down the road. The decision made by the server is final and supported by management - this was confirmed by interviews with the servers. The management will help intervene if the server asks. They are careful to notify other servers that a person is shut off. Even with more than I bar, large spaces and large numbers of servers, it appears that everyone gets notified. Quote from GE: "It is important once a person is refused service that they don't obtain another drink. The entire serving staff should be aware of who is not allowed another drink. Also, the patron [sic.] behavior should be monitored."

VI. INFORMAL DESIGNATED DRIVER ACTIVITIES

A. Do People Assign Designated Drivers on Their Own, Without Encouragement By A Formal Program. Absolutely. Sees it in his own social circle.

I.

a. In What situations and for What Events. Doesn't know.

b. How Is the Desionated Driver selected. No data.

c. How Widespread Are Informal Designated Driver Activities. More and more widespread.

d. How Have You Learned About This. Mostly through conversations with his customers.

e. Other Information About Informal Activities. No data.

VII. WHAT WRITTEN INFORMATION IS AVAIIABLE

A. Will send materials. GE: sent $G E$ and $F$, got buttons at site visit.

COMMENTS :

SV: Program has had a negative impact on liquor sales, down 12 to $15 \%$ in 1 year, or approximately $\$ 80-100 \mathrm{~K}$. Food sales are up, but not directly tied to the DDP; it is the result of a new chef and a new menu. F: "liquor accounts for between 55: 
and 608 of total sales in the dining room and lounge, and $100 \%$ in the nightclub. Urging customers to take it easy could well reduce those profitable sales."

SV: No Ilability insurance - self insured. This means they must be careful or one suit could put them out of business.

SV: strlking how broad based is the establishment's approach preventing problems with alcohol. Several components described in more detail above and below: screening at entry, screening at exit, training (see above), control of parking areas, print media regarding drinking and driving (see above), shut off policy and procedures (see above), non-alcoholic beverages available, written policy, maintain an incident log, rides (see above), etc.

SV \& GE: have a clear written policy which all new staff must sign to show they have read and understood it.

SV: Screening at entry. Doorman at entrance to lounge and nightclub screen entering patrons for intoxication. They may not admit someone who has been drinking. In a few cases, they have physically detained people until the police arrive to take them into protective custody. The doormen "card" anyone they suspect is underage. They have installed boxes which both illuminate and magnify the license so the doormen can view it easily. A chart is posted which shows the various ways a license can be altered. A book is available at entrances illustrating valid licenses for all states. They keep forged licenses and send them to the Registry of Motor Vehicles. Doormen used to get $\$ 25 \mathrm{gift}$ certificate at Great Escape for every invalid license captured. This cost $\$ 14,000$ in one year. Now they get a $\$ 25$ certificate for every 2 captured. The doormen are encouraged not to admit anyone whose credentials are in doubt.

SV: Screening at exit: screen people leaving to see if they are too intoxicated to drive. story about a customer who said he was walking, doorman walked with him across parking lot to be sure he didn't get into car, customer returned a few moments later to ask them to call a taxi (he was going to drive after all).

SV: Control of parking areas: well lit and patrolled by doormen to prevent alcohol consumption. Anyone drinking in parking area not allowed access.

SV: Non-alcoholic beverages available: wines, beers, juices, coffee, frozen non-alcoholic cocktails (bought machines which makes them with or without alcohol).

SV: Problems with DDP: A bartender in the nightclub and a server in the lounge noted that the DDP cuts back on tips, as does 
shutting someone off. They noted that the heaviest drinkers are usually the best tippers. People drinking non-alcoholic beverages usually don't tip, or tip less. WH asked Wade if he would consider rewarding servers for shutting people off, e.g., provide them $\$ 1$ or $\$ 2$ to compensate for tips they might have lost. Wade will consider this and take it up in meeting. The biggest problem is probably low participation. The diners don't really need the DDP since most drink little. Many people in the Iounge and Nightclub enter as singles or same sex pairs looking for dates. Singles are not eligible and those looking for dates, etc. probably are into buying their target a drink. Because Great Escape has so many countermeasures in place, the DDP is not crucial element. Greatest contribution is to reduce number of people driving after consuming any alcohol, but participation is so low this seems a minor contribution. Presence of DDP may have symbolic value as one more bit of evidence to customers that moderate consumption is important in this establishment. Bartender in nightclub noted problem of shutting people off: patrons first defense is "I'm not driving;" sometimes patron just storms out, which is exactly what they do not want; they want the patron to stick around and get sober.

Ground Round (in Newark, DE) - Nancy Smith - 302-737-0808. [RB: Francis Ianni, DE Highway Safety].

Date of Interview: $6 / 23 / 86$

Position: Aissistant Dining Room Supervisor

Address: 801 So. College Ave., Newark, DE 19711

\section{SETTING INFORMATION}

A. Description of Establishment/Location. Primarily a family restaurant with full-service bar.

B. Size. Seating Capacity: 328 (not usually full).

C. Description of Clientele. Basically middle class (few lower income) - not many upper class patrons; mostly families; bar sees a lot of blue collar. Not as many college students.

D. Availability of Public Iransportation. No taxi is readily available; bus stops at 10:00.

\section{PROGRAM ORGANIZATION}

A. When and Why was the Program Started. Late 1984 ; started when "all those mad mothers started shouting around." They discontinued happy hour at the same time.

B. Coordination with other organizations. Ground Round has a nationwide DDP.

III. PROGRAM OPERATION

A. How Is the Designated Driver selected and Identified. StrictIy volunteer; no button used. 
B. How Are Participants Recruited. One poster up: "I think there's one." The servers sometimes mention it to prime target groups where one person is drinking soft drinks.

c. What Incentives Are offered to The Designated Driver. Free non-alcoholic drinks.

D. Who Uses the DDP. Usually middle-aged woman; woman who doesn't drink anyway.

E. Yonttoring Drinking by The Designated Driver. Servers watch; they're careful. No abuse noticed.

F. Eliaibllity Reguifements. Prefer 3 or more; but will do it with 2: there must be drinking people in the party.

G. Publicity. None.

B. Staffing the DDP and Training Staff. None; initial general orientation.

I. When Does the Program Operate. Anytime.

\section{MORE PROGRAY ORGANIZATION}

A. Changes in the DDP since It Began. Used to use buttons; used to have table tents. More hype during the holiday season. Used to offer free mocktails.

B. Annual Cost. Nominal.

C. Resources For Meeting Costs. Table tents (when they used them) were provided by Ground Round.

D. Are other Anti-drunk Driving Programs Present. Informal safe ride done; will call police if necessary.

V. PROGRAM IMPACT

A. How Well Does the Program Work. Not real effective; the only people who come here to catch a buzz go the bar.

B. Reactions to the Program. Positive - nothing negative.

C. What Number Participate/Number of Potential Groups. 3 a day at the most; some days no one use it.

D. Size of Participating Groups. 4 to 8 .

E. Changes in the Drinking of Non-Drivers in Parties with a Desianated Driver. He would imagine that they drink more. He couldn't say for sure.

VI. INFORHAI DESIGNATED DRIVER ACTIVITIES

A. Do People Assign Designated Drivers on Their Own, Without

1 . Encouragement By A Formal Program. Yes

a. In What situations and for what Events. All types.

b. How Is the Designated Driver selected. Persons who don't drink - the group most responsible one.

c. How Widespread Are Informal Desionated Driver Activities. Kot very widespread at all

d. How Have You Learned About This. Personal experience and from customers

e. Other Information About Informal Activities. No data.

$$
F-40
$$


VII. WHAT WRITTEN INFORMATION IS AVAIIABLE

A. None.

Hilton Hotel (in Grand Junction, CO) - Don Bramer - 303-241-8888. [RB: Dan Hopkins, Division of Highway Safety.]

Date of Interview: $6 / 11 / 86$

Position: General Manager

Address: 743 Horizon Drive, Grand Junction, co 81506

\section{SETIING INFORMATION}

A. Description of Establishment/Iocation. Corporate convention luxury hotel with 270 rooms; 1 mid-priced coffeeshop and 1 gourmet restaurant; 1 quiet lounge and 1 top 40 lounge; 1 beer garden.

B. Size. Coffee shop: 150; gourmet restaurant: 100; quiet lounge: 180; top 40 lounge: 140 ; beer garden: 30 ; banquet facilities for 2,000 .

c. Description of clientele. Patrons are in their late 20 s to 40 for lounge, white collar.

D. Availability of public Transportation. Taxi available; no bus; van soon to come, hopefully.

\section{PROGRAM ORGANIZATION}

A. When and Why was the P:ogram Started. Started early 1985; motivation was to make change in type of clientele they were serving: wanted to get away from being a place where people get drunk.

B. Coordination with other organizations. Have worked closely with SADD and MADD; Hilton corporate headquarters do not seem to be involved.

\section{PROGRAM OPERATION}

A. How Is the Designated Driver selected and Identified. When they come in, customers are asked if they have a designated driver for the evening. They wear a button.

B. How Are Participants Recruited. Posters are up throughout hotel.

c. What Incentives Are offered to The Designated Driver. Free non-alcoholic beverage; no cover charge.

D. Who Uses The DDP. Used mostly by younger people (late 20s); older folks (30s and $40 \mathrm{~s}$ ) don't tend to use it. The younger crowd is a little more "trendy" and tend to be more "into it." says women participate more often; in mixed parties, the women are most often the designated drivers.

E. Monitoring Drinking by The Designated Driver. Waitresses watch; hasn't come across any abuse.

F. Eligibility Requirements. None.

$$
\text { F-41 }
$$


G. Publicity. Newsprint and radio.

H. Staffing the DDP and Training Staff. Lounge manager is in cherge of the program; every new employee goes through alcohol awareness program - semi-monthly meetings, also.

I. When Does the Program operate. Anytime.

\section{YORE PROGRAY ORGANIZATION}

A. Changes in the DDP since It Began. None.

B. Annual Cost. $\$ 2,000-\$ 3,000$ per year. "Not much... main expense is management hours... not much overhead;" soft drinks don't amount to much expense. The structure of this program seems very much to emphasize the responsibility of the management, hence his "management hours" statement above.

c. Resources For Meeting Costs. Colorado Restaurant and Bar Association provides buttons and posters.

D. Are other Ant1-drunk Driving Programs Present. Use safe ride (Tipsy Taxi) a little more informaliy, although it seems that the nature of Safe Ride is by necessity less formal. If they feel that someone has had too much to drink, they hand them a business card saying they won't serve them anymore, and they try to arrange for a ride home for the person. If necessary, they call the cops.

They also have a program called the "Demi-drink" program which is where they serve diluted drinks ( $7 / 8$ oz. of liquor). This program is coupled with DDP.

\section{PROGRAM IMPACT.}

A. How Well Does the Program Work. Real well. They have noticed a drop in sales, but they feel that they're getting a more quality person in their establishments; they stopped all happy hours and low-priced liquor promotions to discourage the guzzling crowd. He doesn't think that the drop in sales is necessarily because of the DDP per se, but rather because of the recent laws and publicity.

B. Reactions to the program. positive. He has received letters and phone calls favoring the program.

c. What Number Participate / Number of Potential Groups. 10 drivers per evening - 25-30 potential parties per evening.

D. Size of Participating Groups. 4 or 5 ; hasn't changed.

E. Changes in the Drinking of Non-Drivers in Parties with a pesignated Driver. Thinks others in the party are drinking less, although, he adds, everyone is drinking less; publicity and laws are reason for this moderation, he feels.

\section{INFORYAI DESIGNATED DRIVER ACTIVITIES}

A. Do People Assion Designated Drivers on Their own, Without 1 . Encouragement By A Formal Program. He has heard about it.

a. In what situations and for what Events. Parities. b. How Is the Designated Driver selected. No data.

$$
F-42
$$


c. How Widespread Are Informal Designated Driver Activities. The trend is growing.

d. How Have You Iearned About This. He's heard about it through customers.

e. Other Information About Informal Activities. No data.

VII. WHAT WRITHYEN INFORYATION IS AVAIIABIE

A. He will send materials.

COMDLENTS :

Holiday Inn (in Bangor, ME) - Peter Dagle - 207-947-8651

Note: This establishment no longer has a DDP; program fizzled in late summer 1985.

Date of Interview: $6 / 13 / 86$

Position: Treasurer and General Manager (company which he works for owns 3 Holiday Inns)

Address: 500 Main St., Bangor, ME 04401

I. SETTING INFORYATION

A. Description of Establishment/Iocation. 6 or 7 different outlets; nightclub does most of the business.

B. Size. 250 in night club.

C. Description of clientele. 25-35; yuppies - white collar.

D. Availability of Public Transportation. Taxi service is good.

II. PROGRAM ORGANIZATION

A. When and why was the Program started. Early 1984 ; motivation was part of responsible alcohol management program.

B. Coordination with other Organizations. Based loosely on MADD'S DDP.

III. PROGRAY OPERATION

A. How Is the Designated Driver Selected and Identified. Iargely volunteer - servers asked for volunteer only when there were larger groups.

B. How Are Participants Recruited. Table tents and posters.

C. What Incentives Are offered to The Designated Driver. Designated drivers were permitted to have 1 or 2 alcoholic drinks; after that, free non-alcoholic drinks were provided.

D. Who Uses The DDP. People who are responsibie drinkers/drivers in the first place tended to use the program.

E. Konitoring Drinking by The Designated Driver. Main problem is making sure that the designated driver drives; no way of knowing once they leave the bar. (For example, a party of six assigns one designated driver, and then they leave, heading for their two cars in the lot.)

$$
F-43
$$


F. Eligibility Requirements. 4 minimum.

G. Fubllcity. Mostly in-house.

H. Staffing the DDP and Training staff. Just in the course of regular staff meetings.

I. When Does the Program operate. Anytime lounge was open.

IV. YORE PROGRAY ORGANIZATION

A. Changes in the DDP since It Began. None.

B. Annual Cost. Nominal.

C. Resources For Meeting Costs. In-house.

D. Are other Anti-drunk Driving programs Present. Tipsy-taxi (Safe Ride). This program is active.

V. PROGRAY IXPACT

A. How Well Does the Program Work. Dagle feels that the DDP is a viable solution for the social drinker; but since the social drinkers aren't really the problem - the problem drinkers are - he thinks that the program is largely a fallure. program is not a viable solution for the problem drinker. Thinks that it's great PR, but unless a group of individuals is responsible enough to designate a driver at the start of the evening - before they arrive at the bar with 2 or 3 cars for 6 people - the program will not work. He couldn't justify continuing a program with these inherent flaws.

B. Reactions to the program. Dagle wasn't directly involved in the operation of the program so he didn't hear much feedback.

c. What Number Participate/ Number of Potential Groups. A few per week on the average -- "Not many."

D. Size of participating Groups. 4-6.

E. Changes in the Drinking of Non-Drivers in parties with a Designated Driver. Doesn't know: "not having been there it's hard to say."

VI. INFORYAI DESIGNATED DRIVER ACTIVITIES

A. Do People Assian Designated Drivers on Their own. Without Encouragement By A Formal program. Yes, definitely; "That was the problem with getting it to work because so many
people were doing it already." 1 .

a. In what situations and for that Events. Mostly dances. There are regulars who do it whenever they go out.

b. How Is the Designated Driver selected. Persons who don't drink in the first place are chosen to be the designated drivers.

c. How Widespread Are Informal Designated Driver Activities.

d. How Have You Iearned About This. Personal experiences.

e. other Information About Informal Activities. No data.

$$
\mathbf{F}-44
$$


VII. WHAT WRITTEN INFORYATION IS AVAITABIE

A. None.

Comments :

Hooligan's. (in Bloomington, Ix) - Steve Engle - 812-333-3003.

Date of Interview: $6 / 19 / 86$

Position: General Manager

Address: $430 \mathrm{kirkwood,} \mathrm{Bloomington,} \mathrm{IN} 47401$

I. SETTING INFORYATION

A. Description of Establishment/Iocation. Primarily a bar; they also have a DJ and dance floor; $90 \%$ of sales are liquor.

B. Size. Seating Capacity: 140 .

C. Description of clientele. Virtually all are college students (21-25) - the fraternity and sorority crowd.

D. Availability of public Transportation. Taxi and bus available; "... being in a small town you're really not far from anything once you leave the bar."

II. PROGRAM ORGANIZATION

A. When and Why was the Program Started. Early 1985 (when the bar opened). They thought it was a good idea; it was good common sense.

B. Coordination with other organizations. Independent.

III. PROGRAM OPERATION

A. How Is the Designated Driver selected and Identified. Hand stamp occasionally used for designated driver. They used to use red beer cups for the designated driver. More often they use nothing.

B. How Are Participants Recruited. Poster up; no table tents.

C. What Incentives Are Offered to The Designated Driver. Free non-alcoholic drinks.

D. Who Uses The DDP. Can't generalize.

E. Monitoring Drinking by The Designated Driver. Honor system. ("By offering the program I think we're fulfilling our necessary responsibility; it's not up to us to make sure that the designated driver doesn't drink.") He feels that the DDP is occasionally abused so someone can get a free coke, but the cost is minimal so he doesn't worry about it.

F. Ellgibility Reguirements. Two or more persons. When someone volunteers to the bartender, the designated driver needs to point out who he/she is driving.

G. publicity. No free publicity sought. Occasional newspaper ads are run; program is mentioned in the fraternity and sorority flyers located in the Greek houses.

H. Staffing the DDP and Training staff. None.

$$
F-45
$$


I. When Does the Program Operate. Anytime.

IV. MORE PROGRAY ORGANIZATION

A. Changes in the DDP since It Began. For a while they used red cups (through the Panhellenic office) as identification of the designated driver; after the cups ran out, they didn't try to replace them.

B. Annual cost. Nominal. "A glass of coke costs two or three

C. Resources For Meeting Costs. Posters come from the Panhellenic Office at Indiana University.

D. Are other Anti-drunk Driving Prograns Present. Safe Ride informally; They do not foot the bill for the cab. Also, doormen refuse entrance of drunken customers.

n... basic bartending."

V. PROGRAY IMPACT

A. How Well Does the Program Work. It is hard to peg or gauge.

B. Reactions to the Program. No data.

C. What Number Participate/ Number of Potential Groups. Some nights none, some (good) nights ten (400 possible parties on the average).

D. Size of Participating Groups. 3 to 5 .

E. Changes in the Drinking of Non-Drivers in Parties with a Designated Driver. No way to gauge that. Excessive drinking goes on anyway.

VI. INFORYAI DESIGNATED DRIVER ACTIVITIES

A. Do People Assign Designated Drivers on Their own, without Encouragement By A Formal program. Yes, it happens all the 1.

a. In What situations and for what Events. Various events; any event where alcohol is served.

b. How Is the Designated Driver selected. Hard to tell; probably those that don't drink as much in the first place; "... most people drink to some extent."

c. How Widespread Are Informal Desionated Driver Activities. Quite widespread. d. How Have You leanned About This. From customers and pri-
vate circles.

e. Other Information About Informal Activities. No datia.

VII. WTAT WRITIEN INFORYATION IS AVAIIABLE

A. None.

Comments: 
Jose's (in Fayetteville, AR) - Joe Fenel - 501-521-0194. [RB: Steve Edmisten, Ozark Guidance Center.]

Note: This DDP operates only on New Year's Eve

Date of Interview: $6 / 10 / 86$

Position: Owner

Address: 324 พ. Dickson, Fayetteville, AR 72701

\section{SETWING INFORYATION}

A. Description of Establishment/Iocation. Full-service Mexican restaurant and private lounge (70z of service is food); live entertainment on weekends.

B. Size. 145 for dinner, 140 in bar (up to 200 standing room only)

c. Description of clientele. 25-40; not normally college age; mix of 407 blue and $60 \%$ white collar.

D. Availability of public Transportation. Taxi until midnight; but bar is open until 2:00 on weekends. No other transportation available.

\section{PROGRAY ORGANIZATION}

A. When and why was the program started. Three years in a row on New Year's Eve.

B. Coordination with other Organizations. Ozark Guidance Center and local Miller Brewing Co. provided some help to get it started, but he did most of it himself; aside from the beginning, it's been entirely independent. Says Miller Corporation has a DDP.

\section{PROGRAM OPERATION}

A. How Is the Designated Driver selected and Identified. Person walks in the door and volunteers right away. strictly volunteer. Button used.

B. How Are Participants Recruited. Not much encouragement now, but they hope to start using table tents; he doesn't think that encouraging the program is all that necessary because "it's becoming a habit."

c. What Incentives Are offered to The Designated Driver. No cover charge (hence why they volunteer when they walk in the door), free dinner at a later date, non-alcoholic beverage for the night.

D. Who Uses The DDP. A bit more serious and responsible. He feels his clientele is that way in general.

E. Monitoring Drinking by The Designated Driver. Servers monitor. If someone cheats they ask the whole party to leave.

F. Eligibility Requirements. Parties of six or more. 21 or older (legal drinking age).

G. Publicity. Ozark Guidance Center has helped; local publication has written small articles. He goes on airways durinğ holidays. 
H. Staffing the DDP and Training staff. Once every nine months.

I. when Does the Program Operate. At this time, New Year's Eve only from time doors open at 7:00 p.m. until closing.

IV. YORE PROGRAY ORGANIZATION

A. Changes in the DDP since It Began. Basics are the same; employees are more tuned into it.

B. Annual cost. Nominal, especially since he limits participation to parties of 6 or more.

C. Resources For yeeting Costs. No resources to speak of.

D. Are other Anti-drunk Driving Programs present. Not now, perhaps in the future; depends on the unsteady cab industry in Fayetteville. Ownership has changed hands 4 times recently and they're not staying open late.

V. PROGRAY IXPACT

A. How Well Does the Program Work. Real well; still a lot of loose ends; basics have been instilled in clientele and employees.

B. Reactions to the Program. People stop him on the street to thank him; people involved are very receptive; they have stopped him and thanked him; some said they came to his place specifically because they knew there was a DDP.

C. What Number Participate/ Number of Potential Groups. First New Year's Eve: 8 . Second: 12-15. Third: 17-18 (2/3 of the possible parties in the 3 rd year).

D. Sire of Particlpating Groups. Average of 8 .

E. Changes in the Drinking of Non-Drivers in Parties with a Desiomated DFiver. They're apt to have 2 or 3 more drinks each.

VI. INFORYAI DESIGNATED DRIVER ACTIVITIES

A. Do People Assion Desianated Drivers on Their Own, Without Encouragement By A Formal Program. He has done it himself. 1. There is a trend for it.

a. In What situations and for what Events. Sporting events, music on weekends.

b. How Is the Designated Driver selected. No data.

c. How Widespread Are Informal Designated Driver Activities. Trend is growing.

d. How Have You Iearned About This. Hasn't really heard about it; simply has the feeling that it's happening as a result of liquor liability laws.

e. Other Information About Informal Activities. No data.

\section{WRAT WRITTEN INFORYATION IS AVAIIABLE}

A. Will send materials and possibly the name of a good DDP he had heard about in Boston. 
COMNENTS :

Juke Box Saturday Night (in Minneapolis) - Steve schussler 612-339-5890. [RB: Saw in newspaper.]

Date of Interview: $6 / 16 / 86$

Position: Co-owner

Address: $14 \mathrm{~N}$. 5th St. Minneapolis, 55402

NOTE: Site visit conducted on $9 / 12$ and $9 / 13$ (on latter date met Schussler in his office while club was closed). Site data is preceded by SV:, data from article on co-owner is identified with a JB: ("Juke Box Saturday Night: Steve Schussler's Dream Come True," Ronald Smith, Entrepreneur, March 1986, pp. 32-34, 36.) Interviewed 2 bartenders, 2 doormen, I waitress, bookkeeper, Shussler's Assistant Manager, and 2 DDs.

\section{SETTING INFORYATION}

A. Description of Establishment/Iocation. Night club with dancing; SV: theme is nostalgic rock and roll, mostly $50 . \mathrm{s}$ and 60 's. Slogan on some materials is "the Twin Cities Bandstand." Downstairs is the club, upstairs is a more sedately decorated function room for hire. Began in 1984. Juke Box Saturday Night is part of a chain of 7 nightclubs which Shussler and a partner operate. There are 4 in Chicago where the original club was founded in $1980 ; 1$ in Demoins Iowa, 1 in Minneapolis MN, was one in Massachusetts, one under construction in San Francisco. The one in MA closed after "happy hours" legislation passed because the law caused a projected loss of $350 \mathrm{~K}$ per year in revenues.

B. Size. $600 \mathrm{sV}$ : in club, 300 in function room. on typical Friday or Saturday evening 1000-1200 pass through the club, on other nights 700-800.

C. Description of Clientele. Yuppies 25-40 - white collar. SV: observed a wide range in terms of age and dress, jeans and $t-$ shirts to suits and ties, 21 to 50 years old. Note that the drinking age is 21 and there are no happy hours legislation in MN. Customers come from the city and from suburbs.

D. Availability of Public Transportation. Bus, taxi. Sv: taxi stand almost directly across the street so doorman can hail a $c a b$ almost at any time. Located in busy downtown district with nearby bus stops.

\section{PROGRAM ORGANIZATION}

A. When and Why was the Program started. 1981. "The first designated driver program in the country." SV: Asked Shussler why it began. He said they felt it would help save lives and tended to deny PR motivation although PR value was exploited later. He gets a 108 reduction on his"

$$
F-49
$$


liability insurance and claims he is the only club in the country to get such a break. He says that he convinced insurers that the DDP "was a major policy of ours -- like getting an insurance discount for installing a sprinkler system in a building."

B. Coordination with other organizations. Independent, sv: but all Juke Boxes have a DDP. Exact operation of DDP may vary slightly, but impression is that they are more similar than dissimilar. Also there is a current effort by a IN radio statIon to promote DDPs. KQRS TV lists all the establishments which have DDPs in a free area newspaper called ncity Pages."

\section{PROGRAY OPERATION}

A. How Is the Desianated Driver selected and Identified. Doormen ask people if they would like to be a designated driver for the evening as they enter for the evening. The doormen are trained to ask various questions of customers (serves as process to screen customers to determine whether they've been already drinking) - I didn't ask him what the questions were); doormen do the asking about designated drivers ("It's the only way it's going to work; if you wait for them to volunteer, you're going to get no response." SV: Doormen do not ask everyone if they want to become DD. They, use discretion, generally ask larger parties. One said that it is not necessary to ask everyone since the program is well known by customers. The screening appears rudimentary: have you been drinking, will you be driving others home. A cashier at foyer who collects cover charge may also ask parties if they wish to participate. Occasionaliy a waitress or a bartender may ask someone, particularly if they note that the person is drinking non-alcoholic beverages, but this is not systematic. All DDs turn in their license to doorman (regardless of who recruited them) in exchange for the DD button. This is done so the doorman can assess the DD's state of intoxication prior to issuing DD button and to check on state when they leave and to remind them that they are driving. Also provides a count of DDs per night. During site visit there were 14 on Friday night. Note another feature of DD is that only bartenders can serve DDs their beverages (no waitress) why? because in another location they found that some waitresses were selling DD iree drinks (would come to bar order a free drink and sell it to a non-DD customer). Bartenders ring in all DD drinks separately and keep tabs on same so cost can be tracked.

B. How Are participants Recruited. Posters up; every employee wears a button; he views it as very important that employees set a good example by wearing buttons so that becoming a designated driver and wearing a button is not such a scarlet letter. ("It's a status thing.") Even the big, "macho" doormen wear the buttons, so it's the first thing customers see when they come in the door. sv: one poster read "Welcome to Juke Box Saturday Night. Ask about our designated driver program. We want you to drive alive."

$$
\mathbf{F}-50
$$


c. What Incentives Are offered to The Designated Driver. Free non-alcoholic beverages. SV: they do not have non-alcoholic beers or wines available, do not serve mocktails. Therefore, soda or fruit juice is all that are available. Shussler said they don't need these other drinks because the program is dolng well and it would simply increase his cost.

D. Who Uses The DDP. Range from 19-60. Usually more females than males SV: but this may just reflect imbalance in population in Minneapolis.

E. Yonitorting Drinkting by The Desicmated Driver. Bartenders watch 1t. SV: everyone noted that abuse has never occurred or at least been observed. There isn't even a policy about what to do -- Shussler felt they would take back the DD button, wouldn't kick the person out. I asked if they check to see if DD does the driving; there is no formal mechanism for this; Shussler noted that when DD is recruited they ask others in party if he/she is doing the driving which helps to make sure this is true.

F. Eligibility Requirements. None. Sv: even 1 person party can be a DD. Shussler noted that added cost of single participants may be low and besides the DD may have come to meet others and may well be buying drinks for others which offsets cost of free non-alcoholic beverages.

G. publicity. They participate in charity functions which give them some publicity; radio and newspaper ads.

H. Stafing the DDP and Training staff. Every new employee goes through TIPS; daily meetings. A single trainer from Chicago office does training for all Juke Box locations on rotating basis, once every six months.

I. When Does the Program Operate. Anytime. SV: hours of operation are 4:00 PM to 1:00 AM, 7 days a week.

IV. MORE PROGRAM ORGANIZATION

A. Changes in the DDP since It Began. It has improved in that they've gotten more sponsorship; increased advertising; free coffee for limo and cab drivers was added (see IV. D).

B. innual cost. $\$ 5,000$ (guess) sv: this guess reconfirmed, consists of lost revenue for free drinks, cost of buttons, posters, advertising... Shussler characterized this as minimal expense.

c. Resources For Meeting costs. RC cola now gives them buttons. otherwise independent. SV: they abandoned use of RC buttons because they promote RC, returned to use of their own buttons.

D. Are Other Anti-drunk Driving Programs Present. Safe Ride used. They're in connection with a tow company where the drunk customer will ride in the tow truck as they tow the truck home; they will also foot cab bills. They pay I1mo drivers an incentive of $\$ 5$ for every party they take to the bar. (This is used in situations where a group of individuals - often a couple - hires a limo for a fancy night on the town, and the group/couple leaves it up to the driver as to where they will go to drank for the evening.) schussler contended 
that in cases where the driver makes the decision where to go, be will choose Juke Box Saturday Night's because of the incentive for the driver. They also provide free coffee for cab drivers and limo drivers as an incentive for them to come to the place. SV: a taxi is most frequent alternative ride, patron pays if he seems coherent and has money (they will have taken his keys). If not, club will pay, which happens very rarely. Tow truck company costs club $\$ 25-\$ 50$ per ride depending upon destination. This is used for people who refuse to leave car behind. Used once in the last year; has been in place 2 years. Not advertised to patrons. Juke Box gets a discount from tow company and tow trucks display advertising: "Juke Box Saturday Night Saves Lives."

\section{PROGRAY IXPACT}

A. How Well Does the Program Work. Successful; never been hit with a law suit. "That says something." SV: emphatic about having no problems with program.

B. Reactions to the program. Extremely positive and grateful. sV: said no major complaint from staff, but some grumble. Some said that DDP cuts down on tips cause DDs tend not to tip as much.

c. What Number Participate / Number of Potential Groups. Sometimes 2 per night, sometimes 10 per night: it varies. SV: several sources confirmed a fairly high number of DDs on Friday or Saturday evenings 10-15, and a lower number (5) on weekdays and sunday evenings.

D. Size of Participating Groups. Varies from 2 to 10.

E. Changes in the prinking of Non-Drivers in Parties with a Designated Driver. None. Totally dismisses the idea that others in party tend to drink more. sv: admitted that some do drink more because they are getting a safe ride home and doesn't see that this is a problem. They will still shut off people who become too intoxicated.

SV: asked about any changes in liquor sales attributable to DD. No change, would be impossible to tell cause DDs make up such small proportion of patrons (less than if by WH's calculations).

SV: Asked if any plans to change the program: None.

VI. INFORYAI DESIGNATED DRIVER ACTIVITIES

A. Do People Assion Designated Drivers on Their own. Without 1. Encouragement By A Formal Program. Sometimes.

a. In What situations and for What Events. Doesn't know.

b. How Is the Desionated Driver Selected. No data.

c. How Widespread Are Informal Desicmated Driver Activities. Not widespread; not enough of it going on.

d. How Have You Learned About This. Has heard about it in his personal circles.

e. Other Information About Informal Activities. No data. .

$$
\text { F-52 }
$$




\section{WHAT WRITIEN INFORYATION IS AVAILABLE}

A. No materials. SV: they have no written policy concerning the DDP, got a button and an article on shussler, and a letter from a local licensing board.

Comments: He made the statement that his is the first DDP in the country. While, admittedly, several people have now made that claim, his date of inception (1981) is the earliest by far. said his program was highlighted in the Wall st. Journal and Newsweek.

SV: Description: Located in downtown Minneapolis, surrounded by other bars and restaurants. Establishment is easy to identify: the front end of a 57 Chevy is mounted high over the entrance, neon lights of several kinds announce the name, these is a large TV screen over the door playing nostalgic films, TV shows, etc; smaller screen as well, and gold-colored records of favorite rock and roll songs are imbedded in the sidewalk. The club area on the first floor is divided into several areas, including: a dance floor with a $D J$ playing old rock $n$ ' roll; an area decorated like a beach (with sand), a sports area with a basketball net for use. Decor is $50 \mathrm{~s}, 60 \mathrm{~s}$ nostalgia: pieces of old cars, posters of old films, 2 bars. Function room upstairs is more unified, lacks nostalgia decor, has dance floor with DJ and appropriate lighting, 1 bar, multi-levell.ed. For additional descriptive materials see JB article.

SV: Practices: They have $\$ 3$ cover charge on Friday \& Saturday, $\$ 2$ on rest except Monday and Sunday. Have promos that are ongoing: Tues night is ladies night, lady gets in for free and can buy a glass or cup for $\$ 4$ then drink free all night.

SV: Conversations with DDs I was able to chat briefly with 2 DDs, identified by me from their buttons. Ioud music and crowd made it impossible to do a systematic interview. They both were typically non-drinkers... rarely drink at all. Both like the idea of DDP and one reason they come to Juke Box is the offer of free beverages. They feel a little funny wearing a button because "most people think you are strange if you do not drink." one said he doesn't mind doing the driving for the group, but started to insist that other people let him drive their cars, so his doesn't get used all the time.

Margaritaville (in Capitola, CA) - Doug Beshore, 408-476-2263 RB: Thomas Hicks, San Mateo County DUI Project.

Date of Interview: $6 / 13 / 86$

Position: General Manager

Address: 221 Esplanade, Capitola, CA 95010 


\section{SETTING INFORYATION}

A. Description of Establishment/Iocation. Bar and Restaurant; they do a lot of margaritas and mexican food. SV: It is located on the waterfront in a tourist community. It is in a congested area full of shops. There are Ilve other barg within a six block area. Except for a small lot, parking is available only on the street. Street traffic was heavy but slow because of the congestion. Capitola is south of and adfacent to Santa Cruz. Margaritavilie lies approximately 45 minutes to an hour and a half Irom the large population centers in the San Francisco Bay area. For example, San Jose is 45 minutes away by freeway.

Two other Margaritavilles have been opened in California. Each of these also has a DDP.

B. Slze. Seating Capacity: 120. sv: Seating capacity is regulated by town ordinances that relate seating capacity to the amount of available street parking. There are two areas of tables, each with roughly 12 tables, and one of these areas is located on an outside deck facing the water. A long bar with roughly 20 bar stools runs along much of one table area, though it is raised and separated from the eating area by a walkway. Another small area contains raised tables suitable for standing. Two television sets are wall-mounted in the bar/restaurant area, and music is also piped into this area. Meal prices are moderate.

c. Description of clientele. $80 \%$ is from 18 to under 35 - 21 is the CA drinking age - white collar. SV: The restaurant and bar appear to draw very different patrons. The restaurant on the Friday evening of the site visit was a family restaurant that attracted patrons varying greatly in age. Many parties included children and/or babies. At the same time, the bar attracted a "Young" crowd, 808 falling in the 18 to 35 age range. The bar appeared to be a singles meeting place for many of the patrons. Most patrons were caucasians and white collar.

Margaritaville has a daily happy hour.

In general, 80 of the drinks sold at Margaritaville are margaritas.

DWI enforcement is a high priority in the community. For example, the Capitola police have the highest DWI arrest rate in the county.

Similarly, the Alcohol Beverage Commission (ABC) is very strict with regard to serving underage patrons. They typically wait six months to a year after a new drinking establish:- 
ment opens and then institute a rigorous test for compliance with the ban against serving underage patrons. Doug Beshore reported that during a six-month test period that included surprise visits by the $A B C$ and the carding of patrons, the $A B C$ investigators did not discover a single underage patron being served alcohol. At the same time, Margaritaville staff continue to confiscate large numbers of false IDs.

D. Availability of Public Transportation. Taxi, buses avallable until 8:00 p.m. only

\section{PROGRAY ORGANIZATION}

A. When and Why was the Program Started. July 1984; first program "of its kind" in nation - putting something constructive into the community - getting people home is important. SV: Beshore stressed the importance of putting something back into the community and felt that the resulting good will was well worth the cost of the program.

B. Coordination with other organizations. Initially, no. He eventually called MADD and got them to sponsor them on a "number of programs. " MADD is now getting a number of other restaurants involved.

\section{PROGRAM OPERATION}

A. How Is the Designated Driver Selected and Identified. Buttons available but they typically don't give them out. sv: Some patrons put on the buttons and then wore them at a neighboring bar while they drank. Since it is easy for the waitresses to keep track of who is the DD at a table, the buttons are not necessary.

Hostess announces availability of program to restaurant patrons and informs patrons that they should notify their waitress if interested. During the demonstration by a hostess for the site visit, the conditions of the program were clearly spelled out. However, some patrons who did not participate in the program seemed to have received less information from their hostess. Thus, they would have had to be interested enough in the program to ask the waitress for additional details.

One waitress reported that sometimes a waitress will give an eligible party the benefits of the program after the fact. That is, if someone in a party of four or more patrons has not had alcohol during the dinner, the waitress might announce that the meal was free because they qualify as a designated driver.

There appeared to be no posters describing the program. However, the manager reported that all ads for Margaritaville that appear in print contain a description of the DDP. 
B. How Are Particlpants Recruited. Hostess announces availability of program. No posters up, but they put lots of ads in paper, TV and Radio.

SV: Hostess announces availability of program to restaurant patrons and informs patrons that they should notify their waitress if interested. During the demonstration by a hostess for the site visit, the conditions of the program were clearly spelled out. However, some patrons who did not participate in the program seemed to have received less information from their hostess. Thus, they would have had to be interested enough in the program to ask the waitress for additional details.

One waitress reported that sometimes a waitress will give an eligible party the benefits of the program after the fact. That is, if someone in a party of four or more patrons has not had alcohol during the dinner, the waltress might announce that the meal was free because they qualify as a designated driver.

There appeared to be no posters describing the program. However, the manager reported that all ads for Margaritaville that appear in print contain a description of the DDP.

c. What Incentives are offered to The Desiqnated Driver. Free meal worth $\$ 10$ and non-alcoholic beverages. SV: The DD receives a free meal (any item on the menu) and non-alcoholic beverages.

D. Who Uses The DDP. No generalizations can be made. 21 year old rowdies - 60 successful retired people will participate.

E. Yonitoring Drinking by The Designated Driver. Waitress tells manager about any DDs in the store; manager goes over and thanks them; waitress watches it. sV: At the end of the meal, the manager goes over and thanks them. The waitress is responsible for making sure that the DD doesn't drink.

F. Eligibility Requirements. Party of 4 or more (money clearly the issue here); occasionaliy they'll even ask a 17 year old kid in a family party if he/she would be interested in being the DD.

G. publicity. Newspaper, radio, and TV - all 3 provide free service from time to time.

H. Staffing the DDP and Training staff. Nothing structured for DDP per se. SV: The program involves the hostesses, waitresses, and manager, as explained above. Training for all these individuals is provided by the general manager. There is nothing structured for the DDP per se. 
The staff for all of Margaritaville numbers 86, many of whom, during the summer, are students. Because they leave for school at the end of the tourist season, it is not necessary to lay off staff in the fall. Many of the staff return year after year.

I. When Does the Program operate. Iunch and dinner 11:30 a.m. 10:00 p.m. No DDP for the late night crowd. SV: The program operates only in the restaurant sections of Margaritaville and, consequently, only during the hours that meals are served. DB explained that there are two main reasons for not offering the program to patrons of the bar. One is that in order to make the program attractive, a large incentive, such as the meal offered to the DD, is necessary. No comparable incentive is readily available at the bar. The other reason is that a DDP is very difficult to police at a busy bar. The bartender can not tell how someone ordering several drinks for a group will distribute the drinks. In the restaurant, it is relatively easy for the waitress to keep track of the DD.

SV: J. Program Data.

Each waitress fills out a short report at the end of the shift. This report includes a line on which the number of designated driver meals that were distributed is indicated. Thus, the restaurant has very complete records of the extent of use of the program.

SV: R. Sources of opposition to the program.

The other restaurants in the area do not have DDPs and are somewhat antagonistic.

SV: I. Problems in implementing the program. None.

SV: M. What steps are taken when a DD sneaks an alcoholic beverage?

They are confronted by the manager, and then they are not given a free meal.

SV: N. What methods are employed to insure that the DD actually drives?

None. It is impossible given that nearly all parking is on the street. In addition, many patrons go to other bars before returning to their cars.

\section{MORE PROGRAM ORGANIZATION}

A. Changes in the DDP since It Began. None - they started the DDP on a trial basis and then decided to make it a permanent thing.

SV: Are there plans to change the program? No. 
What are the goals of the program? (Get an explicit statement. )

"To keep the streets safe."

B. Annual cost. $\$ 15,000$. He feels that the tax structure is a problem - when you're only able to write off cost of food ("... What about the cost of gas, wages, electricity?") It's not falr.

SV: $\$ 15,000$, and there are no donated services. Beshore feels that the tax structure is a big problem, since it allows him to write-off fust the cost of the food, which is approximately $\$ 3$ on a meal that sells for $\$ 10$. But his full costs (including wages, utilities, rent, etc.) for that $\$ 10$ meal are $\$ 8$.

C. Resources For Meeting Costs. Buttons gotten from RDON Radio. SV: He foots the entire bili.

D. Are Other Ant1-drunk Driving Programs Present. Safe Ride (formal or informal) - Tow company got involved and will tow cars for nothing. Restaurant will pay for cab. Safe Ride Contact: Bruce Canepa - 408-423-5900 (of the Towing Company)

Margaritaville closes at approximately $12: 30$ a.m., even though they could remain open until 2 a.m. By closing early, they avoid the problem of serving drinks to the hard core drinker who wust drink as late as possible. This early closing probably does not impact on the drunk driving problem, since patrons can simply go to one of the other nearby bars if they want to keep drinking. However, it makes life much easier for the staff at Margaritavilie. DB sees this early closing as another good will gesture. It costs roughly $\$ 80 \mathrm{k}$ per year to

close early.

\section{PROGRAM IMPACT}

A. How Well Does the Program Work. No qualms. SV: Beshore says there are no negatives and is quite pleased with the program's operation. He feels that the program is at least in part responstble for the fact that his sales are up 15 t this year in contrast to the industry average of a $7 \%$ decline.

B. Reactions to the Program. Eases the conscience of the whole party when there's a DD: his impression is that they're glad it's happening. SV: He has received several types of positive feedback. First, patrons who use the program are grateful and enthusiastic. For example, the parties we interviewed universally endorsed the program. Second, Beshore reported that the program generates a lot of good will throughout the community. Third, Margaritaville has received extensive press coverage, including national print and television coverage. 
Waitresses like the program for at least two reasons. First, it tends to increase their tips, since patrons typically pick one of the more expensive meals for their free meal and then tip on the menu price of the iree meal. Second, "At least you have one sober person to talk to."

c. What Number Participate / Number of Potential Groups. 70 dds per week. 1,000 total parties possible.

D. Size of Participating Groups. 4.

E. Changes in the Drinking of Non-Driverg in parties with a Designated Driver. No change.

VI. INFORYAI DESIGNATED DRIVER ACTIVITIES

A. Do People Assign Designated Drivers on their own. Without Encouragement By A Formal Program. No.

\section{WHAT WRITIEN INFORYATION IS AVAIIABIE}

A. Will send materials. Received: one-page "Designated Driver Information."

Comments:

SV Comments: Each waitress may have two to four parties with DDs each night. There are roughly that many more parties for whom it would be a good idea to have a DD.

808 of the patrons have two or more margaritas.

The number of patrons using the program seems to vary with the amount of advertising of the program.

Beshore guesses that it is the free meal, rather than public safety, that attracts most parties that take advantage of the program.

Despite the cost of the program, Beshore believes that the good will brings him enough business to make the program financially attractive.

The manager reported that he never had an intoxicated patron ask to be the DD. While the Friday and saturday crowds appear quite similar, the sunday patrons are more obnoxious.

The hostess was always too busy to be interviewed. But she did come over and make her standard announcement of the program. She stated that there must be at least four persons 21 years old or older in the party in order to be eligible and that the DD would receive a free meal an non-alcoholic beverages. 
Beshore repeatedly emphasized the need to give to the community in order to receive in turn. For example, he regularly meets with the police and community leaders in order to promote good will.

\section{Desionated Driver Parties}

Party 11: The two middle-aged couples in this group have been using designated drivers on their own for 8 ix years. They had read about the program at Margaritaville but didn't come here because of the program. They live in the "boonies" where it is necessary to be sober in order to get home safely. Although the DD for this evening is normally a light drinker, the two men, who drink more heavily, take turns serving as the DD when nobody else is available.

Party 12 : Two families with several children made up this party. They had not heard of the program before coming. The drinkers in the party seemed to be having only one drink.

Party $13:$ The DD in this party of two young couples was pregnant and would not have drunk anyway. In general, if someone with whom they are partying stays sober, then they let that person drive. However, if no one wants to abstain, they drink and drive afterwards anyway. They didn't come because of the program, but they had heard of it before. The non-DDs in the party definitely drink more than normal when they can count on a sober person to drive them home. Everyone was very supportive of the the DDP.

Party 14: The DD from these two couples is a non-drinker. The other woman is a drinker and sometimes serves as the DD. They have been using DDs on their own.

Party 5 : The DD is a light drinker who doesn't feel the need to drink. They had not heard of the program. The offer of the free meal definitely helped the DD to abstain. They sometimes use a DD on their own, especially because they worry about the dangerous drive back to san Jose. None of their eriends are heavy drinkers, and they never let someone who is smashed do the driving.

Non-Designated Driver Parties (total of 3): All parties responded that the free meal was not worth giving up the pleasure of drinking with their friends. However, one patron reported that the brief announcement about the program from the hostess might not have been enough to get them to participate. She explained that unless patrons were quite interested, they would not remember to mention their desire to par ticipate to the waitress. Thus, she recommended that the waitress also inform patrons about the program. None of the patrons in these parties had heard of the program before coming to the restaurant. 


\section{Overall Reaction}

The DDP at Margaritaville seems to be a successful promotional device. Both patrons and community leaders react very positively to the program, and the general manager feels that it brings in enough business to justify the cost.

Its value in reducing drunk driving is hard to estimate, our guess is that it has two types of positive impacts. First, it reduces the drinking of some drivers. Second, it is a highly visible program that heightens awareness.

There are also reasons to be skeptical about the program. Some of the DDs would not have had anything to drink even without the program. Beshore recognizes that some people abuse the program, but feels that the positives outweigh the low level of abuse. Because of its location in an area where there are 6 bars, it is very easy for a DD to leave Margaritaville and then get something to drink elsewhere. Thus, the DDP can work only if people are committed to the principle of someone in the party remaining sober to do the driving.

Mel Rrupin's Restaurant (in Washingtion, DC) - Mel Rrupin 202-331-7000. RB: Barbara Pomerance, Ehrlich, Maines, \& Assoc.

Date of Interview: $6 / 9 / 86$

Position: Owner

Address: 1120 Connecticut NW, Washington, DC

\section{SETTING INFORKATION}

A. Description of Establishment/Location. Dining room, bar and lounge.

B. Size. Seating Capacity: 400 .

C. Description of clientele. White collar, business executives, stock brokers, politicians, athletes, a few yuppies; middleaged crowd.

D. Availability of Public Transportation. Subway, taxi.

\section{PROGRAY ORGANIZATION}

A. When and Why was the Program Started. Summer, 1985; Ehrlich, Maines and Associates encouraged it.

B. Coordination with other organizations. Washington Regional Action Program (WRAP) was also involved in getting the program started.

III. PROGRAM OPERATION

A. How Is the Designated Driver selected and Identified. Button used. A staff person sometimes asks if someone would like to

$$
\text { F-61 }
$$


participate, but he stressed that it would have to be approached very casually (with humor) lest they lose the customer; said the program has to be largely the people's responsibility to want to do it - not the staff's.

B. How Are Participants Recruited. Table tents, voluntary program.

c. What Incentives Are offered to The Desimated Driver. Free non-alcoholic drinks.

D. Who User The DDP. No generalization can be made. One day they will do it, one day they won't. People are not serious about it, but at the same time they're not drinking as much as they used to.

E. Yonitoring Drinking by The Designated Driver. No - not abused.

F. Elialbility Requirements. At least 2 or 3.

G. publicity. Initial blitz, was picked up originally by media; no publicity anymore to speak of. Was and is not interested in having such a full blown affair as Rumors (see entry below) who gave away a car and keeps names of DDs on file.

H. Staffing the DDP and Training staff. If they're drunk they don't serve them; no training beyond that. No training for the DDP per se.

I. When Does the Program Operate. Anytime. Store hours: 11:30 $11: 00,6$ days a week.

\section{MORE PROGRAY ORGANIZATION}

A. Changes in the DDP since It Began. No changes except that there is less interest now than before.

B. Annual Cost. Nominal. Less than $\$ 50$ week.

C. Resources For Keeting Costs. Washington Regional Action Program (WRAP) .

D. Are Other Anti-drunk Driving Programs Present. Informally using safe ride; nothing structured.

V. PROGRAY IMPACT

A. How Well Does the Program Work. Doesn't know if it works. There's no united effort by bars and restaurants. Some do it, some don't. Until they all do it, people are not going to learn that they should participate.

B. Reactions to the Program. Some make fun of it; think it's whimpy. There is more negative feedback than positive.

c. What Number Participate/Number of Potential Groups. Iast DD was 5 months ago.

D. Stre of Participating Groups. 2 or 3.

E. Changes in the Drinking of Non-Drivers in Parties with a Desionated Driver. Others will sometimes get bombed out of their skull. 
VI. INFORYAI DESIGNATED DRTVER ACTIVITIES

A. Do Peorle Assion Designated Drivers on Their Own. Without Encouragement By A Formal Program. No.

VII. WHAT WRITIEN INFORYATION IS AVATIABIE

A. Not to speak of.

COMARETS:

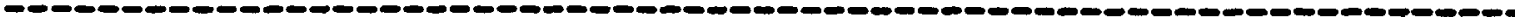

Mick's South (in Moorhead, MN) - Tim Palmer, Kanager - 218-2335221. RB: Jim Schaefer, $D$ of WN Office of Alcoholism other Drug Abuse Programing.

Date of Interview: $7 / 28 / 86$

Position: owner

Address: Holiday Mall, Moorhead, MN 56560

I. SETTING INFORKATION

A. Description of Establishment/Location. Bar with food in the day. In a city.

B. Size. Seating Capacity: 575.

C. Description of Clientele. 19 - 30; college and blue collar.

D. Availability of Public Transportation. Taxi available.

\section{PROGRAM ORGANIZATION}

A. When and Why was the Program started. Program started 8-10 months ago.

B. Coordination with other organizations. Moorhead liquor association started it.

III. PROGRAM OPERATION

A. How Is the Designated Driver selected and Identified. DD volunteers him/herself. sticker says "We Care - Designated Driver."

B. How Are Participants Recruited. There are signs up.

C. What Incentives Are offered to The Desiqnated Driver. DD receives free pop.

D. Who Uses The DDP. People with a drinking problem won't use it. Otherwise can't say what differences there are, if any.

E. Yonitoring Drinking by The Designated Driver. He said there is really no way of doing it, so they don't monitor. However, later he said that if a $D D$ is caught drinking, they take the sticker away and ask him/her to leave the bar; but this hasn't happened often at all.

F. Eliqibility Requirements. Party of 3 or 4 eligible, according to association, but they will give it to anyone who wants to drink pop.

$$
F-63
$$


G. Publicity. Moorhead Liquor Association put up bill boards and put ads on T.V. Ads don't mention specific bars, but promote general awareness about DDPs.

H. Staffing the DDP and Training Staff. General alcohol awareness training.

I. When Does the program Operate. Anytime.

\section{YORE PROGRAY ORGANIZATION}

A. Changes in the DDP since It Began. None.

B. Annual Cost. No idea.

C. Resources For Meeting Costs. The bars themselves pay a fee to the Koorhead Iiquor Association: sometimes bars kick in extra noney. Iiquor Association makes up stickers.

D. Are other Anti-drunk Driving Programs Present. Safe Ride; sometimes they call the police.

V. PROGRAY IMPACT

A. How Well Does the Program Work. DDP has worked well -- he goes through a lot of pop.

B. Reactions to the Program. Positive reactions from clientele and staff.

c. What Number Participate / Number of Potential Groups. 010-50 from 575 (individuals) on a busy night.

D. Size of Participating Groups. About 3-4.

E. Changes in the Drinking of Non-Drivers in Parties with a Desionated Driver. No.

VI. INFORYAL DESIGNATED DRIVER ACTIVITIES

A. Do People Assion Designated Drivers on Their own. Without Encouragement By A Formal Program. Doesn't know.

VII. WHAT WRITTEN INFORYATION IS AVAIIABIE A. No written material available. He would like to receive guide
-if free.

Comments :

Minder Binder (in Phoenix, Az) - Dave Osmond - 602-966-1911

Date of Interview: $6 / 9 / 86$

Position: Manager

Address: $715 \mathrm{~S}$. Hayden, Tempe, AZ 85281

I. SETMING INFORMATION

A. Description of Establishment/Location. Bar and restaurant, lot of food, 608 liquor and 408 food; unique place, downstairs/upstairs, volleyball courts, dance floors.

B. Size. Seating Capacity: 150 upstairs, 370 downstairs. 
c. Description of clientele. 25-34, mixture of blue and white collar, more blue than white.

D. Availability of Public Transportation. No bus available, but taxi is available.

II. PROGRAY ORGANIZATION

A. When and Why was the program started. Program began in 1984 because of general safety concern.

B. Coordination with other organizationg. Iiquor control board and Hensley (Dave Dalton) have helped with some promotion.

\section{III, PROGRAY OPERATION}

A. How Is the Designated Driver selected and Identified. Customers do the inquiring.

B. How Are Participants Recruited. Posters are up.

C. What Incentives Are offered to The Desianated Driver. card is issued for DDs to get free soft drinks.

D. Who Uses The DDP. DDs are different by age; 28-above are much more inclined to volunteer than the younger; also, DD is usualiy a female.

E. Yonitoring Drinking by The Desionated Driver. Honor system doesn't think that the concept is being abused. No requirements - a person who has come alone can be a designated driver to get free soft drinks.

F. Eligibility Requirements. No data.

G. Publicity. Hensley did some advertising, at first (to help get the program going): the local papers ran it.

H. Staffing the DDP and Training staff. Films are shown when monthly meetings are held.

I. When Does the Program operate. Anytime.

IV. MORE PROGRAM ORGANIZATION

A. Changes in the DDP since It Began. None.

B. Annual Cost. Nominal.

C. Resources For Meeting Costs. Main office (Great American Fare).

D. Are Other Anti-drunk Driving Programs Present. Safe Ride done informally - they try to informally call cabs for people, and, if necessary, they will foot the bill; Osmond was unfamiliar with the term "Safe Ride."

V. PROGRAM IMPACT

A. How Well Does the Program Work. Has worked well. He stressed the need to keep pushing the program; mentioned that a primary benefit of the program was that it is good for the nondrinkers because it gives them something to "hold in their hand" even though they don't drink.

B. Reactions to the program. Positive all around; no negatives.

C. What Number Participate/Number of Potential Groups. About 1 per night; 30-35 possible parties per night. 
D. Size of Participating Groups. 2 - 3 people.

E. Changes in the Drinking of Non-Drivers in Parties with a Desionated Driver. Nowadays, yes, because the drinkingdriving laws are so stringent.

VI. INFORYAI DESIGNATED DRIVER ACTIVITIES

A. Do People Assion Designated Drivers on Their own, Without Encouragement By A Formal program. Yes. 1.

a. In mat situations and for what Events. He thinks they're used a lot for sporting events but not for parties.

b. How Is the Desionated Driver selected. No data.

c. How Widespread Are Informal Designated priver Activities. Hore than before; definitely a growing trend.

d. How Have You Learned About This. Has heard about it mostly from patrons, although he does it himself too.

e. Other Information About Informal Activities. No data.

\section{WHAT WRITTEN INFORYATION IS AVAILABIE}

A. Will send a pamphlet. Received material from Grand American Fare: loose-leaf binder with posters, button, sticker, articles, guidelines, general information, etc.

COMDENTS: Minder Binder is one of over 30 establishments throughout several states participating in same DDP promoted by Grand American Fare.

Montana Mining Company (in Missoula, MT) - Jeff Hainline - 406543-8265. [RB: Elien Leahy, Missoula City-County Health Dept. ]

Date of interview: $6 / 11 / 86$

Position: Vice-President of $4 \mathrm{Bs}$ which owns Montana Mining Co. Address: 1210 W. Broadway, Missoula, MT 59802

\section{SETTING INFORMATION}

A. Description of Establishment/Iocation. Restaurant/bar which primarily operates as a steakhouse in the evening. Although the bar is connected to the restaurant, they have a strictly bar clientele, strictly restaurant clientele, and clientele which uses both the bar and restaurant. B. Size. Combined seating capacity of the bar and restaurant is

C. Description of clientele. They used to cater to a blue-collar clientele; now they have a wide range of customers. They target the 25-45 age range. They now have blue collar, professionals, tourists, etc.

D. Availability of Public Transportation. Metro buses run until late evening; taxi service is available. They have a safe rides program called "HOME FREE" which provides free taxi ser-

$$
\text { F-66 }
$$


vice to intoxicated patrons with the establishment paying for the fare.

\section{PROGRAY ORGANIZATION}

A. When and Why was the program started. The DDP began in January 1985. Motivation was wanting to stay in the licquor business given increased awareness of drunk driving problem, increased enforcement, and skyrocketing insurance liability rates.

B. Coordination with other organizations. No coordination with other groups per se. He first read about the DDP concept in a national trade magazine and brought it to the attention of EIlen Leahy of the Missoula City-County Health Dept. They marketed the DDP concept to all liquor establishments in Kissoula. They were really the first to get such a program started and would have done so even without the Health Dept. because they wanted to demonstrate a good faith effort to stop drunk driving. Until this time, Montana still had a rough and tumble image so that "if you could get your head upon the bar, you could get another drink. They wanted to change that for the social good as well as our own stake in the matter."

\section{PROGRAM OPERATION}

A. How Is the Designated Driver selected and Identified. They started the DDP program in Missoula before the city got started with posters. Every server wears a large DDP button which seeks to solicit participation. Server can initiate further conversation about the program. They had to get rid of the buttons since many patrons kept them for whatever reasons and at a buck a pop, they decided to give them "lounge bucks" which could be redeemed in the lounge for a free drink the next time they returned. This saved money lost on nonreturned buttons. People who refuse to participate may simply want to drink or not be as aware of drunk driving as a big problem as those who do participate.

B. How Are participants Recruited. Posters are up; servers wear buttons and may initiate conversation about the program.

c. What Incentives Are offered to The Designated Driver. Free non-alcoholic beverages and redeem the lounge buck next time for any type of drink.

D. Who Uses The DDP. Young people use it more often out of fear of being arrested; they are out more often, better educated, better sense of staying out of trouble, and more socially aware. Those 45 and over have less appreciation of a program like this.

E. Monitoring Drinking by The Designated Driver. Servers and bartenders monitor the behavior of DD only as much as they would that of any customer. In general, they try to monitor closely so that they don't have anyone getting drunk and

F. Eligibility Requirements. 2 or more in the DDP party and all of legal drinking age. 
G. Publicity. Health Dept. handled the advertising and inroads tnto the media which ran some PSAs on TV. Publicity is not essential but surely facilitates the DDP operation.

H. Staffing the DDP and Training staff. Regular staff are involved in the DDP. They have regular staff meetings, train new staff on the DDP and other house policies. Hainilne makes sure that stafe wears their buttons and do what they are supposed to do regarding the DDP. Sometimes they have to be "birddogged" if they are not wearing their buttons, etc.

I. When Does the Program operate. DDP is operational whenever they are open for business.

\section{YORE PROGRAY ORGANIZATION}

A. Changes in the DDP since It Began. They dropped the use of buttons wich were being kept by patrons and substituted the use of "lounge bucks" for redemption coupons for a free drink.

B. Annual cost. A ballpark estimate of $\$ 1000$ per year which is actually 1 ess if one can assume that people come back to the establishment as a result of the DDP perks.

C. Resources For Yeeting Costs. Posters and some buttons come from the Health Dept.

D. Are Other Anti-drunk Driving Programs Present. They do public awareness and education work in conjunction with MADD, the police, and the community. They have a safe rides program called "HOME FREE" which provides free taxi service to intoxicated patrons and they pick up the cab fare. There is greater use of the DDP than the safe rides program.

\section{v. PROGRAY IYPACT}

A. How Well Does the Program Work. Although it started slow, the program has worked real well, "beyond our expectations."

B. Reactions to the program. (a) designated drivers think its great and enjoy it; (b) its appreciated by the companions of the designated driver; (c) no reaction from non-participants except some of the older ones may make jocular remarks about being watched closely; (d) staff think its great although may complain about smaller tips from the non-drinking designated driver; (e) comunity groups love the program.

c. What Number Participate/ Number of Potential Groups. Average of 2-37 of between 100-140 groups on a given day elect to participate. $60 \%$ of our business is in the lounge with 408 in
the restaurant.

D. S1ze of Participating Groups. Average group size is 4 people and there has been no change in average group size since they got started.

E. Changes in the Drinking of Non-Drivers in Parties with a Desicmated Driver. He would speculate that groups with a designated driver have a greater awareness of the drunk driving problem and do not change their drinking behavior in the direction of drinking more as a result.

$$
\text { F-68 }
$$


VI. INFORYA DESIGNATED DRIVER ACTIVITIES

A. Do People Assion Desionated Drivers on Their own. Without Encouragement By A Formal Program. Don't know.

VII. WTAT WRITIEN INFORYATION IS AVAITABIE

A. Will send materials.

COnnENTS: The DDP is being run in 9 restaurants owned by the 4 Bs chain.

No Frills Grill (in Denver, Co) - Tim Seay - 303-759-9079. [RB: Rick Clarke].

Date of Interview: $6 / 24 / 86$

Position: General Manager

Address: $7155 \mathrm{E}$. Hampden, Denver CO 80224

\section{SETTING INFORYATION}

A. Description of Establishment/Location. Bar and restaurant.

B. Size. Seating Capacity: 180.

C. Description of Clientele. 21 - 30; $\mathrm{mix}$ of blue and white collar; more white than blue.

D. Availability of Public Transportation. Bus and taxi available.

\section{PROGRAK ORGANIZATION}

A. When and Why was the Program Started. Early 1984 ; corporatewide decision as a result of high fatality rate; high insurance rates.

B. Coordination with other organizations. Grand American Fare runs this restaurant and numerous others in the west - DDP used throughout.

\section{PROGRAM OPERATION}

A. How Is the Designated Driver selected and Identified. Button and membership card used; once they've been a designated driver they can come back and be one again by showing their card. They usually will wear a button each time they come.

B. How Are Participants Recruited. Servers wear buttons, little flyers on each table.

c. What Incentives Are offered to The Designated Driver. Free non-alcoholic drinks.

D. Who Uses The DDP. Mainly men; he feels that the reason is that they want to feel responsible; good mix of male and female customers.

E. Monitoring Drinking by The Designated Driver. Doormen and, bartenders watch; if they are caught they are talked to. watched pretty closely. 
F. Eligibility Requirements. None.

G. Publicity. Corporation puts out press releases to newspapers, blurbs on TV.

E. Staffing the DPP and Training staff. Initial training for all employees - basic stuff.

I. When Does the Program Operate. Anytime.

IV. YORE PROGRAY ORGANIZATION

A. Changes in the DDP since It Began. None.

B. Annual cost. Total is between $\$ 1000$ and $\$ 1500 /$ year (Buttons cost $\$ 300 /$ year)

C. Resources For Meeting Costs. Grand American Fare.

D. Are Other Anti-drunk Driving Programs Present. No.

V. PROGRAY IMPACT

A. How Well Does the Program Work. Good solid program; regular customers are the ones who tend to use it - it's habitforming.

B. Reactions to the Program. Positive; people are just generally more aware than they used to be. He has never heard any bad feedback.

C. What Number Participate / Number of Potential Groups. 15 to 20/ week.

D. Size of Participating Groups. 6 ; no chairge.

E. Changes in the Drinking of Non-Drivers in Parties with a pesionated Driver. Hasn't noticed it; might be happening, but he doubts it.

VI. INFORMAL DESIGNATED DRIVER ACTIVITIES

A. Do People Assion Desianated Drivers on Their own, Without Encouragement By A Formal Program. On the most part, no. occasionally. For the most part, if someone is chosen, that person is still going to have 3 or 4 beers; they won't completely abstain - they just drink less.

VII. WHAT WRITTEN INFORKATION IS AVAIIABIE

A. No - we have received a folder from Grand American Fare outlining their programs.

Comments :

Northern Lights Inn (in Anchorage, As) - George Briggs - 907-56i-

5200. [RB: Margie Johnson, AS state Alcohol Review Board].

Date of Interview: $6 / 30 / 86$

Position: Exec. Assistant Manager

Address: $598 \mathrm{w}$. Northern Lights, Anchorage, AS 99503

$$
\mathbf{F}-70
$$




\section{SEITING INFORYATION}

A. Description of Establishment/Iocation. Restaurant and Bar entertainment 5 nights a week.

B. Size. Seating Capacity: Restaurant - 107; lounge - 130.

C. Description of clientele. 30 - 50; upper middle-class; bustness people.

D. Availability of Public Transportation. 4 Taxi companies; bus runs until $12: 30 \mathrm{am}$.

\section{PROGRAY ORGANIZATION}

A. When and Why was the Program started. "Program has been here longer than I have" - probably started in 1982. Hotivation: liability issue and that it just "seemed like good business." General manager had had a lot of community involvement $s 0$ he got it started.

B. Coordination with other organizations. Independent.

\section{PROGRAY OPERATION}

A. How Is the Designated Driver selected and Identified. Button used; servers will ask if there is a designated driver.

B. How Are Participants Recruited. Table tents, program is "more or less pushed" by servers.

c. What Incentives Are offered to The Designated Driver. Free non-alcoholic drinks.

D. Who Uses The DDP. Men more so than women; probably more single men than married since single guys get out more often so it's no big deal to volunteer one night to be a DD.

E. Monitoring Drinking by The Designated Driver. Regulate it in the lounge; bartender usually has a good idea by the end of the first round bought.

F. Eligibility Requirements. No.

G. Publicity. Initially DDP was stated in some of the ads they ran; now they just rely on in-house encouragement (table tents): posters up around the Inn to encourage it.

H. Staffing the DDP and Training staff. Very little; initial orientation.

I. When Does the Program Operate. Anytime.

\section{MORE PROGRAM ORGANIZATION}

A. Changes in the DDP since It Began. Very few - if any. "We haven't had to sell the program as much..." since people are aware of it in the first place. High percentage of repeat customers.

B. Annual Cost. Very minimal. No more $\$ 100 /$ year; initial year was \$500-\$600. Initial advertising was largely a part of general advertising of the bar that happened anyway.

C. Resources For Meeting Costs. Independent.

D. Are Other Anti-drunk Driving Programs Present. Safe Ride informally done. Formal Safe Ride used in Palmer and Wasilla, 
As. There, the establishment will pay half of ride; and cab will pay half of ride up to ten miles. After ten miles, the customer pays half of the ride. Briggs said that no formal Safe Ride happening in Anchorage as yet.

\section{PROGRAY IYPACT}

A. How Well Does the Program Work. On a scale from poor to excellent, he would say, "Good."

B. Reactions to the Program. Initially, people thought it was kind of a joke; now people see that it's worked out to their benefit, especially with the laws the way they are. Nonparticipants laugh it off. Staff likes it. Community groups are positive.

C. What Number Participate / Number of Potential Groups. A dozen/ per week; Wed. - Sunday Crowd 1s falrly light. 50 parties in a week.

D. Size of Participating Groups. 4 to 6; no change. Iarger groups tend not to participate.

E. Changes in the Drinking of Non-Drivers in Parties with a Desicnated Driver. Some have drunk less; some still drink quite a bit. He maintained that people are not drinking more. If people come in wanting to drink, they're going to drink regardless of the DDP.

VI. INFORMAL DESIGNATED DRIVER ACTIVITIES

A. Do People Assion Designated Drivers on Their own, Without Encouragement By A Formal Program. No

VII. WHAT WRITHEN INFORYATION IS AVAIIABLE

A. Will try to find materials to send.

Comments :

Oby's (in Starkvilie, MS) - Don O'Bannon - 601-323-0444. [RB: Margaret Eatherly, Mississippi Alcohol Safety Education Program. ]

Date of interview: June 12,1986

Position: Manager and owner

Address: Academy Road, Starksville, MS 39759

\section{SETHTNG INFORYATION}

A. Description of Establishment/Location. Restaurant which serves only beer (wine in near future) located in college town (Mississippi state University).

B. Size. Seating Capacity: 110 .

C. Description of Clientele. College students and older adults.

D. Availability of public Transportation. Taxi service. 


\section{PROGRAY ORGANIZATION}

A. When and Why was the Program started. Campus group initiated the program by asking O'Bannon if he would provide free soft drinks to patrons that promised not to drink and serve as designated driver. Motivation on his part was purely one of good will and had nothing to do with liquor insurance liability rates.

B. Coordination with other organizations. No coordination; the program runs on its own.

\section{PROGRAY OPERATION}

A. How Is the Desionated Driver selected and Identified. The entering customer indicates he/she wishes to serve as a designated driver and is given a tag to wear. Servers don't initiate conversation - patron does. People who participate are more aware and responsible than those who don't.

B. How Are Participants Recruited. Posters are up but staff doesn't wear tags or buttons "although that might be a good idea."

c. What Incentives Are offered to The Desianated Driver. Free soft drinks, and if they bring in a bunch of people, he might give the DD a free meal.

D. Who Uses The DDP. Designated drivers are more responsible and aware.

E. Monitoring Drinking by The Designated Driver. All staff watches to make sure that the DD doesn't drink alcohol. In general, they monitor the drinking behavior of clients very closely. They don't serve people who have been drinking before they come in, and they don't condone intoxication.

F. Eligibility Reguirements. 2 or more in the group and of legal drinking age (currently 18 for beer in Mississippi). Things will change when they go to 21 this october.

G. publicity. Only publicity is a little ad in the college newspaper which, he assumes, helps to keep the program visible.

H. Staffing the DDP and Training staff. Regular staff; no formal training on the DDP but plenty of training on enforcing the drinking laws which are strictly enforced in this small Southern town with religious values.

I. When Does the Program operate. Anytime (1l a.m. to 9 p.m.).

\section{MORE PROGRAM ORGANIZATION}
A. Changes in the DDP since It Began. Rnows of no changes.
B. Annual Cost. Nominal (cost of free soft drinks).
C. Resources For Meeting costs. They provide the resources.
D. Are Other Anti-drunk Driving Programs Present. Informal safe ride in that they will give people rides home.
V. PROGRAM IMPACT
A. How Well Does the Program Work. Tremendous. 
B. Reactions to the program. (a) sense of good deed from DD themselves; (b) no reaction; (c) no feedback; (d) staff members like it: and (e) police and civic groups support it 1008.

c. What Number Participate/ Number of Potential Groups. Not many participate, less than 10\%; there was a rash when it first started but it has dropped off. Don't know how many potential groups there are; varies by night with weekends being the busiest.

D. Stze of Participating Groups. Average is 6 in a group which bas not changed.

E. Changes in the Drinking of Non-Drivers in Parties with a Designated Driver. Hard to answer. He would guess they drink more.

VI. INFORYAT DESIGNATED DRTVER ACTIVITIES

A. Do People Assion Designated Drivers on Their own. Without Encouragement By A Formal Program. He doesn't know.

VII. WTAT WRITHEN INFORYATION IS AVAILABIE

A. Miss. State may have some materials but he didn't know who to contact. Any materials we need could probably be obtained from Margaret Eatherly, Mississippi Alcohol Safety Education Programs).

COMRIENTS:

Tankard Tavern (in Junction City, OR) - Rob stott - 503-998-3123. [RB: Charles Cole, Lane county MADD]

Date of Interview: $10 / 10 / 86$

Position: Owner

Address: 330 Highway $99 \mathrm{~S} .$, Junction City, OR 97448

I. SETIING INFORYATION

A. Description of Establishment/Iocation. Not a big city, but close to Eugene (a big city). A neighborhood tavern. Food and drink, games -pool table, etc.

B. Size. Seating Capacity: maximum 90. C. Description of Clientele. Mostly mill workers, generally in

D. Availability of public Transportation. There is a taxi service. The bus system operates mostly during the day, no nights.

\section{PROGRAY ORGANTZATION}

A. When and Why was the program started. Started a couple of years ago. It was triggered mostly by the new laws on drunk driving, and bar owners wanted to help.

B. Coordination with other organizations. No. It is an independent program. 


\section{PROGRAY OPFRATION}

A. How Is the Desicnated Driver selected and Identified. They have buttons and stickers. Usually if there is a group there is already a DD picked out.

B. How Are Participants Recruited. Posters.

C. What Incentives Are offered to The Designated Driver. He offers free coffee and pepsi.

D. Who Uses The DDP. No difference between users and non-users of DDP.

E. Yonitoring Drinking by The Desigmated Driver. Yes, the bartenders watch the customers.

F. Eliaibility Requirements. No eligibility requirements.

G. publicity. No, just in house advertising.

H. Staffing the DDP and Training Staff. They provide training on bartending and how to recognize people who have been drinking too much.

I. When Does the Program operate. The DDP operates all the time.

\section{YORE PROGRAY ORGANIZATION}

A. Changes in the DDP since It Began. It has slacked off. People don't use it as much as they used to.

B. Annual Cost. A few free pepsis -- not very much.

C. Resources For Meeting Costs. Out of their pocket.

D. Are other Anti-drunk Driving Programs Present. Not in their area.

V. PROGRAM IMPACT

A. How Well Does the Program Work. Fair.

B. Reactions to the program. Most people don't feel they need a designated driver. In his tavern that is probably true because people have learned not to drink too much. In-tavern consumption has gone down; people drink at home more often.

c. What Number Participate / Number of Potential Groups. Iately very few. Not very many potential groups.

D. Size of Participating Groups. Usually. just 4 or 5 in a group.

E. Changes in the Drinking of Non-Drivers in Parties with a pesignated Driver. Yes the companions drink more.

VI. INFORMAL DESIGNATED DRIVER ACTIVITIES

A. Do People Assign Designated Drivers on Their Own, Without Encouragement By A Formal Program. Yes, quite a bit of that. Usually in a group, one person voluntarily doesn't drink. People are learning.

1.

a. In what situations and for what Events. It's an every day thing.

b. How Is the Designated Driver selected. It's just voluntary; one person decides. 
c. How Widespread Are Informal Designated Driver Activities.

- He can't say.

d. How Have You Learned About This. By observing.

e. Other Information About Informal Activities. No.

VII. WHAT WRITTEN INFORMATION IS AVAIIABIE

A. No written materials.

COMDENTS :

Ramada Inn (in Springfield, Mo) - David Schneck - 417-831-3131.

[RB: Vicki Williams, Missouri Div. of Highway Safety.]

Date of Interview: $7 / 29 / 86$

Position: Food and Beverage Director

Address: $2431 \mathrm{~N}$. Glenstone, Springfield, MO 65803

NOTE: This is kind of a combination of DDP and safe Ride. The establishments has vans available to a DD to transport his/her party if it is too big for his/her own car. If DD becomes drunk, staff (usually a bell hop from the hotel) will drive party home. See comments.

I. SETTING INFORMATION

A. Description of Establishment/Location. 203 room high rise luxury hotel. Ramada franchise. Bar/cafe, up scale restaurant and disco. Location: interstate.

B. Size. Seating Capacity: Restaurant: 129, Bar/Cafe: 65, Disco:

C. Description of clientele. Ages 21-30. Upper income.

D. Avallability of Public Transportation. Taxi available. Public transportation poor.

II. PROGRAY ORGANIZATION

A. When and Why was the Program started. Started at the opening of the establishment--Aug. 1985 . Motivation was the recognition of DWI emphasis.

B. Coordination with other organizations. No independent.

\section{PROGRAY OPERATION}

A. How Is the Designated Driver selected and Identified. Servers trained to recognize groups out for an evening of partyinginstructed to ask if there is a DD during orders for first round. DD wears a badge.

B. How Are Participants Recruited. No in-house advertising. Servers initiate conversation.

C. What Incentives Are offered to The Designated Driver. DD gets free non-alcoholic beverages. Can't drink anything alcoholic
all night. 
D. Who Uses The DDP. No differences. DD tends to be someone who wouldn't drink alcohol, or would drink lightly anyway.

E. Konitoring Drinking by the Designated Driver. Servers monitor, and other people in party tend to encourage the DD to stay sober. If DD drinks alcohol, they take away the badge, stop serving non-alcohol, but tell them that the van can still be used.

F. Eligibility Reguirements. No.

G. Publicity. No advertising.

H. Staffing the DDP and Training Staff. Bar Yanager supervises 2 bartenders and 2 cocktail waitresses. There is an initial general alcohol awareness training program for all new employees.

I. When Does the Program Operate. All times.

\section{MORE PROGRAM ORGANIZATION}

A. Changes in the DDP since It Began. None.

B. Annual Cost. Negligible.

C. Resources For Meeting Costs. In-house resources.

D. Are Other Anti-drunk Driving Programs Present. Not in hotel. See note above which describes a combination DDP and Safe Ride.

V. PROGRAM IMPACT

A. How Well Does the Program Work. Successful.

B. Reactions to the Program. Companions and participants feel more comfortable.

c. What Number Participate / Number of Potential Groups. 5/week out of 10 potential groups.

D. Size of Participating Groups. 6 or more.

E. Changes in the Drinking of Non-Drivers in Parties with a Designated Driver. Yes, drinking by companions has increased.

VI. INFORMAI DESIGNATED DRIVER ACTIVITIES

A. Do People Assion Designated Drivers on Their own. Without Encouragement By A Formal Program. Yes Note: here he describes how people informally designate a driver before coming into his establishment, rather than informal DDPs at other events.

1.

a. In That situations and for what Events. Usually party comes in and knows that an individual doesn't drink or drinks 1ightly. This individual is DD.

b. How Is the Desionated Driver selected. Informally, from above knowledge.

c. How Widespread Are Informal Designated Driver Activities. Iess than $10 \%$ of groups that come in.

d. How Have You Learned About This. Cocktail waitresses have told him.

e. Other Information About Informal Activities. No data.; 


\section{WHAT WRITHEN INFORMATION IS AVAILABIE}

A. Will send materials.

Comments: They seem to have a combined Safe Ride and DDP, with amphasis on the DDP. Vans are available to DD if party is too large to fit in one car--and he said that most participating parties tend to have 6 or more people. He said that DD often drinks alcohol, and then the van is driven by a bell hop. He would like to receive a Users Guide if we publish one.

Rumors (In Washington, DC) - Gail Fast - 202-466-7378 or 833-8822 RB: Barbara Pomerance, Ehrlich, Maines, and Associates

Date of Interview: $6 / 6 / 86$

Position: Assistant General Manager

Address: 1900 M St. NW, Washington, DC

\section{SETTING INFORMATION}

A. Description of Establishment/Location. Bar and Restaurant; downtown business area, centrally located.

B. Size. 225 seating capacity; usually pretty full.

C. Description of Clientele. 25-34 white collar.

D. Availability of Public Transportation. Both.

\section{PROGRAY ORGANIZATION}

A. When and why was the Program Started. Started May 1985; problem that needed to be addressed.

B. Coordination with other organizations. They work through program put together by Barbara Pomerance; other restaurants involved. (See entry for Mel Krupin's Restaurant.)

\section{PROGRAM OPERATION}

A. How Is the Designated Driver selected and Identified. Person signs up to be permanently put on record at Rumors as a designated driver. Person is given a card which he/she keeps.

B. How Are Participants Recruited. A car was given away initialIy as an incentive to sign up as a designated driver. The more often the person came in to be a designated driver, the better his/her chances of winning the car. Banner is aiso up

c. What Incentives Are offered to The Designated Driver. Card issued to the person at the time he/she signs up so that he/she can get free non-alcoholic beverages any time the card is presented - button also used.

D. Who Uses The DDP. No difference.

E. Monitoring Drinking by The Desiqnated Driver. Bartender takes card when designated driver comes in. Person must sign a disclaimer at beginning of each evening they come saying that. he/she will say sober, etc. 
F. Eliqiblitity Requirements. 21 or older.

G. Publicity. Original campaign lasted 6 months with the pontiac dealer (car give-away), radio stations. Since then, not much publicity.

H. Staffing the DDP and Training Staff. They had an original training program at a staff meeting. No training of new people to speak of.

I. When Does the Proqram operate. All the time store is open store hours - Sunday - Thursday: $11: 30$ - $1: 30 ;$ Friday - Saturday open 11:30-3:30.

IV. YORE PROGRAY ORGANIZATION

A. Changes in the DDP since It Began. None.

B. Annual Cost. Nominal.

C. Resources For Yeeting Costs. In-house.

D. Are Other Anti-drunk Driving Programs Present. No.

V. PROGRAY IMPACT

A. How Well Does the Program Work. Very well; has created awareness among customers.

B. Reactions to the progran. Favorable all around.

C. What Number Participate/Number of Potential Groups. There are 100 dds on file.

D. Size of Participating Groups. Average of 2 or 3 .

E. Changes in the Drinking of Non-Drivers in Parties with a Designated Driver. No. "It seems to me that the goal of the DDP is to get drunk drivers off the road - not reduce the drinking by others. If you start doing more than that it's not really the Designated Driver Program anymore, is it?"

VI. INFORMAL DESIGNATED DRIVER ACTIVITIES

1. Do People Assion Designated Drivers on Their own, without Encouragement By A Formal Program. No idea.

VII. WHAT WRITTEN INFORKATION IS AVAIIABLE

will send written materials. Received: Button, "Designated Driver Membership Card," Designated Driver contest (for a car) information.

COMDENTS :

Sage's (in Chicago, II) - Nancy Sage - 312-944-1557. RB: Pam Burk of II Highway safety.

Date of Interview: $6 / 16 / 86$

Position: Administrator

Address: $75 \mathrm{w}$. Algonquin Rd., Arlington Heights, II 60005

$$
F-79
$$




\section{SETTING INFORMATION}

A. Description of Establishment/Location. Fine dining restaurant and lounge; suburban.

B. Slze. Seating Capacity: 260.

C. Description of clientele. 30 and up; white collar.

D. Availability of Public Transportation. Taxi available not readily; no bus.

\section{PROGRAY ORGANIZATION}

A. When and Why was the Program Started. 1984; it is part of a comprehensive program to serve alcohol responsibly.

B. Coordination with other organizations. Independently.

\section{PROGRAY OPERATION}

A. How Is the Designated Driver selected and Identified. Person volunteers and is issued a button; strictly volunteer.

B. How Are Participants Recruited. Posters; servers wear button.

C. What Incentives Are offered to The Designated Driver. Free non-alcoholic beverages; credit for two alcoholic beverages on a return trip.

D. Who Uses The DDP. Hard to generalize.

E. Yonitoring Drinking by The Designated Driver. Server watches.

F. Eligibility Requirements. None.

G. Publicity. Their comprehensive program (see II. A.) has had a high profile since 1984; some news stories - free publicity generally obtained.

H. Staffing the DDP and Training staff. New employees go through START - 3 days of training - and a full-day course.

I. When Does the Program operate. Anytime.

IV. MORE PROGRAM ORGANIZATION

A. Changes in the DDP since It Began. None.

B. Annual Cost. Nominal.

C. Resources For Meeting Costs. Independently printed.

D. Are other Anti-drunk Driving programs present. "Whole service procedure" is oriented to avoid excessive drinking on the part of the customer - Safe Ride used; Sage's foots the bill. She thinks Safe Ride is more effective than DDP. They freely publicize the fact that they are willing to foot the bill for a ride home; says that such publicizing goes with the territory in Chicago and Illinois in general - says that it's "part and parcel in the alcohol-serving business."

\section{PROGRAY IMPACT}

A. How Well Does the Program Work. Increased awareness for the public; unfortunately the problem drinkers are not helped by the DDP. Self-policing (i.e. the DDP) is not a solution for the problem. Thinks Safe Ride is a solution for the problem drinker. 
B. Reactions to the Program. Positive.

C. What Number Participate / Number of Potential Groups. 1 or 2 (not many).

D. Size of Participating Groups. 4 to 6 .

E. Changes in the Drinking of Non-Drivers in Parties with a Designated Driver. Couldn't say. "Good question."

VI. INFORYAL DESIGNATED DRIVER ACTIVITIES

A. Do People Assion Designated Drivers on Their Oun. Nithout incouragement By A Formal Program. Yes, she knows they do. There's a lot of "self-policing going on." : The activity is more informal than formal.

1.

a. In what situations and for wat Events. All kinds of things.

b. How Is the Designated Driver Selected. No idea.

c. How Widespread Are Informal Desigmated Driver Activities. Widespread practice.

d. How Have You Learned About This. Through talking to customers.

e. other Information About Informal Activities. No data.

\section{WHAT WRITTEN INFORMATION IS AVAIIABIE}

A. Will send materials.

Comments: She frequently referred to the DDP as a "self-policing" program because they're doing the volunteering. She didn't think that the incentive of free non-alcoholic drinks and two free coupons for future drinks deterred it from being a "selfpolicing" program. She distinguished between DDP and safe Ride by making this point since safe Ride is not such a selfpolicing situation.

Scruples at Sheraton Harrisburg Inn (in Rockingham-Harrisburg, vA) - Alice purdeu - 703-433-2521. [RB: David Rood, Rockingham-Harrisburg Alcohol Safety Action Programs (ASAP)].

Date of Interview: 6/20/86

Position: Assistant Manager

Address: 1400 E. Market St., Harrisonburg, VA 22801

\section{SETTING INFORMATION}

A. Description of Establishment/Location. Restaurant and lounge, live entertainment and comedians, DJ.

B. Size. Seating Capacity: 125.

C. Description of Clientele. 25-45; business people, lawyers, accountants - white collar.

D. Availability of Public Transportation. Taxi available.

Most clients pretty much look out for each other.

$$
\text { F-81 }
$$


II.. PROGRAY ORGANIZATION

A. When and Why was the Program Started. Unsure when it started (She's new).

B. Coordination with other organizations. Coca cola is the parent organization (along with several radio stations) and several area lounges are involved.

\section{PROGRAY OPERATION}

A. How Is the Designated Driver selected and Identified. They volunteer most of the time; button used. Some people won't wear the button. But waitress knows. staff does not usually the bar occasionally are a problem; the regulars aren't a problem.

B. How Are Participants Recruited. Servers wear buttons only during holidays; most of the rest of the year there is not much exposure. We have a "mature crowd."

c. What Incentives Are offered to The Designated Driver. Cokes and coffee given for free - see comments. (Mocktails advertised - usually not for free.)

D. Who Uses The DDP. Usually women; very seldom that a man is going to be a "non-drinker." Usually early 30 's.

E. Konitoring Drinking by The Designated Driver. Not much need for monitoring. People are pretty responsibie.

F. Eligibility Requirements. None.

G. Publicity. Radio advertising each holiday (in connection with other lounges through Coca Cola).

H. Staffing the DDP and Training staff. None.

I. When Does the Program operate. Anytime.

IV. MORE PROGRAY ORGANIZATION

A. Changes in the DDP since It Began. Used to have a minimum eligibility requirement of 4 or more; now there are no eligibility requirements.

B. Annusl Cost. Nominal.

C. Resources For Meeting Costs. Coca Cola provides buttons; Coke provides free cokes during holidays.

D. Are other Ant $j$-drunk Driving Programs Present. Informal safe ride. Scruples "always" foots the bill. Coupon books purchased from the Cab Co. (City Cab Co.). Patrons often share a cab on their own - without any management involvement.

V. PROGRAY IMPACT

A. How Well Does the Program Work. People are more aware now. Laws are tough, so people realize that they need to be careful. Cops sit and wait on the highway right near scruples.

B. Reactions to the program. Some joke that they want a button just so they can have one but they still want to drink; hasn't
heard much feedback. 
c. What Number Participate / Number of Potential Groups. Not more than 2 or 3 in a week; couldn't say how much volume for the week.

D. Size of Participating Groups. 4 or 5 .

E. Changes in the Drinking of Non-Drivers in Parties with a Designated Driver. No. It's a responsible crowd. The crowd knows that the waitresses will cut people off if they've had too much. Waitresses are a little scared about liability, and they watch people closely.

VI. INFORYAI DESIGNATED DRIVER ACTIVITIES

A. Do People Assion Designated Drivers on Their own. Without Encouragement By A Formal Program. Yes, definitely. 1.

a. In what Situations and for What Events. Mostly the nights on the town; not so much at a party.

b. How Is the Designated Driver selected. They generally take turns.

c. How Widespread Are Informal Designated Driver Activities. Fairly widespread.

d. How Have You Learned About This. She's done it herself.

e. Other Information About Informal Activities. No data.

VII. WHAT WRITTEN INFORMATION IS AVAIIABIE

A. None.

Comments :

Sea Cove Restaurant - formerly sea Cove Saloon (in Sea Bright, N.J.) - Kathleen Mendes - 201-842-5319. [RB: Sharane Orendas, N.J. Highway Safety].

Date of Interview: $7 / 10 / 86$

Position: Owner

Address: 1250 ocean Avenue, Sea Bright, NJ 07760

I. SETTING INFORMATION

A. Description of Establishment/Iocation. This is a restaurant which used to be a bar; they are set in a seaside location in a small town with a population of 3000 . The town has one main street.

B. Size. Seating capacity in the summer is 225 (when there is outdoor seating) and roughly half this number during the winter.

c. Description of clientele. The clientele is basically white collar and in their $40 \mathrm{~s}$.

D. Availability of Public Transportation. The restaurant is easily accessible but the only alternative transportation is limo/taxi service. 


\section{PROGRAY ORGANIZATION}

A. When and Why was the Program started. The program was started in 1983; they were the first DDP in the country. The motivation was the fear of being sued and skyrocketing liquor liability premiums. The police were setting up roadblocks at each end of this one street town and scaring away our customers. They instituted the DDP as a public relations gesture. She claims their program is the first of the DDPs.

B. Coordination with other organizations. No data.

\section{PROGRAY OPERATION}

A. How Is the Desicnated Driver selected and Identifled. A waitress will ask who the driver is in a party or group of more than two and if they are interested in being the designated driver. The servers initiate the conversation. They provide $t$-shirts to the designated driver and buttons. They get free soda or other non-alcoholic drinks for the evening. They don't try to determine why people may refuse to participate since it is "none of our business."

B. How Are Pafticipants Recruited: Individuals are encouraged to participate by the server who initiates the conversation and the incentive of free t-shirts and free non-alcoholic drinks.

c. What Incentives Are offered to The Designated Driver. The only way in which designated drivers are treated differently is that they are given free t-shirts and free non-alcoholic
drinks.

D. Who Uses The DDP. The people who participate are those who are non-drinkers to begin with among a group who came in to drink. They are typically abstainers who became more popular among arinkers by a program like the DDP. Without this program, they probably would have stayed home since they wouldn't go out to drink but now drinkers seek them out to act as the designated driver when they go out to drink.

E. Konitoring Drinking by The Designated Driver. Waitresses, if they are good, will monitor their patrons'. drinking behavior, and check to make sure that the designated driver does not
drink.

F. Eligibility Requirements. Only eligibility requirements are more than 2 in the party and they must be of legal drinking age.

G. Publicity. There is no advertising of the programi strictly word of mouth. Publicity not needed to keep the program run-
ning.

H. Staffing the DDP and Training staff. The regular staff of 10 waitresses and 6 bartenders staff the program. They are trained by establishment.

I. When Does the Program operate. The program primarily operates 


\section{YORE PROGRAY ORGANIZATION}

A. Changes in the DDP since It Began. No changes in the program have taken place although they changed from being a saloon to a restaurant.

B. Annual cost. The $t$-shirts cost $\$ 3.50$ each and she gave out 2,000. In addition, there is the cost of free soda. It is a very costly program.

c. Resources for yeeting costs. Resources come out of her pocket.

D. Are other Anti-drunk Driving programs present. There are no other anti-drunk driving programs. The DDP was started as a public relations strategy in response to the DWI hysteria and police state activities it resulted in (by state police) in New Jersey.

\section{PROGRAM IYPACT}

A. How Well Does the Program Work. The program has worked very well.

B. Reactions to the Program. The reaction has been very good from designated drivers, their companions, people who do not participate, staff, and community groups.

c. What Number Participate / Number of Potential Groups. No idea of how many individuals participate nor how many potential groups there are; not something they kept track of.

D. Size of Participating Groups. No idea of average group size.

E. Changes in the Drinting of Non-Drivers in Parties with a Designated priver. There may have been a slight increase in the drinking level of non-drivers in parties with a designated drivers but no one is arunk on the floor.

VI. INFORMAI DESIGNATED DRIVER ACTIVITIES

A. Do People Assign Designated Drivers on Their own, without Encouragement By A Formal Program. Not applicable.

VII. WHAT WRITTEN INFORYATION IS AVAIIABIE

A. Did not get to ask her about written materials.

Comments

TGI Friday's (Corp. headquarters in Dallas) - Diana Hovley - 214450-5400. [RB: Thad Eure, Angus Barn].

Date of Interview: $6 / 23 / 86$

Position:

Address: Dallas, $\mathrm{TX}$

Comments: Spoke with Hovley for a few minutes. While it has been fairly common knowledge that TGI Friday's uses the DDP, 10 and behold, she insisted that as a company they do not endorse:the 
program. (I took it that they have discontinued the program.) When I told her that I had just spoken with the manager of a new Friday's in Raleigh, NC about his DDP, she said that he must have misunderstood the question asked of him because "no Friday's establishment uses the program." The reason they have discontinued it is because of a llability problem. "when a designated driver leave the bar with 3 or 4 drunk companions, we're liable if they are not driven home; if they're driven to their cars..." She made it clear that it does not help in the liability battle.

Todd's at Radisson (in Omaha, NE) - Dan McCard - 402-331-8220. [RB: Ray Niel, Douglas County MADD.]

Date of Interview: 6/20/86

Position: General Manager

Address: 10909 M Street, Omaha, NE 68137

I. SETTING INFORYATION

A. Description of Establishment/Location. Restaurant and lounge.

B. Size. Seating Capacity: 196 .

C. Description of Clientele. 30-45; upper middle class. D. Availability of Public Transportation. Taxi available, no

II. PROGRAY ORGANIZATION

A. When and why was the Program started. The program has been available since the store reopened (after remodeling) in sept. 1984. The motivation was that it was something the management believed in.

B. Coordination with other organizations. Independent.

\section{PROGRAY OPERATION}

A. How Is the Designated Driver selected and Identified. Buttons were originally tried, but this didn't work; people didn't want to wear them. He says there is not much of a problem with overindulging. Sometimes the staff does the asking: "... it's a judgment call; it depends on who's at the table." If someone is holding back in the first place, the staff will ask if he/she would like to be $a$ dd.

B. How Are Participants Recrutted. The posters wouldn't fit in with the atmosphere; mature crowd; very quiet lounge. We're trying to be as quiet about it as possible. Don't want to publicize it too much.

C. What Incentives Are offered to The Designated Driver. Free non-alcoholic beverages.

D. Who Uses The DDP: Can't generalize; all types.

E. Monitoring Drinking by The Designated Driver. Monitoring is computerized. Hasn't noticed any abuse.

F. Eliaibility Requirements. None.

$$
\text { F-86 }
$$


G. Publicity. None.

H. Staffing the DDP and Training staff. None.

I. When Does the Program Operate. Anytime.

IV. XORE PROGRAY ORGANIZATION

A. Changes in the DDP since It Began. Buttons vere eventually discontinued. People wouldn't wear them.

B. Annual cost. Nominal; they started tracking the cost of the program at the beginning, but it proved to be not worth it; it was more expensive to track it than to operate it.

c. Resources For Keeting Costs. No resources to speak of. He doesn't want to advertise.

D. Are Other Anti-drunk Driving Programs present. Safe Ride operates informally. Todd's foots the bill; free coffee offered to over-indulgers or anyone who has had just a couple drinks and feels like lightening up.

V. PROGRAM IMPACT

A. How Well Does the Program Work. "Pretty good." It contributes to an image that they're a "eriendly place."

B. Reactions to the Program. None.

C. What Number Participate/ Number of Potential Groups. More than 10 in a week. $\$ 2,000-4,000$ business per week.

D. Size of Participating Groups. 4.

E. Changes in the Drinking of Non-Drivers in Parties with a Designated Driver. "That is a diffizult question." When told that some people have criticized the program because it can lead to excessive drinking by others in the party, he said, "I think that's a bunch of baloney."

VI. INFORYAI DESIGNATED DRIVER ACIIVITIES

A. Do People Assign Designated Drivers on Their Own, Without Encouragement By A Formal Program. No.

VII. WHAT WRITTEN INFORKATION IS AVAIIABIE

A. None

Comments:

Tom Fooleries (in Westborough MA) - Tom McCabe - 617-366-5959 or 617-366-1244

Date of Interview: $7 / 31 / 86$

Position: Vice President

Address: 95 Turnpike Rd., Westborough, MA 01581.

I. SETTING INFORMATION 
A. Description of Establishment/Location. High volume, casual theme restaurant. Suburban setting - high tech industry and upper middle class residential.

B. Scire. Seating Capacity: 350 (includes function room, cocktail room and restaurant).

c. Description of Clientele. Cross section. Ages 25-55. Families, businessmen and professionals. During day: bankers, lawyers, high tech professionals; in evening: upper middle class residents.

D. Avaliability of public Transportation. Minimal availability. No busses. One taxi, no taxis in surrounding towns.

\section{PROGRAY ORGANIZATION}

A. When and Why was the Program started. May 1986. Motivation: another addition to alcohol awareness programs in restaurant. This is the first customer-oriented program; other programs are employee-oriented.

B. Coordination with other organizations. Yes. "I've Got the Rey" program developed cooperatively by MA Restaurant Association and WBZ TV. Program offered to members and non-members. over 200 developers of the program.

\section{PROGRAY OPERATION}

A. How Is the Designated Driver selected and Identified. Voluntary Program. Servers sometimes initiate the conversation - this depends on the character of the party and how busy the restaurant is. Not sure if customers refuse to participate -- more that many people do it without participating in the program. DD wears a button.

B. How Are Participants Recruited. Table tents, posters, and all servers and bartenders must wear button. Servers sometimes talk up program.

C. What Incentives Are offered to The Designated Driver. DD gets free non-alcoholic beverage.

D. Who Uses The DDP. Cross section. Some rotation. Mostly people who are responsible -- unsuccessful with problem drinkers, and it is often problem drinkers who are arrested DWI and get in DWI accidents.

E. Yonitoring Drinking by The Designated Driver. No monitoring officially done. Almost impossible. He doesn't know if the DD has drunken before he/she arrives at the restaurant, or whether he/she stops afterward to drink somewhere else. The public needs to take responsibility and DDP offers this opportunity -- his establishment won't play baby-sitter.

F. Eligibility Requirements. No eligibility requirements. Not worth it to complicate things, and not worth negative P.R, even if one person party is DD, or DD is under drinking age.

G. publicity. WBZ TV is a main participant in MA Restaurant Association DDP program "I've got the key," and has commercials for DDP. He has also seen announcements in the news media and the radio. The MA Restaurant Association has coordinated 
speaking spots on cable TV and on the radio. Tom Fooleries itself does not advertise the restaurant; if it did it would advertise the DDP along with the restaurant. The MA Restaurant Association encourages other restaurants to include DDP in advertising. WBZ TV is putting together PSAs to encourage people to ask for DDPs when they go out.

B. Staffing the DDP and Training staff. Managers and alcohol servers must go through general alcohol awareness program (TIPS) when they begin employment. TIPS is a 6 hour program -- usually conducted by outside consulting firm unless there is a large volume of new employees. TIPS includes a briefing on "I got the keys" (DDP). Also, there are: two daily shift meetings which sometimes are used to reinforce or clarify "I got the key," especially since liabllity is always such a big issue on management's mind.

I. When poes the program operate. Anytime, but people mostly use it evenings and weekends because of the makeup of the clientele.

\section{YORE PROGRAM ORGANIZATION}

A. Changes in the DDP since It Began. - None.

B. Annual cost. Materials: $\$ 360 /$ year. Services donated to DD's (non-alcoholic beverages) at retail cost: $\$ 10,000 /$ year.

c. Resources For Meeting costs. Time and administrative work donated by the WA Restaurant Association and WBZ TV. Brewers of non-alcoholic beer

-Ringsbury- through United Liquors, have offered to donate non-alcoholic beer to DDPS. Also, support by 3 wholesalers - Consolidated Beverages, United Liquors and another - who have bought DDP starter kits (cost: $\$ 32$ each) and given them to their salespeople to give to restaurants.

D. Are other Anti-drunk Driving programs Present. No. Well, very casual safe ride if intoxicated person is not in the company of someone who can drive; the restaurant will provide transportation through staff or management or taxi (will pay if necessary). Or they will call the police. The problem with safe ride is that there is only one taxi in westborough and surrounding towns have no taxis.

\section{PROGRAM IMPACT}

A. How Well Does the Program Work. Started out poorly, but is working well now. He said his best evaluation of the program is that the public has not fully embraced it. Excited about the growth of the program and the increased participation. It is only one solution to drunk driving problem however.

B. Reactions to the program. There hasn't been a groundswell of reaction. What reaction they have heard has been positive. Big concern at the outset by professional members of the public (not in restaurant/bar industry) was that it would increase the alcohol consumption of companions of DD; this has not been the case. 
c. What Number Participate / Number of Potential Groups. At beginning: unusual when there was one DD/night. Now, 10 weeks later, there are approximately $15-20$ people/day. They serve 800 meals per day; about 400 are lunches where people don't tend to drink a lot, and DDP is not used.

D. Slze of Participating Groups. Real mix 2-10 people. Average group: 4.

E. Changes in the Drinking of Non-Drivers in Parties with a Designated Driver. No changes in alcohol consumption of compantons of DD.

\section{INFORXAL DESIGNATED DRTVER ACTIVITIES}

A. Do People Assion Designated Drivers on Their own, without Encouragement By A Formal Program. Yes.
1 .
a. In What situations and for what Events. All types of events -- sporting events, private parties.
b. How Is the Designated Driver selected. Volunteer, rota- tion, etc.
c. How Widespread Are Informal Deslanated Driver Activities. Widespread.
d. How Have You Learned About This. Conversations with customers, observation of customers, wide circle of ac- quaintances, member/leader of many organizations.
e. Other Information About Informal Activities. No data.

VII. WHAT WRITTEN INFORMATION IS AVAILABLE

A. Will send material.

Comments: He stressed that there is a national trend that people are drinking less; at his establishment he gave the following liquor: food ratio - percentage of total sales - 3 years ago 40:60; now 33:67. Tom McCabe is heavily involved in other organizations: lst V.P. of MA Restaurant Assoc., Vice Chairman of Iiquor Liability JUA; and very active in TIPS

Ye old Regulator (in Bloomington, IN) - Jim williams, former owner - 812-339-2261 (Williams' current \#). [RB: Indiana University Panhellenic office and Chuck McPhèeters.]

Date of Interview: $6 / 27 / 86$

Position: Former Owner/Manager

Address: $319 \mathrm{~N}$. Walnut, Bloomington, IN 47401

NOTE: SEE COMLENTS BELOW.

I. SETTING INFORMATION

A. Description of Establishment/Location. Bar and restaurant open for lunch; pizza and sandwiches in early evening; and late night college bar. 
B. Size. Seating capacity: 289 .

C. Description of clientele. Mostly college students: 21-23.

D. Availability of public Transportation. Taxi available, nass transit stops at 7:00 p.m.

II. PROGRAY ORGANIZATION

A. When and Why was the Procram started. October 1985 ; motivation was increased insurance premiums, $P R$ in relation to that increase; change of image towards "more responsible, productive contribution to community."

B. Coordination with other organizations. In conjunction with retail carry-out Iiquor, and Panhellenic office.

\section{PROGRAM OPERATION}

A. How Is the Designated Driver selected and Identified. Red cups issued to dd; hand stamp ofter used to help identify.

B. How Are Participants Recruited. Posters up; no table tents.

C. What Incentives Are offered to The Designated Driver. Free non-alcoholic drinks.

D. Who Uses The DDP. Good male-female mixture. No generalization can be made.

E. Konitoring Drinking by The Designated Driver. Waitress and bartenders watch; doormen watch also. Check them when they leave. Not abused.

F. Eligibility Requirements. None.

G. publicity. Ran ads in both town newspapers. Flyers distributed on campus.

H. Staffing the DDP and Training staff. When it was implemented, they had a general initiation. Williams is no longer with them, so he could not speak to question about ongoing training.

I. When Does the Program Operate. Anytime.

IV. MORE PROGRAM ORGANIIZATION

A. Changes in the DDP since It Began. None.

B. Annual cost. Varied depending on the crowd; $\$ 10$ to $\$ 35-40$ per night.

C. Resources for Meeting costs. Panhellenic paid for posters; bar paid for coke.

D. Are Other Anti-drunk Driving Programs Present. Informal safe Ride was done occasionally; others in Bloomington do it also. on New Years Eve, Mass transit provided free bus service, he thinks.

\section{PROGRAM IMPACT}

A. How Well Does the Program Work. Moderately. He wasn't there long enough to see the true effect.

B. Reactions to the Program. Designated drivers: positive; companions of DD: no feedback; non-participants: no feedback;"

$$
F-91
$$


staff: "pain in the ass, no tips"; community groups: "improved

c. What Number Participate / Number of Potential Groups. 15 / week at peak times (ie. while school was in session).

D. Size of Participating Groups. 3 or more.

E. Changes in the Drinking of Non-Drivers in Parties with a Desionated Driver. Others felt more comfortable, more relaxed definitely abused it; especially since they planned it before they arrived; "...sloppy drunks increased by 208 with the DDP."

\section{INFORYAL DESIGNATED DRIVER ACTIVITIES}

A. Do People Assion Desianated Drivers on Their Own. without Encouragement By A Formal Program. Yes.

1.

a. In what Situations and for what Events. Bachelor parties, birthday parties, anniversary parties.

b. How Is the Designated Driver selected. Rotation when a group frequently drinks together.

c. How Widespread Are Informal Designated Driver Activities. Today in Indiana with the laws the way they are, it's used 508 of the time or better. 808 of the time with larger groups. People are "scared to get on the road." d. How Have You Learned About This. Talking to customers,

e. Other Information About Informal Activities. No data.

VII. WHAT WRITTEN INFORYATION IS AVAIIABIE

A. No - call IU Panhellenic Office.

Comments: The interviewee, Jim williams, is a former owner of Ye Old Regulator. The current owner, Chuck McPheters (who just took over) said that williams would be the better person to talk to since he's had more experience with the DDP. Presently, Ye old Regulator is closed; when it reopens, the DDP will resume. The phone number given above is williams current number. The number for Ye old Regulator (McPheeters) is 812-339-

Williams said that customers made decisions about who would be a designated driver before coming into the establishment. He made the interesting remark that non-drivers in the DD party tend to drink more - "especially since they plan it before they arrive."

The zephyr Club (in Salt Lake City, UT) - John Fosdick 801-355-2582. [RB: Bart Fitzgerald, Highway Safety Division].

Date of interview: $6 / 12 / 86$

Position: Owner and General Manager

Address: 301 South \& West Temple, Salt Lake City, UT 84101 


\section{SETPING INEORYATION}

A. Description of Establishment/Location. Iounge and nightclub which has live entertainment.

B. Size. Seating Capacity: 250 .

C. Description of clientele. 21-35, upper middle class, educated.

D. Avallability of Public Transportation. Taxi service or they volunteer to give them rides home.

II. PROGRAY ORGANIZATION

A. When and why was the program Started. 1 and a half years ago, in 1985. Yotivation was increasing cost of liquor liability. insurance; he saw the DDP $a s$ an alternative to the increasing liquor liability premiums. They wanted to demonstrate a good faith effort to do something about drunk driving problem.

B. Coordination with other organizations. No other coordination.

\section{PROGRAY OPERATION}

A. How Is the Degionated Driver selected and Identifled. Upon entering the club, the patron (in group of 2 or more) identifies himself as the designated driver and receives a button. Servers or staff do not initiate conversation. People who don't participate simply want to be able to drink alcohol in a nightclub atmosphere.

B. How Are Participants Recruited. Groups are encouraged in that the DDP is advertised in-house with buttons and posters.

c. What Incentives Are offered to The Desionated Driver. Free non-alcoholic beverages. That is the only incentive.

D. Who Uses The DDP. Designated drivers are different from others in that they agree to assume responsibility for the safe transportation of their companions.

E. Monitoring Drinking by The Designated Driver. Waitresses make sure by observing what the designated drivers are drinking.

F. Eligibility Requirements. Two or more and they all must be of legal drinking age.

G. publicity. They've done PSAs on TV, but they are not really needed to keep the program running. The community has shown little interest in the program. Neither the state nor the city have allocated resources.

H. Staffing the DDP and Training staff. They use regular staff and there is no special training; no need for training; they must simply make sure the person wearing the button does not drink alcohol.

I. When Does the Program Operate. Anytime (6 p.m. to 2 a.m.).

\section{MORE PROGRAM ORGANIZATION}

A. Changes in the DDP since It Began. No changes.

B. Annual cost. They've spent $\$ 20.00$ on buttons.

C. Resources For Meeting costs. All resources come from within house. 
D. Are other Anti-drunk Driving Programs Present. No other formal programs, although they informally provide free rides home to those who can't drive because they drank too much (Safe Ride).

V. PROGRAM IMPACT

A. How Welt Does the Program Work. The program has worked poorIy. People would rather drink in a nightclub setting than remain sober. The program has recelved little exposure with no apparent interest or funding coming from the city or state.

B. Reactions to the Proaram. (a) designated drivers like the program; (b) companions of designated drivers appear to be happy but he's had no specific input from them; (c) no feedback from those who don't participate; (d) community groups are only slightly aware of it.

c. What Number Participate / Number of Potential Groups. Two people a month may participate out of 200 on a typical evening. There are probably 50-70 groups on a given night.

D. Size of Participating Groups. Average of 3 to a group. No change in group size since the program started.

E. Changes in the Drinking of Non-Drivers in parties with a Designated Driver. He hasn't noticed any changes in drinking levels or behavior in parties with a designated driver.

VI. INFORMAL DESIGNATED DRIVER ACTIVITIES

A. Do People Assign Designated Drivers on Their own, without Encouragement By A Formal Program. Not applicable.

VII. WHAT WRITIEN INFORMATION IS AVAIIABIE

A. He suggested we contact Parastyle Bottled Water (801-467-9421) for materials on the DDP.

COMIENTS: He noted that Utah has a "no free pour" law which means that liquor must be dispensed from snip. bottles which at 1.7 ounces typically contain more alcohol than you would get from a iree pour of $1-1$ and a half ounces. He complained that this was a crazy law in light of the increased enforcement of DUI and contrasted the desire to get tough on drunk driving with the lack of interest in the DDP.

\section{Membership Establishments}

Formal Programs

Elks \#78 (in Atlanta) - Betty Hill - 404-634-0169 
Date of Interview: $6 / 17 / 86$

Position: Manager

Address: 2728 Northeast Expressway, Access Rd., Atlanta, GA 30345

NOTE: This is not a DDP in the strict sense as first thought. It certainly is not a formal program. Five people (the same people every night - one of whom is the manager with whom I apoke) are always on hand to drive people home whenever it is necessary. See Comments.

I. SETPING INFORYATION

A. Description of Establighment/Iocation. Food sometimes, Iiquor always, general gatherings, private parties also.

B. Size. Seating Capacity: 150 .

C. Description of Clientele. Mostly over 48 - mostly white collar.

D. Availability of public Transportation. Taxi available.

\section{PROGRAM ORGANTZATION}

A. When and Why was the Program Started. Dec. 1985; no particular motivation just decided it would be a good idea.

B. Coordination with other organizations. No.

\section{PROGRAM OPERATION}

A. How Is the Designated Driver selected and Identified. New people do not volunteer. Five people have been "designated" as ongoing drivers to do drive people home whenever necessary. (At the big monthly meeting, when there are a lot of people, they ask for a few additional volunteers.)

B. How Are Participants Recruited. Posters up.

C. What Incentives Are Offered to The Designated Driver. None; free coffee and donuts avallable for anyone who wants it in the hopes that people won't get as tanked.

D. Who Uses The DDP. NA.

E. Yonitoring Drinking by The Designated Driver. NA.

F. Eliaibility Requirements. NA.

G. Publicity. Advertising in lodge newsletter.

H. Staffing the DDP and Training staff. None.

I. When Does the Program operate. Anytime.

\section{YORE PROGRAM ORGANIZATION}

A. Changes in the DDP since It Began. More publicity soon to come.

B. Annual cost. None.

C. Resources For Meeting Costs. Independent.

D. Are Other Anti-drunk Driving Programs Present. If necessary they will provide taxis for patrons (safe ride) although they don't seem to be pursuing that too strenuously. See comments.

$$
\mathbf{F}-95
$$




\section{FROGRAY IMPACT}

A. How Well Does the Program Work. We don't have much trouble.

B. Resctions to the Program. Positive.

C. What Number Participate/Number of Potential Groups. NA.

D. Sire of Participating Groups. Not many at all.

E. Changes in the Drinking of Non-Drivers in Parties with a Designated Driver. No..

VI. INFORYAI DESIGNATED DRIVER ACTIVITIES

A. Do People Assion Designated Drivers on Their own. Without Encouragement By A Formal Proqram. Yes.

1 .

a. In what situations and for what Events. General social events.

b. How Is the Designated Driver selected. In some parties, they alternate; in others, it's always the one who doesn't drink in the first place.

c. How Widespread Are Informal Designated Driver Activities. Said off-premises participation (amongst Elks patrons) is about 50-50.

d. How Have You Learned About This. Talking to patrons.

e. Other Information About Informal Activities. No data.

VII. WRAT WRITTEN INFORMATION IS AVAILABLE

A. None.

COMnIFNT: She used the term "designated driver" to describe what they're doing, although it really doesn't fall inside the boundaries of the DDP. It's really more an informal safe ride program. They seem to even go so far as to advertise their program as being a DDP.

VFW (in Fridley, MN) - Doug Bistodeau, Manager - 612-780-3694

Date of Interview: $6 / 13 / 86$

Position: Manager

Address: 1040 Osborn Rd., Fridley, MN 55432

\section{SETTING INFORMATION}

A. Description of Establishment/Location. On Saturdays they have either a steak fry, roast beef sandwich or a fish fry night. Hors d'oevres served the rest of the time; liquor served throughout all events; they have weddings there as well. suburb of Minneapolis.

B. Size. Seating Capacity: Hall - 500, bar - 200.

C. Description of Clientele. $10 \%$ is $40-65 ; 90 \%$ is midaleclass. 
D. Availability of public Transportation. Taxi available, no bus to speak of, "but people are always avallable to drive somebody home if someone has had too much."

II. PROGRAM ORGANIZATION

A. When and Why was the Program Started. 1983.

B. coordination with other organizations. Independent.

III. PROGRAM OPERATION

A. How Is the Desionated Driver selected and Identified. No identification used; they volunteer.

B. How Are Participants Recruited. No; used to be in newsletter, but it is not anymore since everyone seems to know about it now.

c. What Incentives Are offered to The Designated Driver. No incentive.

D. Who Uses The DDP. Most DDs are non-drinkers in the first place -- "...there's getting to be more and more non-drinkers, and that's a good thing."

E. Monitoring Drinking by The Designated Driver. No need since most of the drivers don't drink in first place.

F. Eligibility Requirements. None.

G. Publicity. originally through monthly flyer, but no longer any publicity.

H. Staffing the DDP and Training staff. None.

I. When Dises the Program Operate. Pnytime.

IV. MORE PROGRAM ORGANIZATION

A. Changes in the DDP since It Began. None.

B. Annual Cost. None.

C. Resources For Meeting Costs. None.

D. Are other Anti-drunk Driving Programs Present. Safe ride done informally -- patrons drive patrons home. (See Comments.)

V. PROGRAM IMPACT

A. How Well Does the Program Work. Program would work well if everybody followed it; in his case, many people are following it; people are changing because of the DWI laws.

B. Reactions to the Program. Not much feedback; anything he's heard has been positive.

c. What Number Participate / Number of Potential Groups. 1 to 5 per week.

D. Size of Participating Groups. 1 or 2. (It seemed clear from his answer that only those who over-indulged got driven home; there's nothing established at the beginning of the night.

Rather at the end of the night, they make an assessment of the situation.) Not really a DDP per se.

E. Changes in the Drinking of Non-Drivers in Parties with a Designated Driver. People drink less. People don't drink" as much as they used to. 
VI. -INFORYAI DESIGNATED DRIVER ACTIVITIES

A. Do People Assign Designated Drivers on Their Own, without Encouragement By A Formal Program. No.

VII. WHAT WRITPEN INFORYATION IS AVAIIABLE

A. None.

COMDENTS: The terminology "DDP" is used, but in essence the program is a safe ride. Nothing seems structured or decided at the beginning of the evening. Rather, people are just "on hand" if someone is in need of a ride home at the end of the night. VFW (in Spring Lake Park, MN) - Rick Millette, Manager- 612-780-
1900

Date of Interview: $6 / 11 / 86$

Position: Manager

Address: 8100 Pleasant View Dr., Spring Lake Park, MN 55432

I. SETTING INFORMATION

A. Description of Establishment/Location. Bar, food served; functions include: banquets, weddings, club bands on weekends.

B. Size. Seating Capacity: 700 . C. Description of Clientele. Middle-aged to older crowd, middle

D. Availability of Public Transportation. Taxi available; no

II. PROGRAY ORGANIZATION

A. When and why was the Program started. Dec. 1985 ; motivation was to protect himself from liability.

B. Coordination with other organizations. Independently run.

III. PROGRAY OPERATION

A. How Is the Designated Driver selected and Identified. Waitress asks if someone would like to be a DD.

B. How Are participants Recruited Posters used to be up but have been taken down; information about the program is put in
their post newsletter.

c. What Incentives Are offered to The Designated Driver. Free non-alcoholic drinks; if someone ever wants to buy the person a drink, the DD is given a chip for a future date.

D. Who Uses The DDP. Middle-aged are doing it more than older

$$
\text { F-98 }
$$


E. Monitoring Drinking by The Desionated Driver. Waitresses are "pretty sharp." They watch. He doesn't feel it's been abused.

F. Elialbility Reguirements. No requirements.

G. publicity. No advertising.

H. Staffing the DDP and Training stafe. The program is explained to staff when they are hired.

I. Then Does the Program Operate. Friday and Saturday, 7:00 until close is when DDP is usually used; available at any time, though.

IV. YORE PROGRAY ORGANIZATION

A. Changes in the DDP since It Began. More people are aware of it than originally.

B. Annual Cost. Nominal.

C. Resources For Yeeting Costs. Don't have any materials at this time; will be receiving materials from some organization (he couldn't remember the name).

D. Are other Anti-drunk Driving Prodrams Present. Safe ride used for special functions when they charter van or bus to go to other places, eg. other posts, etc.

V. PROGRAM IMPACT

A. How Well Does the Program Work. Not too successful; "It's been pretty slow." Not a lot of response. People aren't drinking as much. They're paying more to drink less.

B. Reactions to the Program. Real positive response from those who participate.

c. What Number Participate / Number of Potential Groups. Varies; 1,2 or 3 - not more than 2 or 3 in a week; 500 people on a given Friday or Saturday.

D. Size of Participating Groups. 4.

E. Changes in the Drinking of Non-Drivers in Parties with a Designated Driver. Not that he can see.

VI. INFORMAL DESIGNATED DRIVER ACTIVITIES

A. Do People Assion Designated privers on Their own, Without Encouragement By A Formal Program. A few groups do it informally, especially when they have to drive a long distance. 1.

a. In what situations and for What Events. No data.

b. How Is the Desionated Driver selected. No data.

c. How Wldespread Are Informal Designated Driver Activities. Not widespread.

d. How Have You Learned About This. Heard about it from his clientele.

e. Other Information About Informal Activities. No data.

VII. WHAT WRITTEN INFORMATION IS AVAILABLE 
A. None.

COMnENTS: This program is a full-fledged DDP although it has very limited use (See V. C.).

Moose (in Cincinnati, OH) - Carl sims - 513-242-2760

Date of Interview: $6 / 11 / 86$

Position: Manager

Address: 607 Vine st., Cincinnati, OH 45216

I. SETTING INFORMATION

A. Description of Establishment/Location. Family lodge with bar in the middle of a cincinnati village.

B. Size. Seating Capacity: 90 in lodge, 90 in dance hall.

C. Description of clientele. About 40's, "welfare crowd." He said cllentele is not really white or blue collar.

D. Availability of public Transportation. Taxi and buses nearby.

II. PROGRAM ORGANIZATION

A. When and Why was the Program started. $21 / 2$ months ago because of the liquor liability.

B. Coordination with other organizations. Independent.

III. PROGRAM OPERATION

A. How Is the Designated Driver selected and Identified. Customers volunteer. No button; no identification of any
kind.

B. How Are Participants Recruited. Brochures at the end of bar - that's it. The brochures were just "dropped off by somebody" one day when he wasn't there. Since then the program has been used.

C. What Incentives Are offered to The Desianated Driver. No incentive offered.

D. Who Uses The DDP. Made no generalizations; he says that they trade off being DD each time they go out.

E. Monitoring Drinking by The Designated Driver. Honor system; He doesn't think it's being abused.

F. Eliaibility Requirements. None.

G. Publicity. None.

H. Staffing the DDP and Training staff. None.

I. When Does the Program Operate. Anytime.

IV. YORE PROGRAM ORGANIZATION

A. Changes in the DDP since It Began. None, although it's brand new.

B. Annual Cost. No cost at all.

C. Resources For Meeting Costs. He was unsure where the brochures came from. 
D. Are other Anti-drunk Driving Prograns Present. Safe ride informally done, but when you try to drive them home, "They tell you to go to hell. They think they can take care of themselves." He says that it's more of a general practice that if someone has had too much they just "cut them off."

\section{PROGRAY IYPACT}

A. How Well Does the Prooram Work. Has worked well; he has some regulars doing it every week with a different nember being the DD.

B. Reactions to the Program. Positive.

C. What Number Participate/Number of Potential Groups. I a week; he couldn't say how many potential parties there are.

D. Size of Participating Groups. 4 or 5.

E. Changes in the Drtaktng of Non-Drivers in Parties with a Designated Driver. No change; it's stlil brand new.

VI. INFORMAI DESIGNATED DRIVER ACTIVITIES

A. Do People Assion Designated Drivers on Their Own. Without Encouragement By A Formal Program. He's heard of one case of this happening.

1 .

a. In what situations and for that Events. For sports events.

b. How Is the Designated Driver selected. They trade off for each event.

c. How Widespread Are Informal Designated Driver Activities. No data.

d. How Have You Learned About This. No data.

e. Other Information About Informal Activities. No data.

VII. WHAT WRITTEN INFORMATION IS AVAIIABLE

A. None.

COMAENTS :

VFW (in San Diego) - Jerry Blissmer - 619-281-0137

Date of Interview: $6 / 11 / 86$

Position: Hanager

Address: 4370 Twain Ave. San Diego, CA 92106

I. SETTING INFORMATION

A. Description of Establishment/Location. Industrial complex, liquor bar, private club, food on Friday through Monday evenings.

B. Size. Seating Capacity: 125 in he dining room, 50 in the lounge.

c. Description of clientele. Average age is 50; mix of blue and white collar. 
D. Availability of Public Transportation. Taxi, no buses at night.

\section{PROGRAY ORGANIZATION}

A. When and Why was the Program Started. Dec. 1985.

B. Coordination with other organizations. Independent.

III. PROGRAY OPIRATION

A. How Is the Degignated Driver selected and Identifled. Program used most frequently "when there is a function;" the several members who don't drink are the ones who volunteer.

B. How Are particlpants Recruited. Their monthly newsletter plugs it.

c. What Incentives are offered to The Desionated Driver. Free non-alcoholic drinks.

D. Who Uses The DDP. He didn't think that generalizations could be made.

E. Konitoring Drinking by The Designated Driver. No need to monitor.

F. Eligibility Requirements. None.

G. Publicity. Nothing beyond the above mentioned newsletter.

H. Staffing the DDP and Training staff. None.

I. When Does the Program Operate. Anytime.

IV. MORE PROGRAY ORGANIZATION

A. Changes in the DDP since It Began. Too early to say - no problems so far.

B. Annual Cost. Nominal.

C. Resources For Keeting Costs. None.

D. Are other Anti-drunk Driving prograns present. Safe ride done informally; it's not followed so much by the management as by the general clientele; since the clientele are all good friends, "everyone takes care of each other." And, he says, if someone has had too much, someone else just takes their keys away.

V. PROGRAY IYPACT

A. How Well Does the Program Work. Worked well.

B. Reactions to the Program. "Everybody likes, it."

C. What Number Participate/ Number of Potential Groups. 3 or 4 for a given function: 6 total possible.

D. Size of Participating Groups. Average in party is 6 . He says they really pile them in.

E. Changes in the Drinking of Non-Drivers in Parties with a Designated Driver. There has been no increase. Rather, drinking has gone down across the board; business has dropped considerably. He says it's because of the laws.

$$
\mathbf{F}-102
$$




\section{INEORYAI DESIGNATED DRIVER ACTIVITIES}

A. Do People Assign Designated Drivers on Their own. Without Encouragement By A Formal Program. Yes, he has done it himself.

I.

a. In that situations and for that Events. Sporting, pionics, events.

b. How Is the Desionated Driver Selected. No data.

c. How Widespread Are Informal Desionated Driver ictivities. It's done all over the town; "a lot of people are paranoid."

d. How Have You Iearned About This. No data.

e. other Information About Informal Activities. No data.

VII. WHAT WRITHEN INFORMATION IS AVAIIABLE

A. None.

ConneNTs: Strongly felt that informal activities were happening due to the laws.

Membership Establishments

Informal Programs

VFW (in Sandy, OR) - Fran Taylor, wife of commander Ray Taylor VFW: 503-668-5211. (home: 503-668-7618)

Position: President of the Auxiliary

Address: Sandy, OR

I. SETTING INEORMATION

A. Description of Establishment/Location. Private club, nonprofit. Small community.

B. Size. VFW has about 600 members, both men and women. The function room holds 75-80.

c. Description of clientele. Age varies (21-94). There is a real mixture.

D. Availability of Public Transportation. No taxis. There is a bus that comes in twice a day.

II. INFORMAL DESIGNATED DRIVER ACTIVITIES

A. Do People Assion Desionated Drivers on Their Own, Without Encouragement By A Formal Program. They have people who do the DDP. Yes people informally designate a driver.

1. Bartenders keep an eye on the people. Reys are taken away.

a. In What situations and for that Events. Sometimes in bar and at functions. Sometimes people police themselves. :

$$
F-103
$$


b. How Is the Desionated Driver selected. Bartender is there.

- In couples, they want to go along with the law and not cause an accident. Couples take turns.

c. How Widespread Are Informal Designated Driver Activities. In their club it is widespread. Because of the problems of liquor liability, they try to enforce it. But people are gung-ho.

d. How Have You Learned About This. They tell her or bartenders tell her.

e. Other Information About Informal Activities. It is agreeable; it seems to work out well. In private clubs, they have a lot to lose. And it is a very different clientele than in a public bar. People that come in are people who know each other. You can tell what kind of driver they are, so you can stop problems before they are started. In general, they police their own.

\section{ARE OTHER ANTI-DRUNR DRIVING PROGRAMS PRESENT}

They have a transportation fund which they donate to, through raffles, etc. At dances, functions (big gatherings)' they pay high school kids to take person and their car home.

They encourage one person to stay sober, but if they arink they have other people to take them home.

We can call back about safe Ride component.

They have cards at the bar. Everyone, if they are drinking or not, has to fill out a card which says that they know the laws and what they are doing, and they don't hold the club liable.

\section{COMDENTS :}

University of Nebraska-Omaha - Pi Kappa Alpha - John Bucklin 402-331-2122

Date of Interview: $10 / 27 / 86$

Position: Former President; now alumni

Address: Omaha, NE

\section{SETTING INFORMATION}

A. Description of Establishment/Location. It's a social fraternity. In a city.

B. S1re. 40 guys.

C. Description of Clientele. All college guys.

D. Availability of Public Transportation. Public transportation is real good - buses and taxis. 
II. INFORYAI DESIGNATED DRIVER ACTIVITTES

A. Do People Assion Designated Drivers on Their own, without Encouragement By A Formal Program. "No formal deal like that. one guy will say he will drive and he's usually pretty reliable.n

1.

a. In What situations and for what Events. Any function. Bspecially during the weekend.

b. How Is the Desicnated Driver selected. Somebody says they will drive. They volunteer. Maybe they take tums.

c. How Widespread Are Informal Desicnated Driver Activities. Around three fourths $(3 / 4)$ of the members participate.

d. How Have You Iearned About This. Something they've done since he's been in the fraternity. In fact, they did it in high school.

e. other Information About Informal Activities. No.

III. III, ARE OTHTR ANTI-DRUNR DRIVING PROGRAYS PRESENT

Not to his knowledge.

COMAIENTS :

University of Cincinnati - Bob Dawson, Alpha Tao Omega - 513-2810881

Date of Interview: $6 / 6 / 86$

Position: President

Address: Cincinnati, oH.

I. SETTING INFORMATION

A. Description of Establishment/Location. Fraternity.

B. Size. No data.

C. Description of clientele. college age.

D. Availability of Public Transportation. People usually just walk.

II. INFORMAL DESIGNATED DRIVER ACTIVITIES

A. Do People Assign Designated Drivers on Their Own, Without Encouragement By A Formal Program. Not really.

I.

a. In That situations and for what Events. For a drink late at night, they'll drive to a bar; normally they walk.

People "watch out" for each other informally. If someone is too drunk to drive, then someone else just "takes away his keys, and that's the end of that."

b. How Is the Designated Driver Selected. No data.

c. How Widespread Are Informal Designated Driver Activities. No data.

d. How Have You Learned About This. No data.

$$
\text { F-105 }
$$


e. Other Information About Informal Activities. Generally, there's not much need because if someone comes into the fraternity and gets drunk, he'll just spend the night.

COMLENTS :

San Diego State - Doug Case - 619-265-5742

Date of Interview: $10 / 29 / 86$

Position: Advisor to fraternities

Address: Housing and Residential Life office. San Diego state University, San Diego, CA.

\section{SETTING INFORYATION}

A. Description of Establishment/Location. The university is Iocated in San Diego, the seventh largest city in the country.

B. Size. There are 30,500 students.

C. Description of Clientele . Very mixed. Students vary from 1883; the average is 24 for undergraduate students, and 29 for graduate students.

D. Availability of Public Transportation. There are civil bus lines that come to campus.

\section{INFORYAI DESIGNATED DRIVER ACTIVITIES}

A. Do People Assign Designated Drivers on Their own, without Encouragement By A Formal Program. Sometimes.

1.

a. In What situations and for what Events. This is a large university. It is hard to tell for entire university.

b. How Is the Designated Drfver selected. Normally it is a person who doesn't drink or they use rotation.

c. How Widespread Are Informal Designated Driver Activities. It is used occasionally, not frequently. Most people aware of it, but they don't use it.

d. How Have You Learned About This. People in organizations mention these activities to him.

e. Other Information About Informal Activities. Nothing to

\section{ARE OTHER ANTI-DRUNK DRIVING PROGRAMS PRESENT}

They do have an active SADD. Students used to always drive in cars. Now, it is frequent that they either go in buses or split the rental of limousines when they go to dances. Peter Hansen, active in SADD, his fraternity telephone number is 619-265-9503.

COMIENTS :

$$
\text { F-106 }
$$




\title{
APPENDIX G
}

\section{DDP RTTS}

This Appendix lists some organizations which provide DDP kits and describes the content of the kits. Some examples of these materials are contained in Appendices $I, J$, , and $R$.

ORGANIZATION (Program Name)

Anheuser-Busch, Inc. Iocal Wholesalers ("I'm Driving")

\section{CONTHENTS}

Back Bar Banner

Counter Cards

I'm Driving Buttons

Owner's Manual

Rain Check (food/drink coupon)

Sample News Release

Table Tents

Wall Plaque

window Decal

ARIS (Alcohol Research

Information Service)

1120 E. Oakland Ave. Lansing, MI. 48906

("Know Your Driver")

\author{
Buttons \\ Certificate of Appreciation \\ Matchbooks \\ Personalized Cards \\ Posters \\ Reorder Form \\ Sample Bumper sticker \\ Sample Cocktail Napkins \\ Sample "Newsletter" \\ "Server Tips" Booklet \\ Sponsor Rit Box \\ Sponsor's "Handbook" \\ stickers \\ Table cubes
}

coca cola

Point of Sales Service Dept.

Booklet

Atlanta, GA.

(404) 676-4052

("Be the Iife of the Party")

\author{
customer Menus \\ customer stickers \\ Mixer Sheets \\ Newspaper Ad Slick \\ order Form \\ Placue \\ Radio Commercial script \\ server Buttons \\ Table Tents
}

G-1 
DEPARTMENT OF THE NAVY

Naval Military Personnel Command

Washington, DC. 20370-5000

("No Thanks")

DOT/NHTSA

Washington, DC.

("I'm Driving")

("A Rey to Life")

National Restaurant

Association

311 First St, N.W.

Washington, DC. 20002

("Help Prevent Drunk Driving")

This program is a comprehen-

sive Alcohol Awareness Program

with a DDP component.
BAC Chart

Letter of Appreciation to

Designated Driver

Managers Message for Club Bulletin

Program Description

Publicity Flyers

Publicity Materials

Responsible Server Information

Sample News/Feature Article

Sample News Release

Server Training Guidelines

Table Tent slogans

\section{Bookmark}

Camera-Ready Art

Decal

Idea Sampler including:

Camera-Ready Clip Art

DDP Information

Drinking-Driving Information

Fund Raising Ideas

Sample Editorial

Sample Governor's

Proclamation

Sample Mayor's Proclamation

Sample Radio Announcements

Mock-Cocktails and Munchies Recipes

Pamphlet - DDP Program

Pamphlet - How to Spot Drunk and Drugged Drivers

Table Tent

Alcohol Awareness Program Training

Camera-Ready Badge Design

Camera-Ready Button Design

Camera-Ready Gift Certificate Design

Camera-Ready Participation Announcement

Camera-Ready Poster Design

Coaster

Designated Driver Program Information

Liquor Liability Information

Non-Alcoholic Drinks Recipes

G-2 
National Restaurant

Association (continued)

National safety Council 444 North Kichigan Ave. Chicago, II. 60611

(312) 527-4800

("Designated Driver Program")
Order Form

Restauranteur's Guide

Sample Table Tent: Rnow Your Iimit

Suggested Snacks

BAC Chart

Buttons

Counter-top Display

Idea sheet

Reytag

Order Form

Pamphlets

Poster 


\section{APPENDIX H \\ CHARACTRRISTICS OF DESIGNATED DRTVER PROGRAYS}

CHARACTERISTIC

FREQUENCY

\section{YEAR STARTED}

$\begin{array}{lr}1981 & 1 \\ 1982 & 2 \\ 1983 & 3 \\ 1984 & 13 \\ 1985 & 18 \\ 1986 & 1 \\ \text { unknown/unclear } & 2\end{array}$

EIIGIBIIITY REOUIREMENTS - SIZE OF PARTY

Mininum in party

2

3

4

6 (in one car)

Maximum in party

6

WHO INITIATES PARTICIPATION?

Party approached

By server

By doorman

By staffperson

Patron volunteers

INCENTIVES FOR PARTICIPATION

Free non-alcoholic drinks $\quad 40$

coupons for food/drink 7

Free food 3

Free cover-charge 2

Contest giving away car 1

T-shirts 1

METHOD FOR IDENTIFYING THE DESIGNATED DRIVER

Button

sticker/tag

Hand stamp

19

5

3

H-1 
Membership card

Red cup

IN-HOUSE PUBLICITY

Posters/signs $\quad 22$

Table tents $\quad 12$

Iiterature

Staff wears buttons

Disk jockey promotion

Banner

Bulletin board

None

OUTSIDE PUBLICITY

Mass Media

Radio announcements 9

Newspaper ads

Newspaper (format not specified) 7

PSAs on TV

Newspaper articles

TV ads

other publicity

Flyers

Billiboards

Bulletin boards

Charity participation

Newsletter to members

YANPOWER REOUIREYENTS

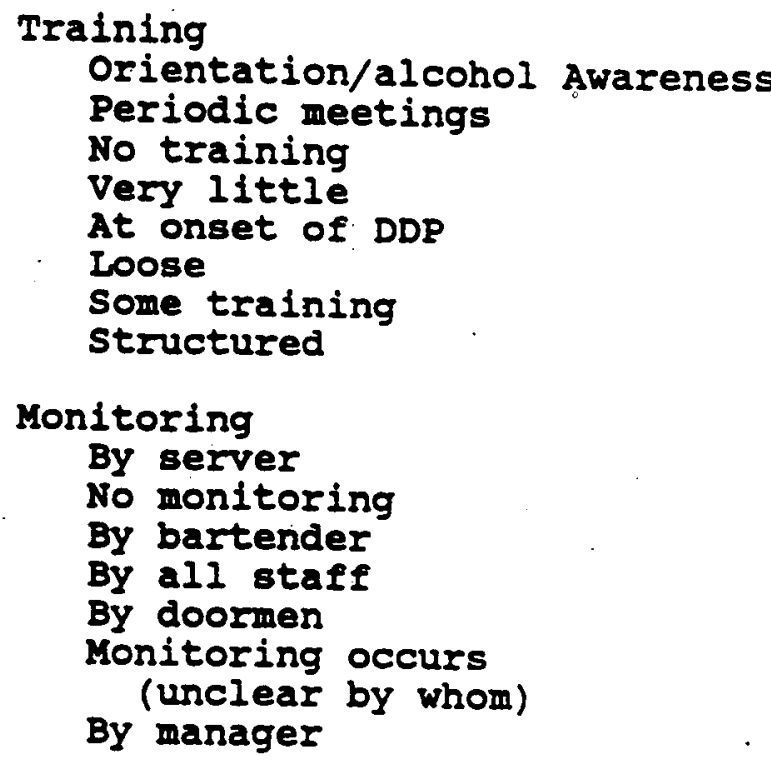

15

11

4

2

2

1

1

1

19

7

4

2

2

2

1

H-2 
OTHER ANTI-DWI PROGRAMS THAT ARE PRESENT

Safe ride (formal or informal) 34

Breathalizer

Demi-drink

Free coffee

TIXIES OF OPERATION

Whenever open

Evenings

Holidays

Evenings/weekends

AVERAGE SIZE OF GROUPS WHO USE THE DDP

$1-3$

$3-6$

4 or more

6 or more

8 or more

TYPICAL CHARACTERISTICS OF DESIGNATED DRIVERS

Gender

Females 9

Males 2

Age

Middle aged 1

Young

late $20^{\prime} \mathrm{s}$

early 30's 1

under 45

Type of drinker

Would stay sober or drink

lightly anyway

Responsible/aware

Rotation

"Regulars"

"Very friendly"

No generalization possible

2

1

1

1

ANNUAL COSTS OF THE DDP

$\$ 100$ or less/"nominal"
$\$ 1000-\$ 1500$
$\$ 2000-\$ 5000$
$\$ 7000$
$\$ 10,000$
$\$ 15,000$


SUBJECTIVE EVAIUATION OF THE DDP

Successful or positive 19

Mixed/moderate

Unsuccessful or negative

Fairly sucessful

Can't judge

7

4

2

MISUSE OF DDPS

There is misuse of DDPs

PROBIFAS WITH DDPS

Effect on drinking by companions Drinking unchanged Drinking increased Drinking changed (Unsure how)

servers dislike DDP because they lose ttps

DIFFICUIT SITUATIONS AND COPING STRATEGIES

If DD drinks alcohol:

Remove identification for free drinks

Ask whole party to leave

Don't serve them

Recharge for previously

free drinks

Remove identification and ask DD to leave

Hard to know if DD drives 1

1

Note: Data were often available on only a portion of the 40 DDPs that were telephoned. In a few cases, programs were counted more than once under a particular characteristic because more than one option applied. 


\section{APPENDIX I \\ SAYPIE ITHYS QSED TO PUBLICIZE DDPS}

Item Number

1

2

3

4

5

6

7

8

9

10
Description

Table Tent from Anheuser-Busch.

Table Tent from National Drunk and Drugged Driving Awareness Week, National Highway Traffic Safety Administration, Washington, D.C.

Table Tent from Anheuser-Busch.

Poster Erom Rockaway Tavern Owners' Association, looth Police Precinct, New York City stop-DWI Program, Rockaway, New York.

Flyer from Department of the Navy, Washington, D.C.

Flyer from National Drunk and Drugged Driving Awareness Week, National Highway Traffic Safety Administration, washington, D.C.

Flyer from Department of the Navy, Washington, D.C.

Participation Announcement from National Restaurant Association, Washington, D.C.

Button from Missoula City-County Health Department, Missoula, Montana.

Decal from Missoula City-County Health Department, Missoula, Montana. 


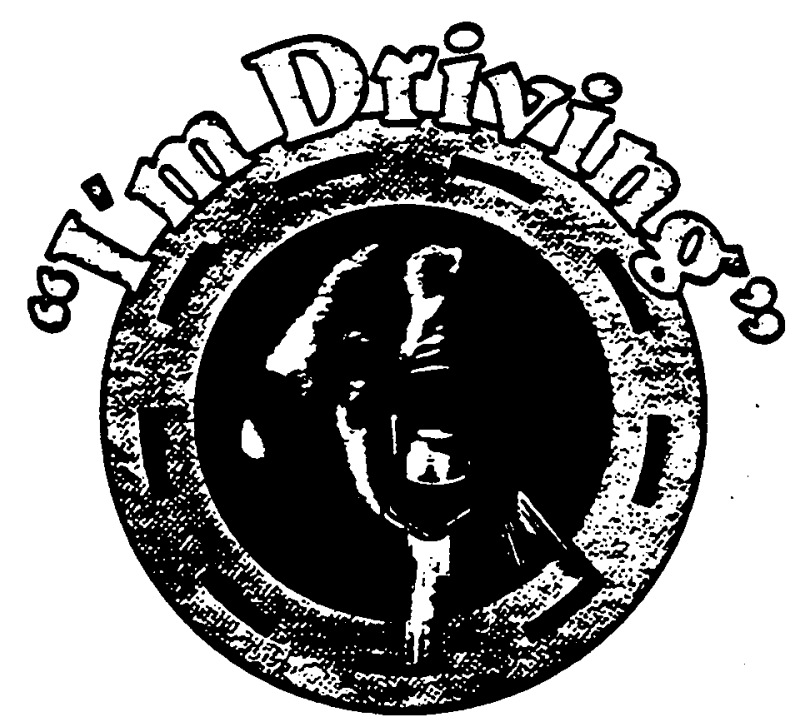

\section{Can Be A Key Part Of Your Good Time}

1

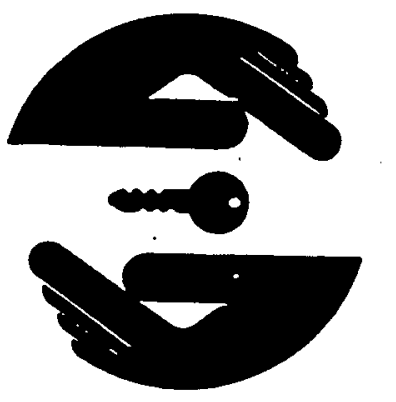

\section{DESIGNATED \\ DRIVER}




\section{It Can BeAKeyPart Of Your Good Time}

We care about our customers.

For this reason, we cordially invite you to ask about Tm Diving," our designated driver program.

The idea is simple. You designate one person from your group to provide trans. portation during your night out on the town at our place. The "designated driver" refrains from drinking alcohol, but it is not a sad refrain. Your group's "designated driver" will receive some free goodies that we will tell you about.

Why are we doing this? Because safe highways are everyone's responsibility. Because we care about your safety as you are enjoying yourself in our establishment.

Most of all, we are doing this because you are an important part of our future. So. ask about "im Driving." And enjoy.

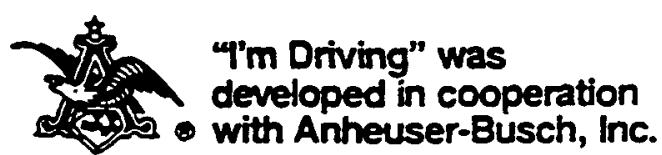



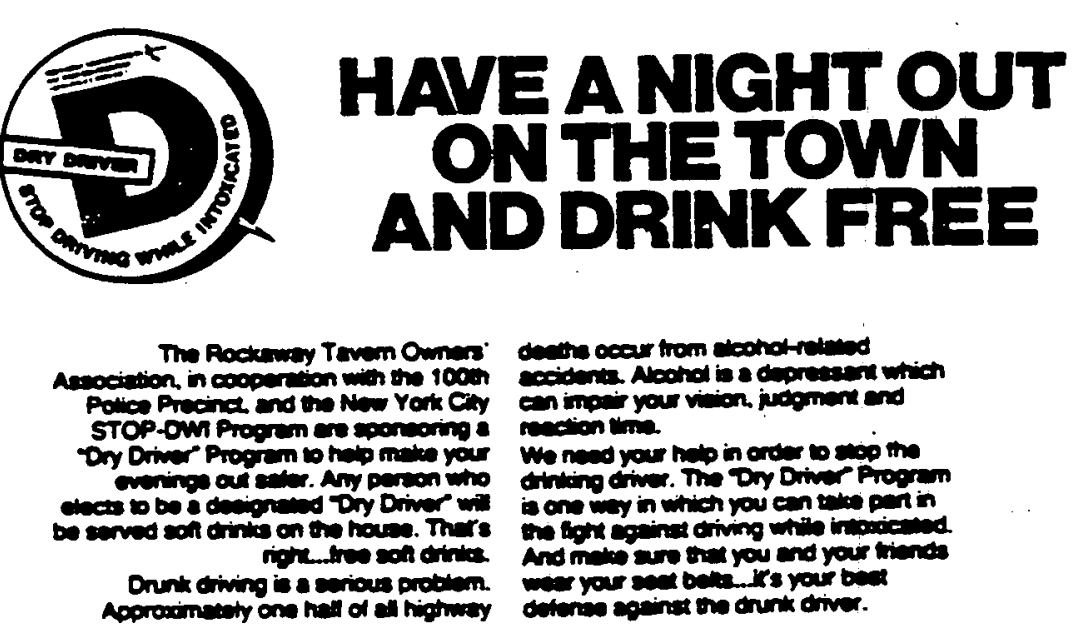

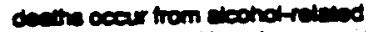

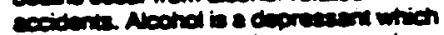

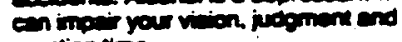
ivetion line

we nod you ho h in eres to the thing diver. Th Dr Din Pregen is on win winch you en twe peris is on wy in which you ean the pen

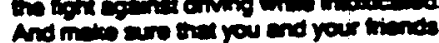

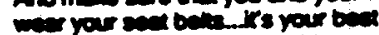

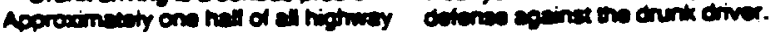

HERE'S HOW THE PROGRAM WORKS:

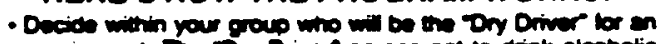

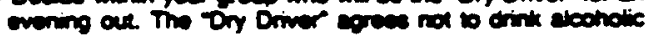
covereges be nighe

- Go with your triendes to any perticipation

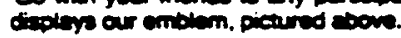

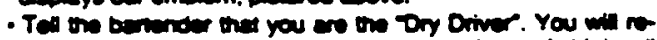

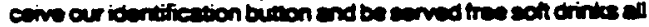
exping.

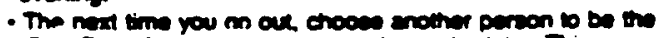

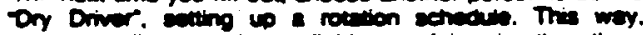

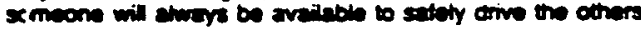
nome.

\section{PARTICIPATING DAY DRMER ESTABLUSHMENTS:}

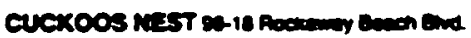

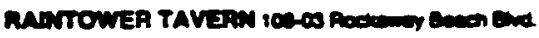

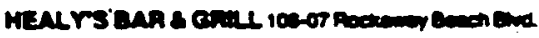

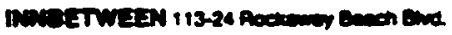

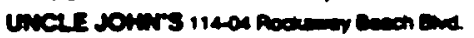

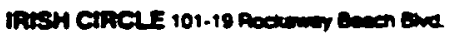
CuRaurs EaA 217 bouch 116 se

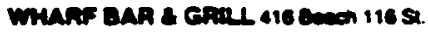

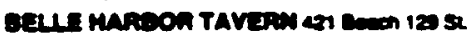

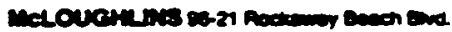

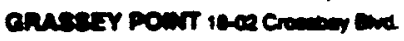

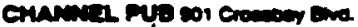

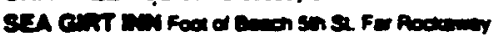

Pith $92 \sin 8$ anch 928

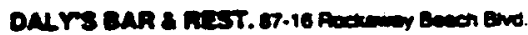

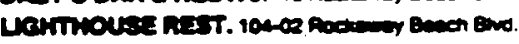

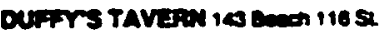

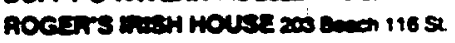
moxourrs BARH \& Podoury the

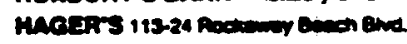

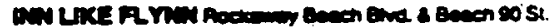

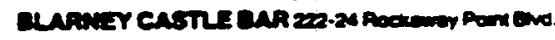

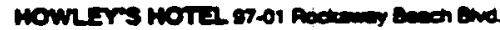

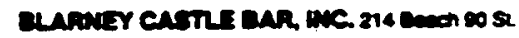

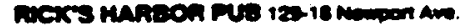

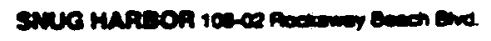




\section{BE A FRIEND}

As a Designated Driver,

you can help your

friends get home safely

\section{... and still have a good time yourself.}

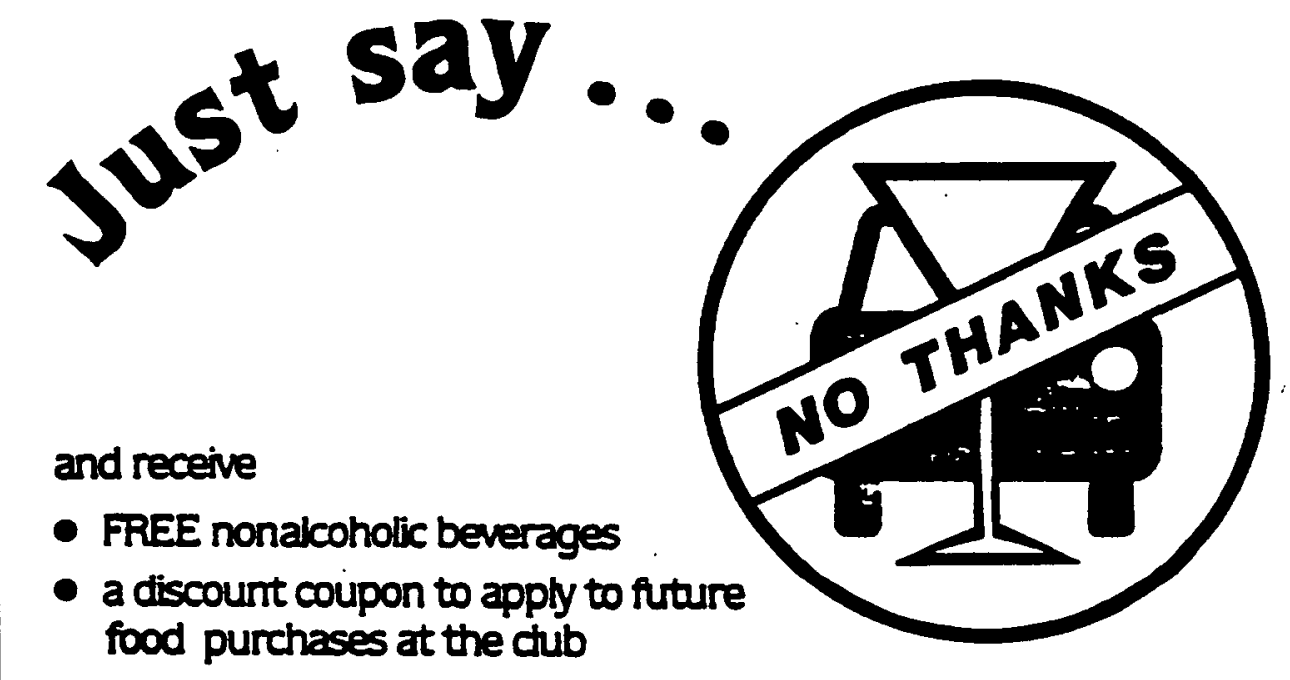

- a "No Thanks" button

Vatt the Nay ctub on your bese todty 


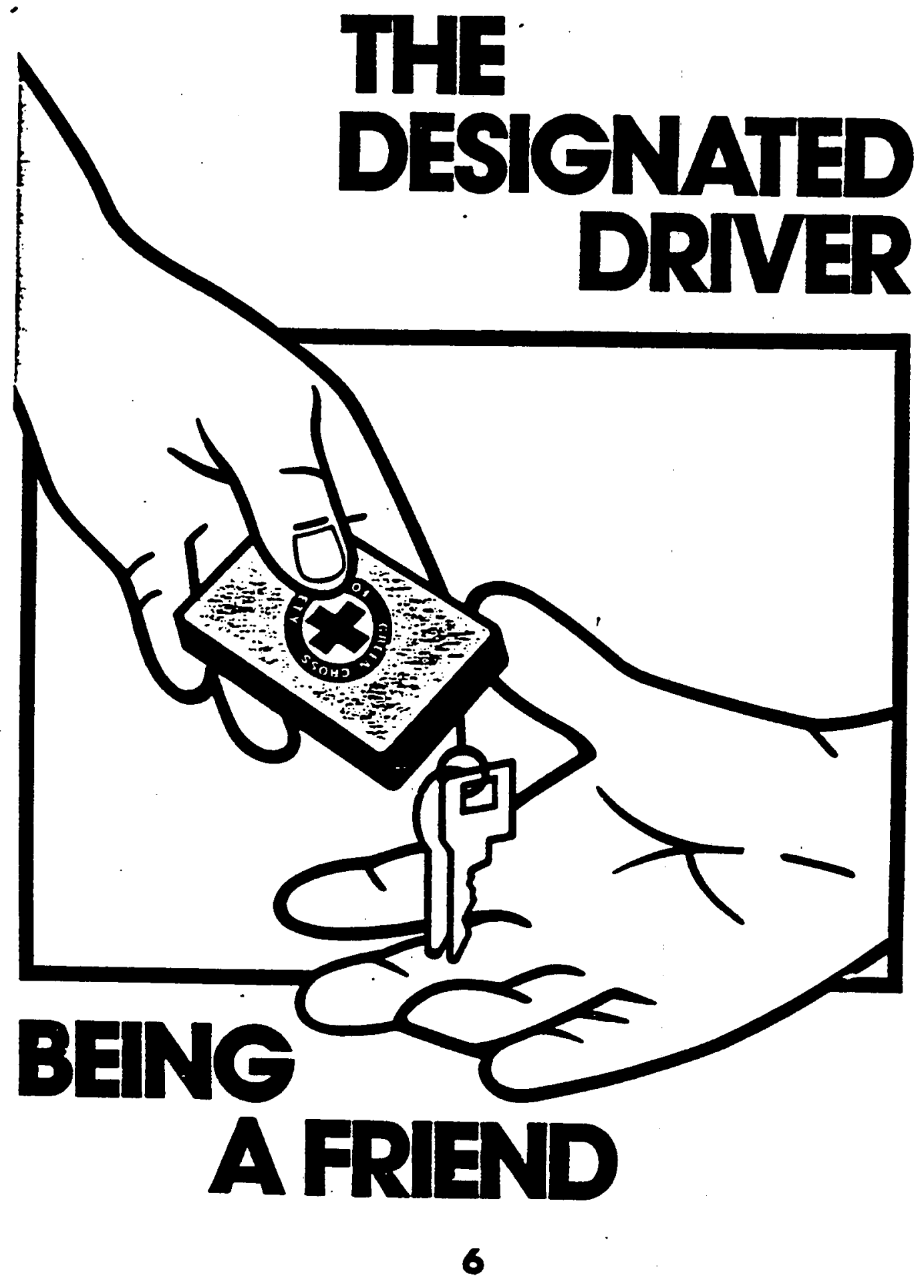

I-6 


\section{Want to be the LIFE of the party?}

Eat, Drink* and be Merry.

* Unlimited nonalcoholic beverages to Designated Drivers.

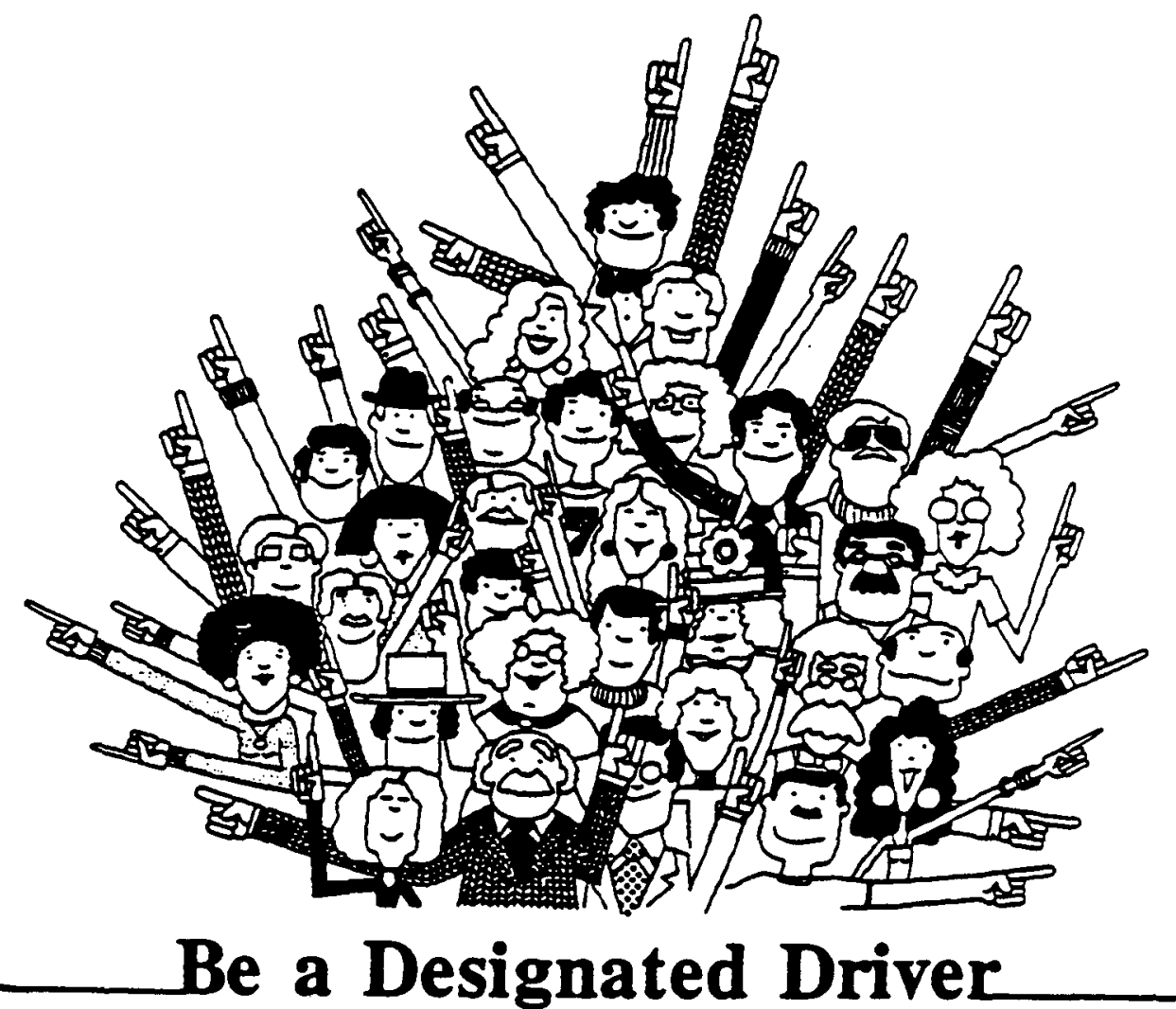

Visit your Navy club. 


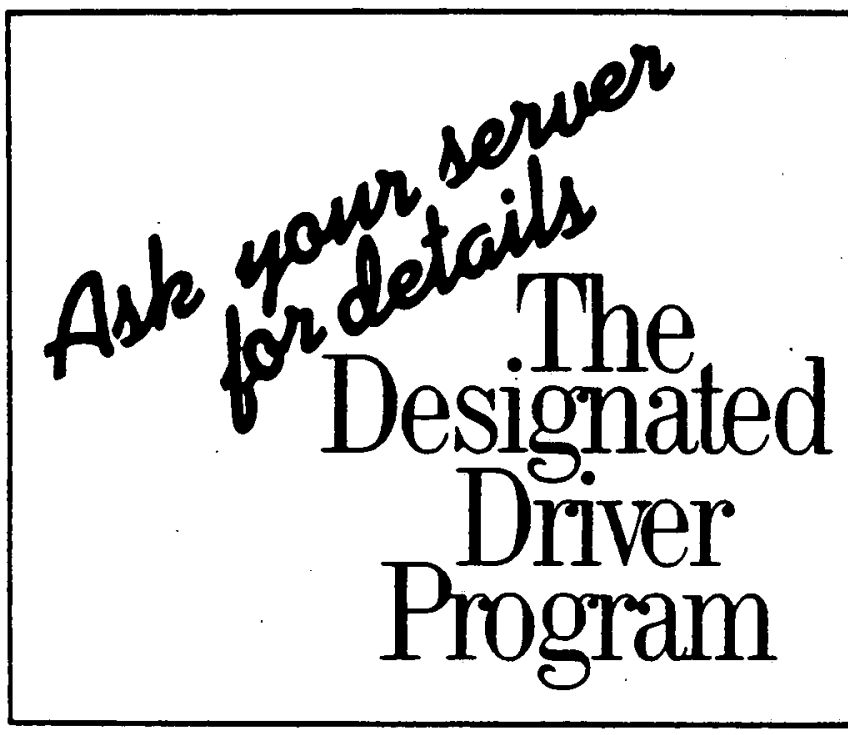

8

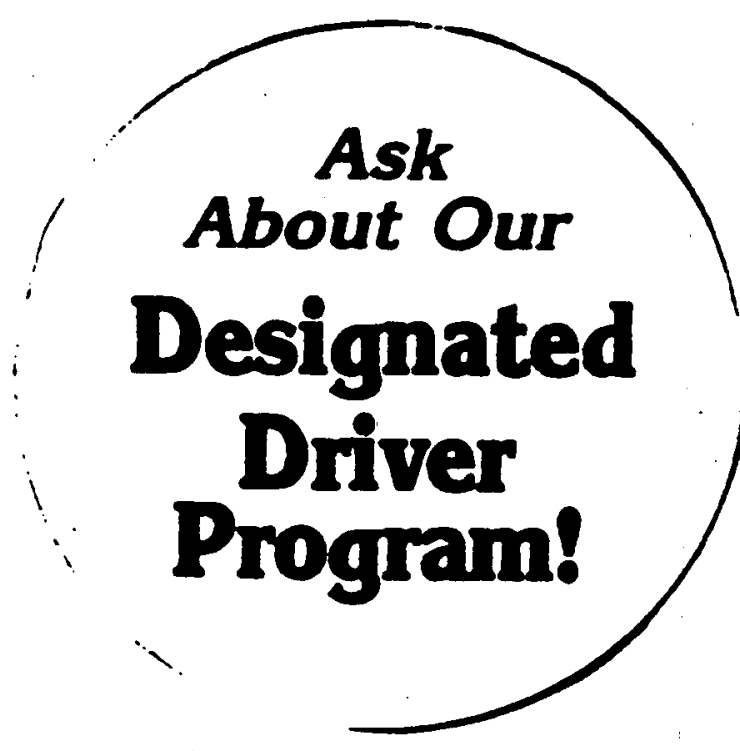

9

$I-8$ 


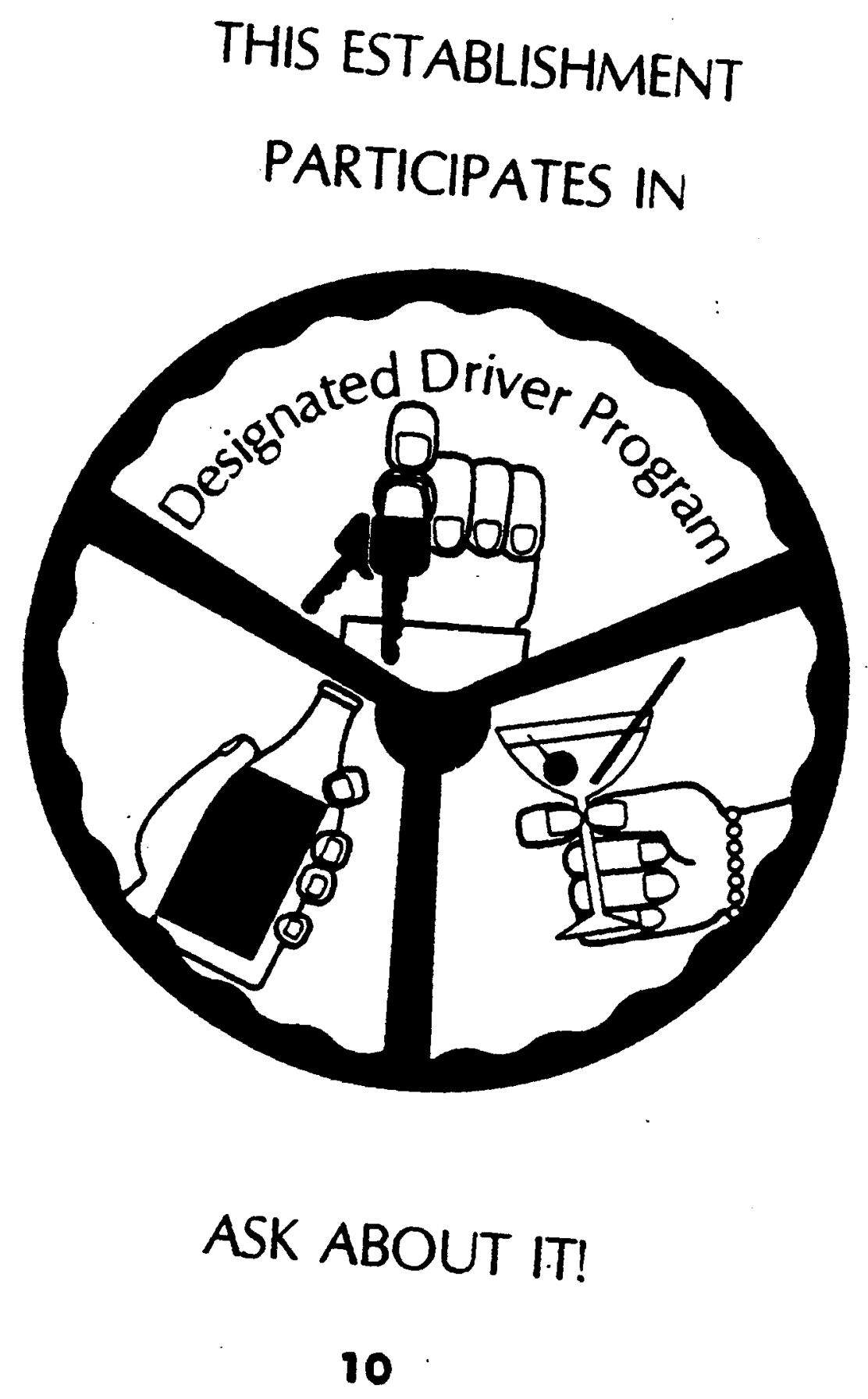




\section{APPENDIX J}

\section{SAMPLE COUPONS USED AS INCENTIVES IN DDPS}

\section{Item Number}

1

2

3

\section{Description}

Coupon (both sides) from Black Angus Iounge, Raleigh, North Carolina.

Coupon ("Driving Certificate of Appreciation") from Graffiti's, waterford, Connecticut.

Generic Gift Certificate from National Drunk and Drugged Driving Awareness Week, National Highway Trafflc Safety Administration, Washington, D.C. 

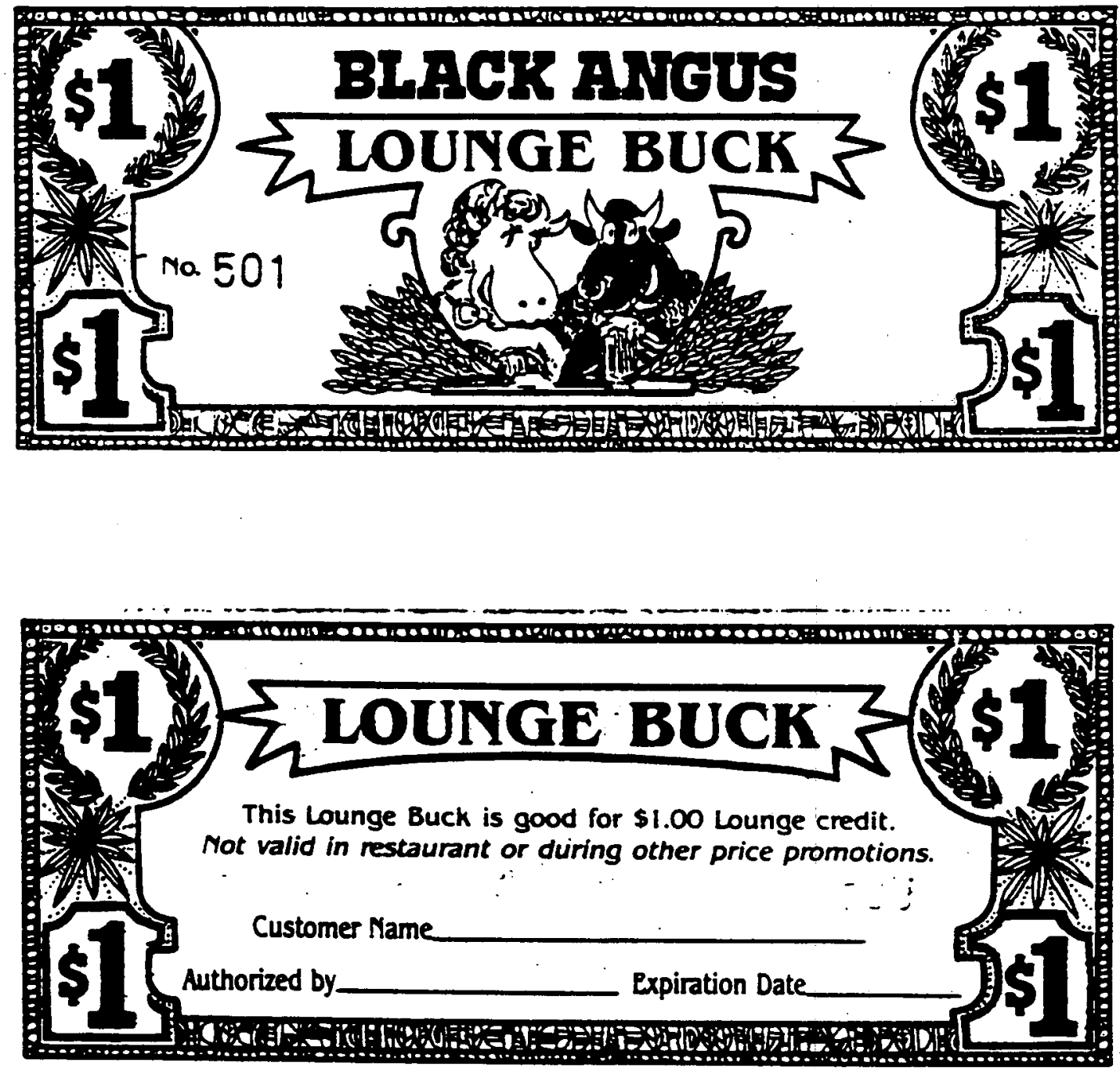
2

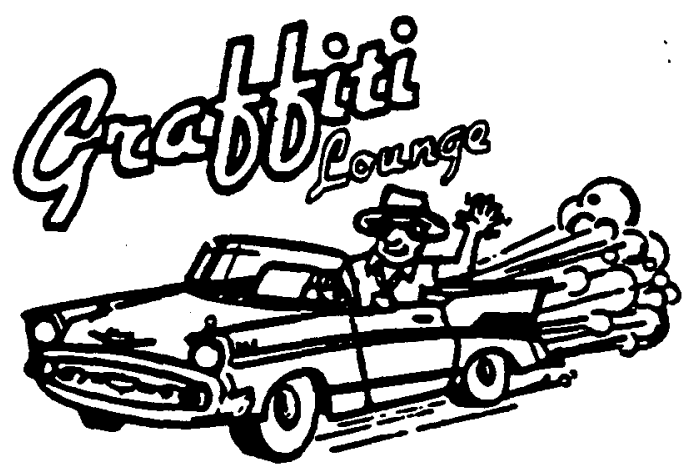

297 Willets Avenue Waterford, Connecticut

Pm Driving Certificate of Appreciation

In recognition of your concern for your friends by partici. parting in the $\mathrm{Tm}$ Driving Program, Graffiti Lounge hereby awards you with this Certificate of Recognition.

This certificate entitles you to a free open-face sandwich during a future visit to our establishment.

Thank you for making Connecticut highways safer.

The Management

2

4

$\mathrm{J}-3$ 


\section{Gift Certificate}

This certificate can be redeemed for

Designated driver

Expiration date

Restaurant

Designated Driver

3

$J-4$ 


\section{APPENDIX K}

\section{SAMPIE ITENS USED TO IDENTIFY DESIGNATED DRIVERS}

\section{Item Number}

1

2

3

4

5

6

7

8
Description

Button from Juke Box Saturday Night, Minneapolis, Minnesota.

Button from The Great Escape, Weymouth, Massachusetts.

Button from Rumors, Washington, D.C.

Button from Rockaway Tavern Owners' Assoclation, 100th Police Precinct, New York City Stop-DWI Program, Rockaway, New York.

Button from Grand American Fare, Santa Monica, California.

Button from Minnesota North Stars, Minneapolis, Minnesota.

Generic Badge from National Restaurant Association, Washington, D.C.

Badge from The Washington Traffic Safety Commission, Olympia, Washington. 


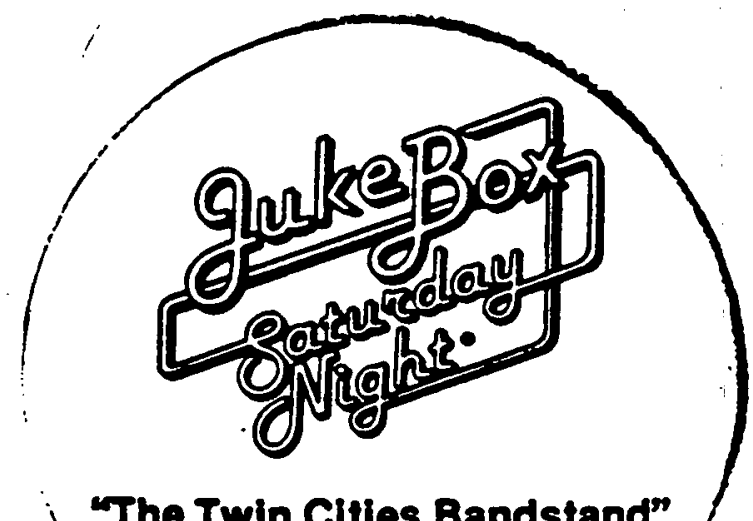

"The Twin Clties Bandstand"

\section{DESIGNATED DRIVER}

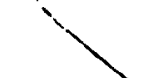

1

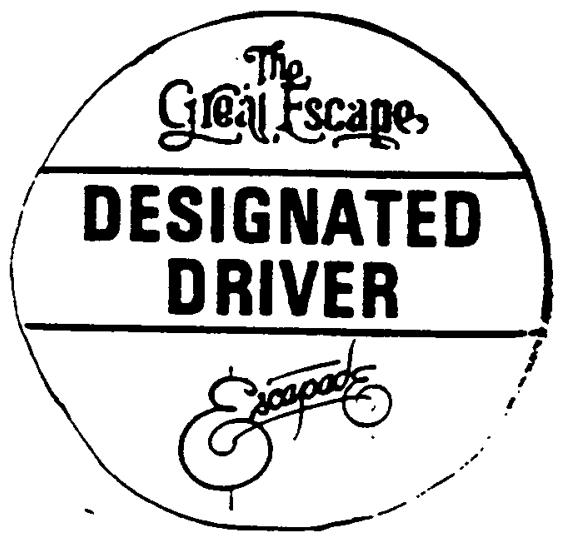

2

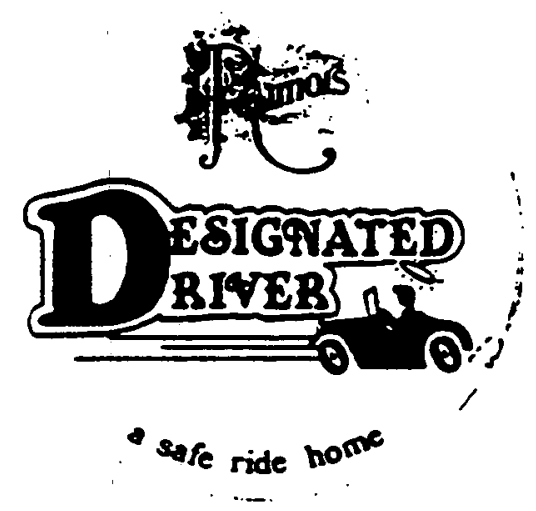

3 


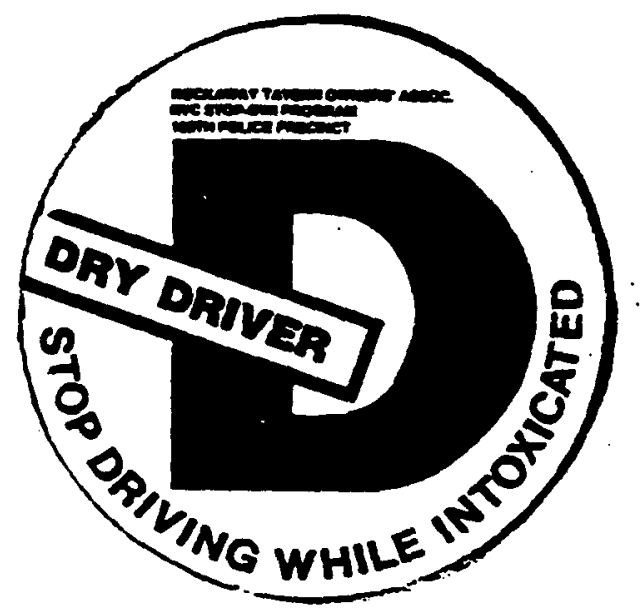

4
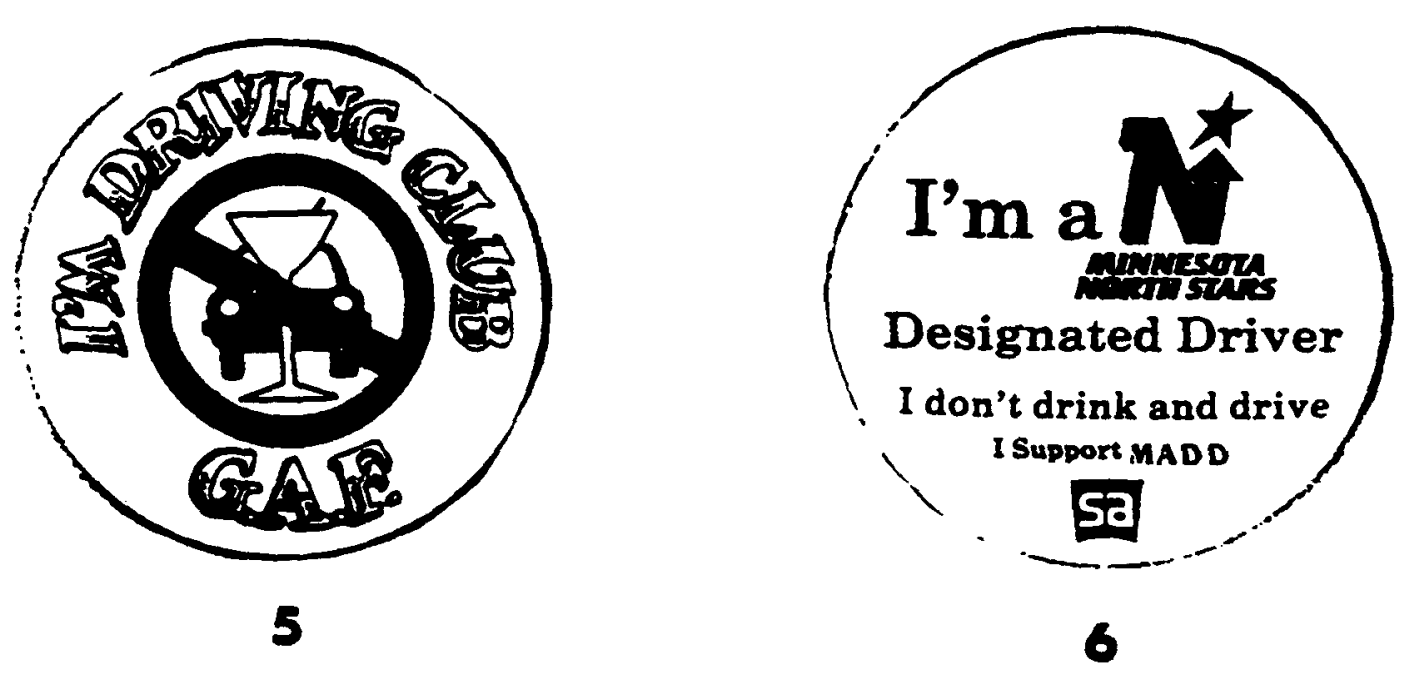

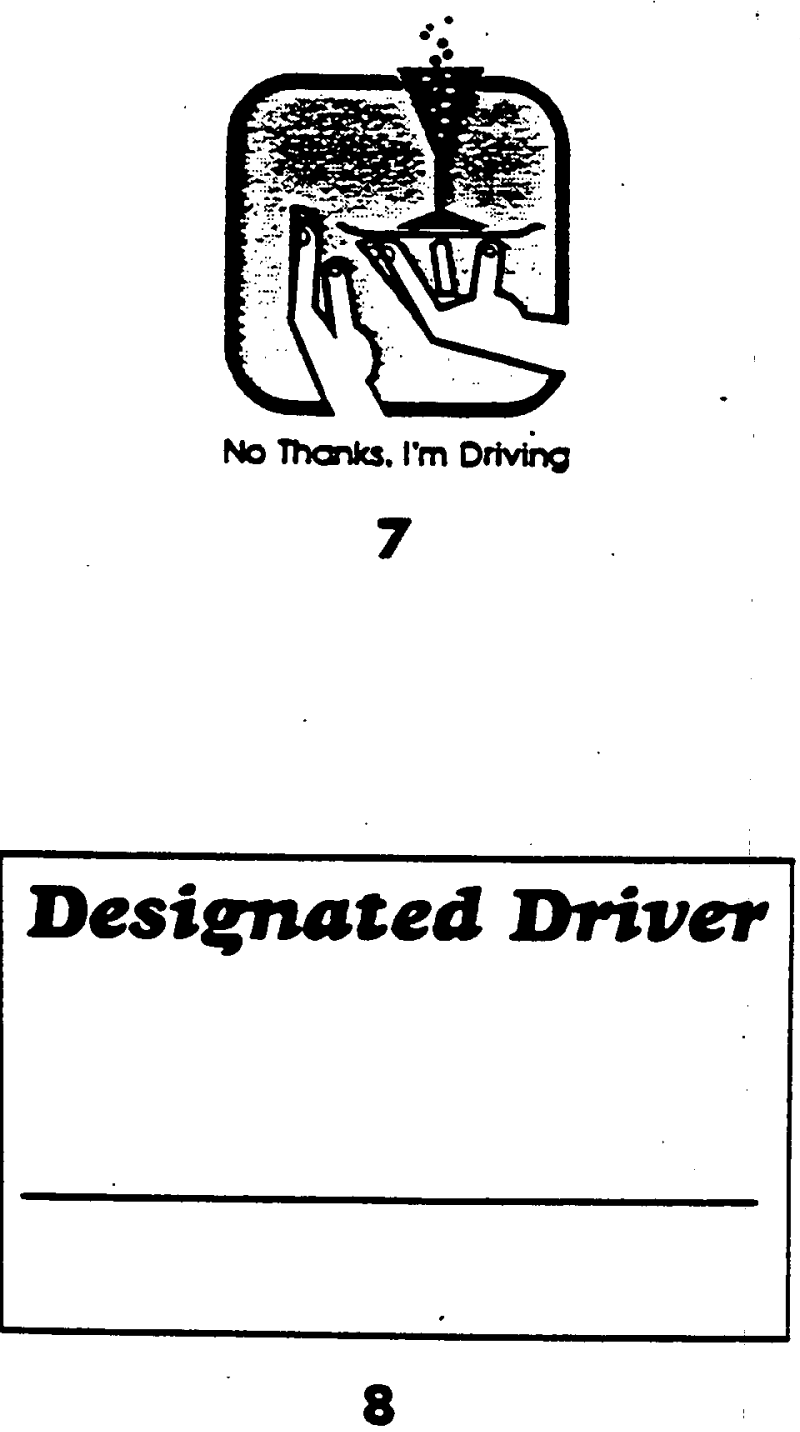

$K-4$ 